University of Louisville

ThinkIR: The University of Louisville's Institutional Repository

Electronic Theses and Dissertations

$5-2017$

\title{
A curriculum of civic responsibility : transitioning Black American students to college-level writing.
}

Jamila M. Kareem

University of Louisville

Follow this and additional works at: https://ir.library.louisville.edu/etd

Part of the Curriculum and Instruction Commons, Curriculum and Social Inquiry Commons, Other Rhetoric and Composition Commons, and the Scholarship of Teaching and Learning Commons

\section{Recommended Citation}

Kareem, Jamila M., "A curriculum of civic responsibility : transitioning Black American students to collegelevel writing." (2017). Electronic Theses and Dissertations. Paper 2695.

https://doi.org/10.18297/etd/2695

This Doctoral Dissertation is brought to you for free and open access by ThinkIR: The University of Louisville's Institutional Repository. It has been accepted for inclusion in Electronic Theses and Dissertations by an authorized administrator of ThinkIR: The University of Louisville's Institutional Repository. This title appears here courtesy of the author, who has retained all other copyrights. For more information, please contact thinkir@louisville.edu. 


\title{
A CURRICULUM OF CIVIC RESPONSIBILITY: TRANSITIONING BLACK AMERICAN STUDENTS TO COLLEGE-LEVEL WRITING
}

\section{By}

Jamila M. Kareem

B.A., Indiana University-Purdue University Indianapolis, 2007

M.A., University of Indianapolis, 2012

\author{
A Dissertation \\ Submitted to the Faculty of the \\ College of Arts and Sciences of the University of Louisville \\ in Partial Fulfillment of the Requirements \\ for the Degree of
}

Doctor of Philosophy

in English Rhetoric and Composition

Department of English

University of Louisville

Louisville, Kentucky

May 2017 



\title{
A CURRICULUM OF CIVIC RESPONSIBILITY: TRANSITIONING BLACK AMERICAN STUDENTS TO COLLEGE-LEVEL WRITING
}

\author{
By \\ Jamila M. Kareem \\ B.A., Indiana University-Purdue University Indianapolis, 2007 \\ M.A., University of Indianapolis, 2012 \\ A Dissertation Approved on
}

April 17, 2017

by the following Dissertation Committee

$\overline{\text { Brenda Brueggemann, Dissertation Director }}$

Bronwyn Williams

Karen Kopelson

Karen Chandler

Derrick Brooms 


\section{DEDICATION}

For Carla and Aisha. Everything I do is inspired by you. 


\section{ACKNOWLEDGEMENTS}

I thank my committee chair, Brenda Brueggemann, for her diligent reading, brilliant feedback, and excellent help in helping my build a personal-scholarly voice. I thank each member of my committee for their support throughout this overwhelming, sometimes discouraging, sometimes uplifting process from idea development to defense: Karen Kopelson, Bronwyn Williams, Karen Chandler, and Derrick Brooms.

I thank my younger sister, Aisha, for listening to me drone on about the research and writing process. I thank her for being patient when I chose this project over time with her and the rest of our family and friends. I thank my Aunt Linda and Uncle Louis for their encouragement and always celebrating the small victories.

I thank my doctoral program cohort for their love, support, humor, critiques, and understanding: Travis, Rachel, Laura, Keri, and Megan.

I thank my best friend, Elizabeth Chamberlain, for giving a shoulder to cry on and a partner to laugh with just when I needed it.

I thank my mother, Carla, because although she can't be with me to share in this accomplishment, I would not have even attempted to accomplish it without the values and morals she imparted on me.

Finally, I thank all of the students in my study that allowed me to pick a part their education experiences and help scholars in our field learn more about those experiences. 


\section{ABSTRACT \\ A CURRICULUM OF CIVIC RESPONSIBILITY \\ Jamila M. Kareem}

April 17, 2017

This dissertation considers how racialized differences educational experience transition with Black students as they perform the expectations of college writing curriculum. I address the question: in what ways can a first-year writing curriculum centered on civic responsibility aid in smoother transitions from secondary to postsecondary academic writing for Black students at predominantly White institutions? My study applies racial and critical race methodologies framed within the tenets of critical race theory, institutional whiteness, and the absent presence of race in composition studies. I apply the methodologies in three key ways: analyzing transition practices through racialized perspectives; evaluating general education writing curriculum through institutional whiteness; and examining the rhetorical education and writing education experiences of transitioning Black American students today and historically. Through these approaches, I argue that, due to its focus on academic writing as one resource for influencing community development, applying a curriculum of civic responsibility to first-year writing courses can effectively address Black students' complexities in transitioning to college-level writing at predominantly White institutions.

The dissertation includes five chapters. Chapter One reviews scholarship on race and academic writing, transitioning from secondary to post-secondary writing, and 
community-based writing pedagogy. Extending from that review, Chapter Two uses the critical race theory principle of counter-story, or the unique voice of color, to review historical models of Black American-centric education from the Civil Rights era. Chapter Three presents the results of an institutional analysis I conducted of the policies and curriculum designed for transitioning students at one institution. Chapter Four demonstrates the need for race-consciousness and civically responsible curriculum by discussing the qualitative interview responses of nine Black American students at the aforementioned research university. I conclude the dissertation by exemplifying the potential for a writing curriculum of civic responsibility entails at both the program level and course level. For Black American students living in a society with a racial social system built on whiteness as most desired and blackness as most disgraced, teaching academic writing practices as one of many resources to build communities can prove critical in helping Black American students transition to academic writing at the college level. 


\section{TABLE OF CONTENTS}

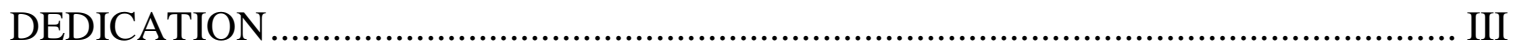

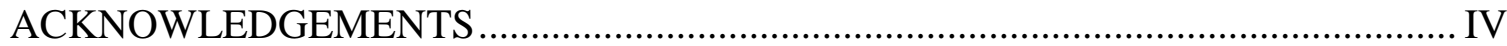

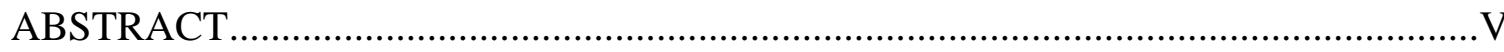

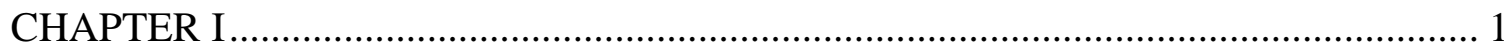

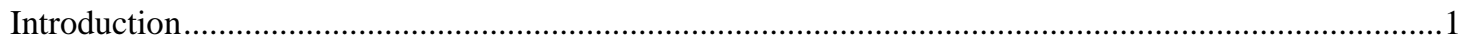

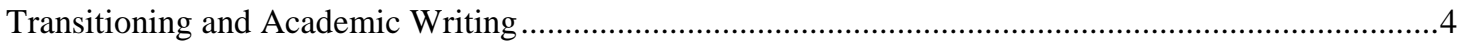

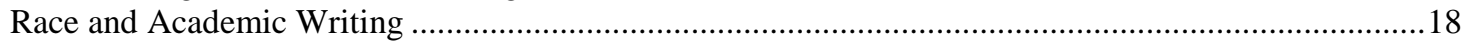

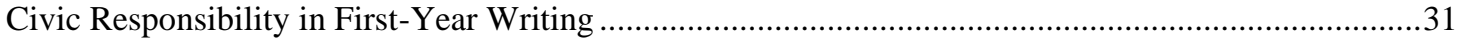

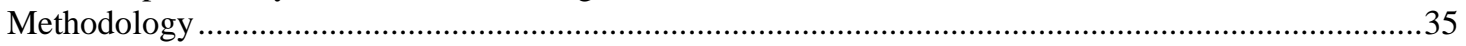

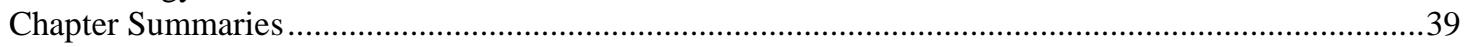

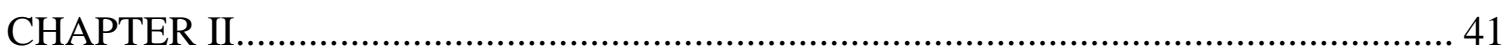

Counter-story of Critical Race Theory ..................................................................................43

Counter-stories to American Rhetorical Education .......................................................................45

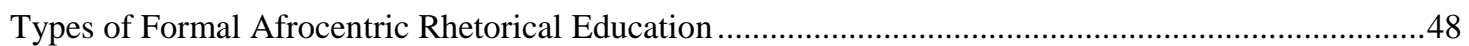

Civic Responsibility in Models of Black American Rhetorical Education ..........................................50

Significance of Rhetorical Education Counter-story to Inclusive Curriculum Design .........................64

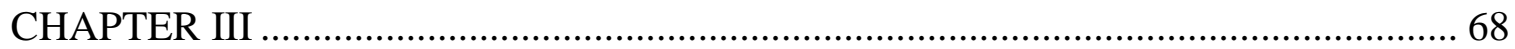

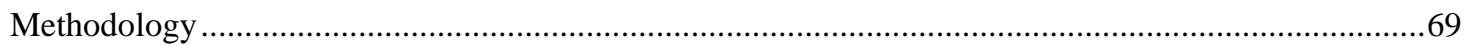

Eurocentric Epistemologies and Academic Writing Standards...................................................72

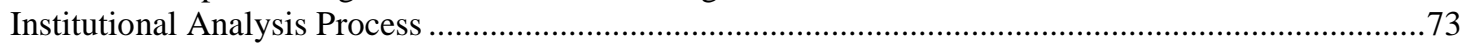

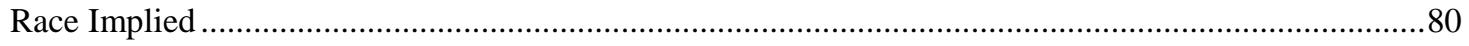

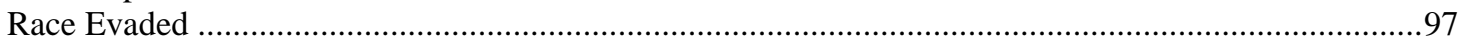

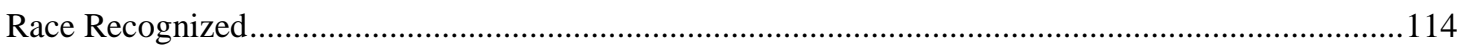

The Need for Race Presence in the Writing Program ................................................................... 118

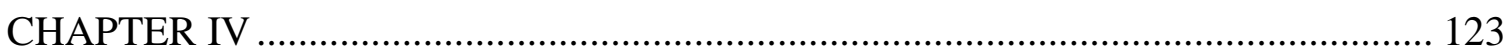

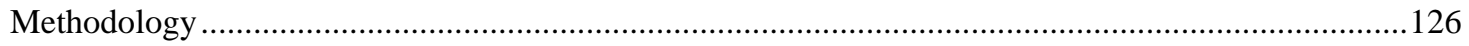

Personal Histories of Literacy and Academic Writing .................................................................129

Conceptions of Transitioning and Meaning of College Student Identity ...........................................141

Impact of the Absent Presence of Race for Success in College Writing .........................................149

Adding a "Unique Voice of Color" to the High School to College Writing Transition Tales ...............157

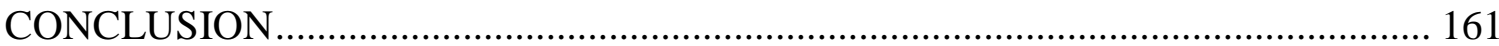

Implications for Minding, Bridging, and Crossing the Gap ............................................................ 164

Implications for Research on Academic Writing and Race ........................................................... 166

Implications for Community-Based Pedagogy in First-Year Writing...........................................172

Transitioning from the Margins: Race-Conscious and Civically Responsible Writing Programs ........175

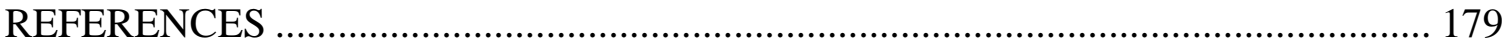

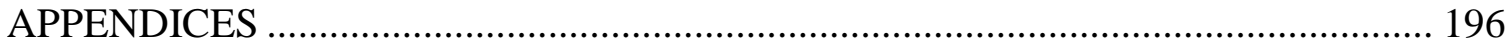

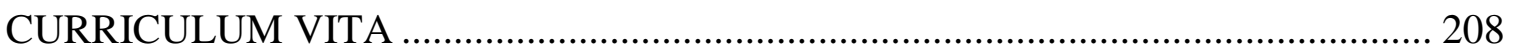




\section{TABLE}

\section{LIST OF TABLES}

1. Presence of Race in Institutional Documents ......................... 84 


\section{LIST OF FIGURES}

PAGE

1. Image on Office or Diversity and International

Affairs website home page................................................................. 90

2. Office of Admissions High School Recruitment Flyer, side 1....... 91

3. Office of Admissions High School Recruitment Flyer, side 2....... 92

4. Office of Admissions Campus Visit Website Menu..................107 


\section{CHAPTER I}

\section{RACE, ACADEMIC WRITING TRANSITIONS, AND CIVICALLY RESPONSIBLE COLLEGE WRITING CURRICULUM}

\section{Introduction}

I hated academic writing by the time I reached the first year of my undergraduate education. My disdain had nothing to do with ability. I knew how to habitually reproduce the models of syntax, grammar, semantics, and style taught to me over the last twelve years of schooling. I use schooling here in contrast to education, the former happening in an institutionalized physical space 35 - 40 minutes from my all-black neighborhood and the latter happening daily in that neighborhood and multiple homes within it. From a young age, teachers had doted on me to my parents about how nice my English was and then how gifted my writing was. Finally, as this assimilation into the formal school system continued in middle school, my inclination for writing well in the standards of school English dialect indicated a form of definitive intellectual capability.

I enjoyed writing responses to reading more than solving algebra equations, but even in middle school and high school English courses, I spent half the time listening to the teacher talk about stories and poems and the other half writing my own. Being from an all-Black, economically excluded, politically disregarded neighborhood of 
Indianapolis, Indiana, I can look back now, as a Black PhD candidate studying academic writing practices, and say that for most of my schooling, those practices seemed to serve no real purpose for me. At least, they provided no purpose that anyone ever made apparent. I knew that since I could comprehend well what I read and write well in Edited American English (EAE), I could feign interest in the material. In truth, until I reached college, writing for school was bothsomething I did for a grade and a "way out of the black ghetto" (Smitherman 202). My parents supported the school system with convincing me of the latter. If I could write well, I could get into college. If I could get into college, I could have the opportunities they didn't have, and I could escape the trappings of poverty and injustice. At least, that ideal prevailed over others.

In this dissertation, I intend to offer a writing curriculum which aims to scaffold the transition into college writing by examining how racialized experiences affect high school to college transitions of academic writing practices and why a curricular approach of civic responsibility in first-year writing (FYW) courses ${ }^{1}$ best responds to these experiences. This chapter provides background knowledge on the multiple explanations writing studies has given about transitioning in from high school to college-level writing. These explanations have mythologized several notions about transition occurrences, but especially the absence of social factors from these occurrences. As the field has proven the relevance of social factors to writing practices across contexts, I investigate their absence from theories of crossing the gap from secondary to postsecondary writing. This dissertation concentrates, in particular, on social factors related to race.

\footnotetext{
${ }^{1}$ I use first-year writing over the similar term first-year composition to emphasize curriculum that includes the study of writing rather than the historical practices associated with freshman composition.
} 
Considering the denial of racialized experiences as contributing to transitioning, this chapter then details how issues of race have been applied to scholarship about on academic writing. This examination exposes a race gap in transitioning studies research, which few scholars have addressed (Kynard; Anson). Most of these discussions occur in work about assessment and work about language difference. My study adds to these discussions by suggesting curriculum that focuses on inclusion rather than difference. I submit that especially Black students who have had discouraging encounters with literacy educators are more apt to engage with writing curriculum that values their ways of knowing while also introducing them to new, adaptable ways of knowing. Based on the history of Black Americans in sites of rhetorical education, community-based and civically responsible writing curriculum have been proven as key types of curriculum that can offer these opportunities.

After looking at the intersections of race and academic writing in writing studies scholarship, my discussion then explores how work on community literacy and community-based writing courses continue to address inclusive perspectives of writing. I explore the blurring of the line between public and academic. On the other hand, discussions of students' racial identity subjectivity are often absent from critical conversations about incorporating community engagement with writing curriculum. Like theories about transitioning, suggested practices for having students collaborate with extra-academic communities tend to rely on a generic, neutral student. Afrocentric curricular models for literacy and rhetorical education provide an alternative approach to community education. These models practice citizen engagement and what I call civic 
responsibility in writing curriculum. I end the chapter with a discussion of the qualitative methodologies I used for this research as well as a summary of the succeeding chapters.

\section{Transitioning and Academic Writing}

Due to school district and legislator concerns about the college-ready quality of secondary curriculum, writing studies has proliferated with transitioning research to complement dual enrollment writing scholarship. Transitioning studies, a term coined by the creators of the Transitioning to College Writing Symposium at University of Mississippi, has generally relied on the experiences of the generic student. Having experienced public education as a racial other of the institution from first grade through higher education, and having taught aspirational dual enrollment high school students from racially and linguistically underrepresented populations, I see this emphasis on generic student identity as negligent. These experiences and the work of scholars concerned with race and success as college writers drive the research for my dissertation study. Jacqueline Jones Royster and Jean C. Williams describes the representation of the generic student in writing studies scholarship. For these authors, "While this seemingly neutral approach could be thought of as placing all students on equal level, the neutrality often erases the presence of students of color with the resultant assumption that, in not being marked as present, they in fact were not there" (Royster and Williams 568). The lack of attention to identity leaves a gap in the understanding the field has about writing movement across academic sites of writing. More critical for writing program administrators, a muddled understanding of student transition experiences in FYW deters efforts to create effective, relevant curriculum. 
For many secondary and post-secondary educators, a wide-open space of uncertainty separates much of American high school level writing from college level writing. Some high school and college pedagogues refer to this space as a gap in knowledge and practice (Budden et al.; Jordan et al.; Mosley; VanDeWeghe; Farris). However concerned teachers, scholars, and administrators might judge it, what persists in this space is the perception of a lack of preparation for college-level writing. This perception stems from, as Christine R. Farris explains, unequal rigor across all institutions involved in transition, from high schools to two-year and four-year colleges, because they do not need to have the same degree of rigor ("Minding the Gap" 272-73). Budden et al. challenge these perceptions about rigor, contending that "because we believe that literacy, and thus literacy instruction, is local and individual, we do not insist that twelfth-grade English should look like first-year college composition" (74). The authors add that emphasizing engagement and accountability for student work makes more sense than attempting to establish college-ready rigor. Due to these and other differences, writing program administrators need to a critical understanding of how the "school culture divide" determines what counts as good writing (Farris, "Minding the Gap" 273). I expand these arguments to suggest attention to the transitional experiences of Black college students.

While I focus on Black students in order to address curriculum effectiveness and engagement, graduation, and retention from a writing program perspective for this population, the curricular model of civic responsibility has the potential to serve multiple student populations. Attending to the transitional moments from secondary school writing experiences to college writing experiences gives us a critical opportunity to understand 
what all students bring with them and leave behind as $\mathrm{we}^{2}$ take on new writer identities. While I realize that transitioning from high school writing is one of many transitions that college writers make, it is the emphasis of this research project. For marginalized populations of students, the challenges in closing the gap from high school to college academic writing can prove even more significant due to of social factors underlying their transitions. If the scholarship claims that a gap exists between what students do for their high school English teachers and what they are expected to do for the college writing teacher (Strachan; Dombek and Herndon; Hoffman et al.; Farris; Sehulster), someone or some entity must be responsible for bridging that gap.

Some scholars propose that all institutions involved, as well as the parties invested in those institutions, have the bridging responsibility (Strachan; Hoffman et al.; Sehulster). The gap separating high school English from postsecondary writing expectations represents a disconnection between writing instruction in high school and writing instruction in college (Strachan; Farris; Denecker), instructional goals in high school English courses and college composition courses (Strachan), a difference in the institutional culture of writing at secondary level and postsecondary level (Budden et al.; Mosley; Sehulster). This cultural difference shapes a functional difference at each of these institutions as well (Conley). Teachers and other curriculum designers at both the university and high school level must investigate how specific "notions of good writing and our institutional constraints differ across the school culture divide" (Farris, "Minding the Gap" 273). As Chapter Four of this dissertation will illustrate from interview

\footnotetext{
${ }^{2}$ In the Black Feminist Intellectual tradition, I am using the first person to indicate my association with all of the groups I identify with in this project including Black community members, writing instructors, and composition studies researcher. When using the third person to discuss Black students, I am positioning myself as a teacher.
} 
responses, the way many students perceive the required purposes of secondary written work and postsecondary written work differs.

Secondary teachers are often condemned by college faculty for their focus on teaching to the test. While standardized assessment-based pedagogies can be one aspect of the curriculum in public secondary schools, the real concern lies in that "college theory and high school practice differ greatly" (Mosley 60). Labor conditions, school district or administrative restrictions, and standards such as the Common Core place controls on both secondary and postsecondary teachers of writing, yet at the secondary level those controls can seem to result in a loss of pedagogical flexibility. Controls such as the General Education Written Communication Criteria and student learning outcomes analyzed in Chapter Three give college writing curriculum similar pedagogical limitations, even if they are presented differently. A key difference between the writing pedagogies in a traditional high school and those at the college level is that the former occurs most frequently in a literature survey course (Hansen et al.; Mosley 61) and the latter occurs in courses dedicated to the subject and act of writing. Exceptions exist to this divide, but it is one of the key differences that causes complications for new, transitioning high school graduates.

High school teacher and college composition adjunct instructor ${ }^{3}$ Milka Mosley describes writing for high school courses as "formulaic," clarifying that "[h]igh schoollevel writing is usually very predictable," because "students typically write mainly to conform" (59). From an instructional perspective, Mosley writes that high school teachers "have too many students and too little time for grading, so [they] often allow students to follow a formula to produce a product" (58). Writing primarily literary

\footnotetext{
${ }^{3}$ Mosley was an adjunct at the time the chapter used in this discussion was written.
} 
analysis and response papers based on topics from literature courses allows students to adopt formulas for success without much difficulty. These formulas which focus on specific structural elements-introduction with thesis and claim, specific number of body paragraphs with designated amount of support, and conclusion with reiterations-allows students to focus on superficial writing skills. These stylistic, quite quantifiable elements of written work shape the instructional goals of writing in many secondary English courses. High school teacher Mary Nicolini disagrees with generalization about high school English, because she expects her students "to grapple with essential questions such as 'How shall we live?' and 'What does it mean to live well?'” as a part of their development of original theses and support through examples (Budden et al. 75). This perspective shows much of what writing studies has published about problems in minding, bridging, and crossing the high school to college writing gap comes from college representatives and not high schools.

Rick VanDeWeghe suggests that the purposes of formulaic writing in high school relies on the superficial features of writing that construct writing as an end product of actions rather than those actions (62). Contrasting writing as a noun against writing as an action creates a distinction between placing ideas into a formula for writing and using a precise formula to best convey ideas. VanDeWeghe argues that college-level writing asks the latter of students, and students must make a "paradigm shift" as they transition from seeing writing as something that is made to something that is done as it is made (63). The restrictions and conformity needed for helping students learn to both "develop into writers and thinkers" (Mosley 59) and pass the written portions of standardized tests can hinder some students in college-level writing where "assignments call for analysis, for 
understanding how something works or why it works the way it does" (Farris, "Minding the Gap" 274). Jeanette Jordan et al. contest this myth about formulaic writing in high school, stating, "We value nonformulaic writing and struggle to push our students beyond the very limiting five-paragraph structure that they find so comforting and familiar" (38). What's more, the research results, provided by the "unique voice of color," within my study challenge many of these notions about restrictions and conformity in high school writing assignments.

To situate the rhetorical purposes of college-level writing in comparison to the secondary school writing, VanDeWeghe cites a study conducted by Nancy Sommers and Laura Saltz at Harvard University about attitudes and approaches to writing in the freshman year of college. Sommers and Saltz recommend that students embrace the position of the novice on essay topics to close the gap from high school-level writing to college-level writing (134). The role of novice does not imply the complete ignorance of subject matter. However, thinking principally about transitioning to college-level writing practices, a novice perspective "involves adopting an open attitude to instruction and feedback, a willingness to experiment, whether in course selection or paper topics, and a faith that, with practice and guidance, the new expectations of college can be met" (Sommers and Saltz 134). This idea of students writing themselves into topics and subject areas reflects the argument David Bartholomae (1986) makes in one foundational text for transitioning and college composition, "Inventing the University."

Like novices in professional research, students create their university through trial and error in using academic discourse. When students begin to write for college, instructors judge authority is created by the ability to employ academic discourse not by 
demonstrating knowledge of a topic (Bartholomae 5). Bartholomae suggests that, like all writers, student writers imagine themselves as insiders on topics (10) and are consequently writing in unfamiliar discourses to demonstrate knowledge (11) rather than writing to learn as Sommers and Saltz advocate. Even when students are just beginning to transition, instructors expect them to write within a discourse they seldom understand the purpose of, despite the significance of purpose to how discourses are put into action. Sommers and Saltz argue that students can acclimate to the discursive uses of collegelevel writing by shedding the habits they have formed in previous academic writing scenarios and accepting the new opportunities that college-level writing practices will permit them (134). While the approach suggested by Sommers and Saltz is hopeful, Bartholomae's work suggest that relying on students to venture into these discursive unknowns by their own accord can be pedagogically irresponsible (10). Both high school and college teachers should, but often do not, make apparent those moves that are associated with academic discourse and the purposes for engaging this discourse (Bartholomae 11). As most students have had limited exposure to the specific ways of knowing, selecting, evaluating, reporting, concluding, and arguing practiced in collegelevel writing (Bartholomae 4), they are often, for a period, caught between their primary or previous academic discourses and the academic discourses they have yet to master. Therefore, one effective goal of introductory college writing instruction is to help students understand how rhetoric and discourse operates within academic communities. In Chapter Two, I further this argument by proposing that students learn to understand discourse and rhetoric in general as a way to create action in multiple civic communities, without privileging academic communities. 
The concept of writing within discourse communities or communities of practice does not coincide with the institutional writing goals of most high school education. Hence, the notion of multiple academic discourses is alien to most first-year college students. While some high school teacher-scholars claim to "help seniors develop habits of mind or dispositions about the writing process that they can adapt and transfer to college-level assignments" (Budden et al. 74), others focus on preparing students to write for different purposes and different audiences expecting various outcomes (Jordan et al. 39). According to several scholars examining pre-college credit composition curriculum practices, high school teachers often perceive students as vessels to reflect information, and college instructors see students as creators and contributors of ideas (Mosley; VanDeWeghe; Farris; Denecker). Christine Denecker describes the shift between primarily reporting facts and textual information in high school and researching ideas or inquiries in college-level writing. This difference is one of many that reinforces the divide between secondary academic writing conventions and postsecondary writing habits. It "reflect[s] a difference in perception of the relationship of students to their subject matter" as well as "perceptions of learning and knowing" (Strachan 143). These varied perceptions are formed by the cultures of high schools and universities, and scholars (Vivion; Strachan; Farris; Sehulster) have argued for critical dialogue between colleges and high schools to overcome how the approaches affect student learning. Farris urges high school teachers to demystify the practices needed to navigate academic discourses before students get to college classrooms.

To give formulaic writing more meaningful purposes than practicing syntax and organization, Farris advises high school instructors of writing to concentrate on preparing 
students for the inquiry practices that breed good intellectual work ("Inventing the University" W438). In a focus group interview, secondary teachers told university writing professor Wendy Strachan that they see their job responsibilities as ensuring their students attain a good mark on the [state] standardized exam (138). These practices do not result in the kind of inquiry-based intellectual engagement with writing that Farris advocates. Instead, they give rise to weekly writing responses and writing tests that prepare students to take exams to get into college rather than produce college-level work. Even college prep high school courses, which claim to prime students for the skills they will need to be successful with college-level writing, do this by way of formulaic, onesize-fits-all rules (Farris, "Inventing the University," W441). As indicated by Sommers and Saltz, many students struggle to move past these rules (134), and the variety of college-level writing practices often challenge their notions of good writing (Strachan 146). That attitude might be remedied in part by secondary English teachers reconceiving "their roles as not so much about inoculating students against future writing tasks or forecasting success or failure but making the next stage in students' intellectual curiosity and development possible" (Farris W440). Certainly, to do this high school teachers must have an inclination of what that next stage involves.

Jeanette Jordan et al. (2006) question whether high school teachers actually know what scholarly obstacles students will face in college. Even if they do know, personal and institutional notions about academic writing and what students should do with it can still hinder true preparation for college-level written work. Jordan et al. explain that they sometimes justify 
that writers need to understand the traditional rules before they can learn a sense of how and when these rules can be broken. But that theory leaves me with the feeling that I, as a high school teacher, am saddled with the burden of teaching the rules and gaining the reputation of a stickler, while professors get to sail through uncharted linguistic waters, throwing rules overboard at whim, gaining their students' approval and respect at every turn. (37)

These uncertainties are vindicated when college writing instructors turn to berating high school teachers for what we perceive as incompetent or "poor quality" writing (Budden et al. 75; Mosley 59-60). This berating and blaming leads to further misunderstanding between the secondary and postsecondary institutional culture around writing curriculum rather than attempting to understand systemic constraints. Since no FYW course and no writing program is alike, prepping all students for the college of their choices seems unfeasible and a terrible use of resources (Budden et al. 76). Nicolini argues that "the best way to meet ... students' diverse needs is to have them think about ideas and generate original theses about topics of interest" supported by specific details and examples, all valuable writing habits at any college (Budden et al. 76).

Better practices for college-ready writing instruction in high school may be a moot point since, as implied by Patrick Sullivan and Howard Tinberg, the field has yet to come to a consensus on what exactly constitutes college-level writing. In fact, the question of how the student participants in this study define college-level writing is one of the topics of the interviews in chapter three. The meaning of college-level writing is layered by many contexts outside the classroom and even outside the writing program. 
Within these layers exists "a whole range of interrelated and interdependent skills associated with reading, writing, and thinking" (Sullivan and Tinberg xix). If literacy instruction is relevant to the needs of the site of the instruction, the administrators of the instruction, and the recipients of the instruction, FYW and high school senior English cannot serve the same purpose (Budden et al. 74). College-level writing can only be understood by the combined network of efforts between departments, institutions, and state governments (Gentile 315). The same can be said of twelfth grade English. No matter the specific institutional definition, James M. Gentile marks college-level writing as any written assignment in college courses that "requires a significant level of cognitive engagement" (311). Although, defining college-level writing in such a way implies that pre-college writing does not expect that level of intellectual rigor. High school and college writing curriculum become mismatched when specifying what that engagement should look like on the printed page (Denecker). Budden et al. suggest that preparation for college writing means teaching writing that is well-received in general. For example, senior English should require work that encourages confidence for texts and critical thinking rather than attempting to meet a vague standard of college-level writing (Budden et al. 74).

The inability to define what college-level writing is creates just one obstacle for both high school and college teachers in helping students transition to college writing. Differences in goals for writing curriculum can confuse students about what constitutes good academic writing. Even outside of managing issues of race, poor communication between colleges, high schools, legislators, and standardized test developers can make college writing readiness difficult to achieve. The National Council of Teachers of 
English and College and the Council of Writing Program Administrators have provided guides for high school and college writing teachers through the Framework for Success in Postsecondary Writing and "WPA Outcomes Statement for First-Year Composition." These documents offer a general overview of what college-level writing often involves at many colleges. I qualify the statement with several terms, because these guidelines cannot apply to every situation, teacher, student, or college. College professors and high school teachers alike often complain that any writing instruction prior to senior year of high school is primarily for test preparation purposes. If the writing situations--timed, five-paragraph essays--actually matched the types of writing situations practiced in college classrooms, the test prep strategy would be fine. However, the strategy has basic flaws.

Most common secondary writing curriculum aims to reduce controversy (Farris, "Minding the Gap" 277). Tests like college entrance exams and graduation qualifying exams encourage uniformity in writing, not only in structure but in content. Similar expectations can be found in university assessments as well. Carmen Kynard's "Writing While Black" details a university-wide writing assessment, in which her Black students' reactions ranged from refusing to play the game of the assessment to showing their intelligence in their own discourses to playing the game and writing as was expected, giving the evaluators the rhetorical moves they wanted to see and the content they wanted to read. The students who conformed to the test-makers' expectations in form as well as content received the highest passing scores, while the students who resisted received failing scores. This case study provides a clear example of how writing assessment at the secondary and postsecondary levels can act as another form of dominant values 
enculturation, and students who question these values at the wrong time are, at least academically, punished.

On the other hand, college courses focus on critical thinking and encourage controversy where necessary (Farris, "Minding the Gap"). Principles of academic freedom and inquiry promote some choice, if not extensive choice, in the topics students write. This amount of choice is unusual to most students. In a conversation with high school English teachers, college professor, Strachan discovered that students are neither expected nor encouraged to position themselves within a debate on a topic. One of the teachers explains that the student would not have gathered enough research or information on the topic to engage the debate in a meaningful way. This reflects the literacy practices for writing in most United States high schools, where students are expected to collect and reflect the knowledge that others have created (Farris 274-75), but not to question that knowledge or create new perspectives on it.

With a focus on inquiry and discovery (Farris, "Inventing the University" W439), the habits of mind (CWPA, NCTE, and NWP) needed for writing in college receive little attention in secondary curriculum. When they do take place in high school classrooms, the daily realities of the high school culture do not support the processes of deep critical thinking or metacognition for example. With nineteen to twenty-five students in sometimes seven classes, and without the support of a writing center or other peer tutoring services, luxuries like drafting or revision are not feasible for high school writing pedagogy (Strachan 147). Instead, teachers hope and expect that when introduced to the traditional writing process, students will habituate the process on their own accord. 
Transitioning to college writing sees most students learning how to make this process work with their own for the first time.

Transitioning students bring their past few experiences and associations with inschool writing with them to college courses. What they think they know about academic writing comes from these associations. Many of these assumptions are based on three basic trends in high school writing instruction: writing pedagogy within literature instruction, the influence of state and nationally mandated standards on writing curriculum, and the minimal amount of writing due to paper load of high school teachers. Farris suggests that high school courses may have success in aiding transition by teaching portable concepts. Concerned with more than the subject matter, goals, or rhetorical means of specific reading assignments, "essays with portable concepts offer new lenses for understanding issues, phenomena, images, and events, some of which students may have taken for granted" (Farris, "Minding the Gap" 277). Nicolini's emphasis on essential questions (75), discussed earlier in this chapter, is one example of a portable concept. Secondary teacher Alfredo Celedon Lujan's voice-based writing curriculum focused on getting students to "manipulate the task" (56) by using voice as "a rhetorical stamp" (55) is another. This pedagogical approach might address the obstacle of transitioning from the problem/solution pattern of high school academic writing to the inquiry-based practices of college-level academic writing. This difference is probably most clearly exemplified in articulation of FYW credit from concurrent enrollment programs. According to Hansen et al., "Designers of college FYW courses generally plan the curriculum to challenge emancipated young adults who should be ready for the rhetorically challenging and perhaps morally and ethically challenging texts that are often 
a part of FYW" (Hansen et al. 10); high-school-aged individuals may not be prepared to face, analyze, and intellectually discuss the content of such texts. Several scholars propose that the first step in crossing this threshold is a meeting of the minds between high school and college instructors and administration. I agree with this supposition, based on the qualitative study provided in this dissertation, which offers both student narratives and institutional analysis from the college perspective. One further step includes conducting institutional analysis at the secondary level as well. In the next section, I demonstrate the ways that the realities of racialized experiences in our society and public education system further disrupt our field's discourse about writing in the high school to college transition.

\section{Race and Academic Writing}

\section{Critical Race Theory and Academic Writing}

Compositionist Gary Olson suggests that the field of writing studies should familiarize with critical race theory (CRT) for the purposes of building writing pedagogies and programs that are conscious of and responsive to issues of race in the student body (216). I argue that CRT can help teachers and program administrators see the effects the racialized social system of academic writing on Black American students, especially, as they transition from high school to college-level writing. The racialized social system of college-level academic writing is part of what Eduardo Bonilla-Silva calls a society of racisms without racists. Bonilla-Silva hypothesizes that color-blind approaches to social institutions, like education, actually support white supremacist actions, because those approaches eliminate any space for dialogue over race or race consciousness. By promoting writing student learning outcomes as necessary for 
employment and prosperity without considering the embedded role of dominant White perspectives, colleges and writing programs participate in racism without racists. FYW courses, right at the point of transitioning into college academic identities, are a key component in this hidden curriculum.

Critical race theorists in education define the hidden curriculum as an underlying effort by the mainstream education system to keep the values and customs of Eurocentrism in dominant circulation (Ladson-Billings and Tate; Ladson-Billings; Leonardo). For rhetorical education, mainstream cultural participation has conventionally been portrayed as the ultimate goal. Rhetorical education is frequently used to assimilate those with marginalized traditions into the social actions and language performances of the dominant society. However, as recent scholarship reconsidering rhetorical education has highlighted, mainstream social participation has not necessarily come from mainstream education (Royster; Glenn, Lyday, and Sharer; Enoch; Logan). Chapter two of this dissertation considers why unconventional education practices, specifically Afrocentric practices, are more useful than standard practices for teaching rhetorical education towards participation in multiple communities. These Freedom School, Citizenship Education, and independent Black institutional models of education (Cobb; Gillespie; Levine; Perlstein) directly challenge the implicit value of whiteness-invested education systems. Observing the success of these models shines a light on the investment in whiteness of college-level rhetorical education, especially, as it is constructed as preparation for lifelong social, cultural, and political membership.

In particular, the transition from high school to college writing can be difficult for students whose individual and social identities are far removed from that of what the 
institution imagines as the typical college writer. Bronwyn Williams suggests that institutional culture conceptions of literacy and literacy identities can clash with individual conceptions of literacy and its associated identities. If literacy practices are one way to perform identities (Williams 4), then those practices perpetuated by most higher education institutions represent those that reinforce cultural norm and power structures (Williams 3). Institutional writing standards at the majority of American universities represent the interest of the culturally dominant majority. Values of whiteness are a part of these majority interests because whiteness is the background of all social action, the backdrop to Americanness (Ahmed; Barnett; Harris; Inoue). This trend is not only reflected in college writing courses but in composition and writing studies disciplinary histories as well. If the perspectives a discipline chooses to include as part of its histories represent what it privileges, the "spaces left" by Black perspectives in writing studies histories points to the disenfranchisement of Black American viewpoints about writing and teaching writing (Royster and Williams). These disciplinary absences manifest in how administrators create programmatic goals and how instructors engage with student writing.

Catherine Prendergast argues that these absences have created race as an absent presence in writing studies. More directly, racial perspectives are seen as irrelevant to composing processes. Where race is an absent presence, Prendergast argues that racism has been an "absent absence," suggesting the evasion of racial influences, "white included," in methodologies and theories about composing (36). These gaps in studying writing prevent us, as a field, from fully examining the racialization of university policies and their impact on teaching and learning in the writing classroom. Investigating these 
institutional policies proves difficult, in any case, because they are so ingrained in cultural conceptions of whiteness and Eurocentrism that they have become "unconscious" in the academy and in writing curriculum, especially (Brandt 348; Prendergast 37). Chapter Four of my dissertation analyzes this phenomenon more closely through a curriculum analysis of the General Education program at the University of Louisville, including a primary example to make considerations of cultural diversity separate from critical thinking and effective communication practices. As an instructor, junior administrator, and community citizen at the University of Louisville, I want to shed light on the strengths and, more importantly, the limitations of the current curriculum related to teaching and learning college writing practices at the transition level. I detail the situation at the University of Louisville in the Methodology section of this chapter and in Chapter Four, I discuss the implications for learning of separating these competencies rather than including cultural diversity, for example, as part of effective communication. Doing so is one way to help the overall curriculum expectations move beyond the privileging of whiteness in culture.

A byproduct of this attachment to whiteness culture is that negative connotations associated with cultural conceptions of blackness manifest in K-16 literacy classrooms. Historically, composition courses, like most English language education in American, have seldom if ever had the goal of teaching students of color to use academic discourse for purposes of social or political critique (Smitherman; Delpit). Higher education is one of many social institutions that exist to establish whiteness as the highest achievement and anti-whiteness or blackness as the lowest failure. Whiteness has less to do with racial identity than it does with the practices and enactments that reproduce the values 
representing Eurocentric cultures, such as their language, education, and employment preferences. Hence, when Black Americans speak and write in Edited American English (NCTE), they are deemed articulate, educated, and intelligent by the standards of traditional rhetorical education.

Blackness as a racial signifier in Western culture symbolizes many attributes, but literate ability is not among them. That is, literacies and literacy practices that stem from Black American culture symbolize a complete removal from the institutional literacies of academic institutions. Whereas constructions of whiteness directly correlate to dominant American ideals--individual accomplishment, prosperity towards upward social mobility, and the ability to overcome struggle with grace--blackness correlates to anti-American ideals. Gloria Ladson-Billings contends with the cultural narratives of "conceptual blackness" such as "gangs," "basketball players," and "welfare recipients" to suggest that society constructs whiteness as a scale along which all experiences are ranked (9). Dodging racialized experiences serves to normalize White--the socially dominant-experiences. Such is the case even as our college student bodies shift in many ways, race included. Responding to the most socially and politically valued life experiences alone reinforces the prejudice and subjugation many students of color have contended with throughout their time in literacy education. Students who consider ourselves distant from the values of the prevailing American culture, whose worldviews privilege the ideals of blackness, may be unsure of how we fit into the customs of the traditional college settings. 


\section{Race in the Transition to Postsecondary Writing Practices}

Transition-focused writing studies scholarship has given attention to what is at stake when the generic student population fails to make the shift from secondary-style academic writers to college-style academic writers. This dissertation expands on research about minding, bridging, and narrowing the gap between high school and college-level writing to suggest attention to the transitional experiences of Black college students as one under-researched academic population. Writing studies scholars suggest that writing links to, creates, enacts, and represents identities and associated ideologies (Scott et al. Ch. 3), and American society and culture are largely predicated on a racialized social system "or white supremacy for short” (Bonilla-Silva Ch. 1). Therefore, racialized experiences in literacy instruction, rhetorical education, and education overall must be taken as vital to understanding transitions across academic writing contexts. If a society built in large part on a racial caste system legitimizes whiteness as the most highly coveted asset in all mainstream institutional spaces, the influence of this racial hierarchy on the engagement with writing curriculum for new Black college students should be examined (Harris 277). Still, the key disciplinary texts discussed below, which explicitly discuss transitioning generally, omit race from the conversation.

Two prominent texts which discuss crossing the threshold between secondary and postsecondary writing have been published in the last five years. One, College Credit for Writing in High School: The "Taking Care of" Business from which Farris's "Minding the Gap" essay derives, details the realities of teaching college writing courses in various dual enrollment and pre-college environments. The contributors describe complications of teaching writing in preparation for college and strategies for addressing these 
complications. This text includes just one reference to racial identity, in Barbara Schneider's discussion of early college high schools, a type of pre-college credit opportunity targeted at families from racially underrepresented, English language learning, and working class backgrounds. The other book, Naming What We Know: Threshold Concepts in Writing Studies, takes a writing-about-writing approach. The contributions of multiple scholars outline the concepts which define the field of writing studies, or the threshold concepts of the field. While concept three, as outlined above by Scott et al., suggests a connection between writing processes, identity, and ideologies, the section "Using Threshold Concepts" describes how threshold concepts apply to writing program student learning outcomes and first-year writing but give little attention to any student identity, let alone racial identity. Instead of arguing for making race a central theme of these texts, I suggest that scholars who aim to put theory into practice through the development of regulations like writing program outcomes take note of what they leave out by not giving any attention to racial culture of students.

Frequently, if race is not ignored entirely in transitioning studies literature, then it is referenced as almost a footnote. Chapter Twelve of Teaching Writing in High School and College: Conversations and Collaborations exemplifies how race is implied as a factor but not confronted. In “"Why Do I Have to Take Remedial English?': A Collaborative Model to Solve a National Problem," Chris Jennings and Jane Hunn speak of the rate of high school students from Salem High School that enroll in remedial English at a local community college. The authors conclude that "aligning instruction, empowering students, decentralizing classrooms, and heightening attention to better serving the needs of the graduation high school student/incoming first-year college 
student" is critical to writing instruction at both secondary and postsecondary institutions (Jennings and Hunn 199). What is left out is who many of those students are. When, as part of the collaborative project between the two institutions, providing an example letter from a high school student to a community college English student, the letter is from a presumably Black American student. The student writes, "I am involved in two school clubs, which include: [sic] DECA (Distributive Education Clubs of America) and BCC (Black Cultural Club)" and "My top three college choices include: Hampton University, Clar[k] Atlanta University, and Old Dominion University" (Jennings and Hunn 192). As the majority of students who join Black student organizations and choose to attend HBCUs like Hampton and Clark Atlanta are Black American, the student's racial identity is almost certain. Moreover, in the 2015-2016 school year ${ }^{4}, 60 \%$ of Salem High School students were of a racial or ethnic minority, and $37 \%$ were considered economically disadvantaged (Virginia Beach City Schools 2). In their discussion of collaboration and addressing student needs, neither racial identity nor racialized experiences are mentioned. I deem this as an implication of race based on our field's tendency to conflate Black students and English language learners with remedial writing (Royster 570). If Black students are, for the most part, expected to enroll in developmental, remedial, or basic writing courses, then this is not worth noting in transitional writing scholarship.

According to the Office of Institutional Effectiveness at Tidewater Community College, the community college discussed by Jennings and Hunn, Black students comprised 34\% of the Fall 2014 student population, but this is left unexplored. Data collected by institutional research at this college shows Black students have made up 33$36 \%$ of the total student body between all community colleges in the system (Office of

\footnotetext{
${ }^{4}$ Note about years of study discussed in article.
} 
Institutional Effectiveness, "Student Demographics"). Per the college's Office of Institutional Effectiveness Quick Facts, the school has the "[1]argest undergraduate African American enrollment in Virginia higher education and 7th largest associate degree producer among two-year colleges for African American students" (The Office of Institutional Effectiveness). With at least some of the $49 \%$ of Black students from Salem High constituting over a third of the student community at Tidewater, the inattentiveness to racialized experiences leaves wide gaps in any conclusions drawn from this study. Issues of racial identity are minimally considered in the volume What is "College-Level" Writing? Chapter Four, on helping students hone their voices in their academic writing, indicates identity as a component of this approach. Some of the student writing samples include those of multilingual (Spanish and English) students writing in both languages or in the non-English language alone. Although author Lujan argues that "[w]riting without voice is breathing without rhythm—is speaking without body language, accent, dialect, or inflection" and therefore, "good writing rings true with voice authenticity" (43), the correlation between voice, race, and institutional writing standards is lacking. While it may be somewhat effective to help students develop authority and ownership of the writing by helping them gain voice authenticity, this has its limitations as they transition across academic sites which represent cultural norms of language and literacy. These norms exclude and frequently attempt to colonize the voices of many Black students. The intersection of race with teaching writing receives some discussion in the transitionfocused anthology Critical Passages: Teaching the Transition to College Composition. However, to more fully assess the issues related to racialized experiences and 
transitioning into college-level writing practices, I look to a range of scholarship on race and academic writing.

Influenced by critical race theorists, I propose that the racialized social system (Bonilla-Silva) of American society is mimicked in the public education system and more specifically in the recommended writing curriculum of college writing courses and programs. Many Black students in predominantly White academic environments, whose cultural identity of blackness stands in opposition to the institutional orientation with whiteness, contend with this social structure of the education system from an early age. Some scholarship in writing studies does take into consideration how racialized life and college experiences influence students' interaction with writing curriculum. Much of this research comes out of writing assessment research. Race and Writing Assessment edited by Asao B. Inoue and Mya Poe directly confronts constructions of race in writing assessment practices. This collection addresses race as a contributor to writing assessment from a programmatic level.

Writing assessment at the programmatic level influences classroom practices as institutional assessment tells instructors what they should teach about writing to prepare their students for success in the academy. A study conducted by Judy Fowler and Robert Ochsner, which entailed cross-institutional assessment of student essays, found that for one of the institutions, "an unfamiliar dialect [in the essays] earns less favor from a reader or teacher than those of familiar dialect" (119). In this case, unfamiliar dialects based in racial culture may be discouraged in writing courses at that institution rather instead of engaged with academic discourses. Section four of this same anthology, Race and Writing Assessment, poses questions and answers regarding the affordances and 
limitations of placement testing for determining the start of first-year writing students' college writing education. The chapters are specifically concerned with the "negative impact on those populations who are often most vulnerable in educational contexts" (Inoue and Poe 139). The contributors consider the limitations of directed self-placement for students of color (Ketai) and the racialization of writing practices by placement technologies at two east-coast American art schools (Lioi and Merola). Each of the institutional and programmatic assessment practices indicate how "flawed interpretations of assessment results" can have detrimental consequences for especially Englishlanguage learners and students of colors (Inoue and Poe 139).

Some consequences of writing assessments on vulnerable populations include penalizing students for communicating in their home or native literacies, even if that communication is articulate and critical (Kynard). This phenomenon is a result of "sociospatial features" of academic settings (Bloomaert 2). Rather than being a passive place within which writing and other literacy practices happen, teachers should think of college as "an agentive force" where "[a]rticulate, multilingual individuals could become inarticulate and "language-less"” as they move into this space that generally devalues their discursive resources (Bloomaert 2). Although teachers may have little input in institutional-level writing assessment, Inoue offers grading contracts as racially-inclusive course-level writing assessment.

Beyond assessment of student writing alone, programmatic considerations of racial experiences should account for writing across the curriculum. Chris Anson regards the impact of racial diversity in writing across the curriculum (WAC) in both classrooms and programs (15). Suggesting that the majority of WAC scholarship generalizes student 
identity rather than conceiving them "as individuals who bring specific histories, experiences, and 'vernacular literacies' to their learning" (Anson 23), Anson calls for faculty training and program assessment attentive to racialized experiences. Michelle Hall Kells' writing across communities $\left(\mathrm{WAC}^{2}\right)$ approach to WAC programming seems to address this call, in part. Kells argues that to connect college literacy practices to students' home communities, WAC should be re-imagined to engage multifaceted discursive representations (371). This approach engages students' ethnolinguistic diversity as an asset of the linguistic resources they bring with them rather than a problem to be solved. While neither Anson nor Kells specifically identify issues of transitioning, their emphasis on the histories and verbal traditions students carry with them to college writing curriculum applies to the high school to college writing transition.

Rather than leaving issues of program administration and racialized experiences to WAC alone, Staci Perryman-Clark details possibilities for writing program learning goals centered on investigation of various linguistic practices. The essay, "Toward a Pedagogy of Linguistic Diversity: Understanding Ebonics Linguistic Practices and Programmatic Learning Goals" offers "Ebonics" as one of those language practices to study in FYW. This case study provides a useful example of how aspects of race can become a part of the curriculum instead of an adjacent discussion. Kynard similarly creates racially inclusive FYW courses, noting that first-generation Black and Latinx students enter the university from sub-par public education situations. Since Black students are one of the student populations most affected by this teaching labor trend, these specific experiences are racialized in our culture. Such experiences can create troubled transitions for these students and a distrust of the viability of FYW courses 
taught by inexperienced graduate students, for example. Ignoring the effects of the social racial hierarchy on FYW students, as presented by these researchers, results in perpetually marginalizing, exclusionary writing pedagogies and programs.

Taking a critical race lens to the transitional moments from secondary to postsecondary writing experiences gives us a critical opportunity to address deeper societal issues that often makes transferring literacy practices across institutional cultures a constant struggle for many students, specifically those from "underclass" (Wilson) Black communities. Community-based FYW pedagogies and civically-engaged writing programs move writing curriculum in the direction of addressing societal issues that affect writing. For students who value rhetorical practices in traditions not represented in academia, such as some of the Black American students interviewed for my study, connecting academic writing practices to the language practices they use to communicate in their churches, clubs, and families demonstrates conscious recognition of their raciallinguistic communities. However, most of the research in the areas of community literacy and community-based writing centers on the relationship of the institution to the community partners rather than how this curriculum drives student engagement with writing. Even as these approaches address social issues related to composing, they overall fail to explore the correlation between students' racial identities and community engagement projects. By creating a foundation of writing for civic responsibility in students, I submit that FYW courses can create a space for all students, regardless of racialized experiences, to connect academic writing practices to community involvement. 


\section{Civic Responsibility in First-Year Writing}

\section{Defining Civic Responsibility}

Civic responsibility as I use it refers to the accountability community members have for contributing to, influencing, shaping, and remaining informed of citizen community life. In the case of FYW courses, students are those community members. A civically responsible writing curriculum brings teachers and students together by privileging a variety of written and spoken discourses and language practices. It includes the historical uses of power and techniques of rhetoric (Coogan 2010) behind particular discourses. In this way, writing courses concerned with civic responsibility are also concerned with the "ethical dispositions" (Duffy) of engaging citizenship through language and rhetoric. Effectively, centering on civic responsibility in writing encourages students to take the steps necessary to making informed, responsible, and ethical claims, because they are engaging with writing beyond success in a 15 -week course.

Students can gain a sense of civic responsibility from academic writing practices by working with community agencies, and this has been the most common approach to community-oriented writing pedagogy. Public service (Deans), public engagement (Flower), and service learning (Herzberg; Lisman; Green; Coogan) pedagogies operate from the notion of academy representatives — usually students - offering their services to community representatives. In writing courses, these services may include non-writing tasks in which the students write about their experiences for course assignments. Otherwise, they may include writing tasks in which students write with or for the community representatives (Herzberg; Flower; Deans). In this relationship, students are often positioned as givers and the community representatives as receivers. 
While Flower argues that this model of rhetorical pedagogy can begin to teach students how to use rhetoric to speak against oppression and injustice (Ch. 3), other scholars have contested the effectiveness of the model in sustainable community development (Williams and Brydon-Miller). In "Participatory Action Research, Agency, and Representation," Bronwyn Williams and Mary Brydon-Miller argue for participatory action research (PAR) as an approach to community-centered work in writing research. This approach is based in collaborative efforts between researchers—or students, as the case may be - and community members. It suggests that there is no need to speak against injustices for community members, if they have the tools and resources to speak for themselves. This shift in perspective about the relationship between the students and the community representatives has the potential to sustain social change for communities more categorically. However, even in implementing writing pedagogies like the PAR model, students still need to understand the history of the communities and community agents with whom they are engaging. Applying materialist rhetoric to service learning pedagogy, David Coogan contends that "[e]ffective advocacy does not begin with principles of good argument ... but with an analysis of those historical and material conditions that have made some arguments more viable than others" (211). Civically responsible writing for community partners investigates and assesses these conditions and their outcomes in order to adequately engage with communities.

When writing courses teach students to "read public discourse as an [sic] historical project" (Coogan 228), they can comprehend and respond to the role of discourse in community social issues, with part of the goal being in the students' own communities of belonging. Especially for students from historically oppressed 
sociocultural groups, this pedagogy for community-based writing encourages them to exercise their right to use their words and experiences for the advancement of their communities (Freire 88). In addition to focusing on building students' foundational knowledge of community histories and discourses, a curriculum of civic responsibility situates writing as a way to be accountable for community progress. In this sense, civically responsible approaches work to eliminate the need for "false charity" (Freire 45), which service learning curriculum, most notably, can reinforce (Herzberg; Lisman; Green). Where civic responsibility is based in accountability and efforts at meaningful social action, service learning is often based in the spirit of volunteerism (Lisman), which promotes false charity. False charity maintains the status quo by keeping in place systems that force the socioeconomically less fortunate to remain in a position of needing, and the privileged to remain in a position of giving. A writing curriculum of civic responsibility allows students to address these broader concerns, because they are able to use academic writing practices and other written discourses to speak as members of communities.

\section{Civic Responsibility and Race-Conscious Writing Curriculum}

Some conventional approaches to community-based writing curriculum perpetuates what Paolo Freire calls the dehumanizing project of education, because they imply a need for service, a need for the social conditions that make charity and oppression possible. Herzberg questions what service learning projects help his students learn about the nature of the social problems that necessitate community agencies and organization (308). Students often see these "problems as chiefly or only personal" and never search for systemic explanations (Herzberg 309). This outcome might result from the ethic of service and spirit of volunteerism approach to service learning that 
emphasizes character formation rather than social justice, as suggested by David C.

Lisman. In this model, prioritizing volunteerism outweighs other purposes such as justice, strengthening of civic infrastructure, or community development. Learning is focused on student outcomes rather than community outcomes.

Afrocentric education approaches, on the other hand, privilege community as an extension of the individual — the student for the purposes of this argument. These approaches therefore, avoid the singular self-development outcomes of many Eurocentric community writing curricula. By borrowing from the independent Black institution model of education, as discussed in Chapter Two, FYW courses might focus on the connection between the personal, social, educational, and civic. The teacher aims to make the curriculum reflect students whenever applicable (Lomotey 459). This connection between students' multiple ways of being means that community engagement work requires a grounding of community consciousness. Multiple social identities, including cultural, community, racial, and national (Lee 166) would be taught as influential and necessary to understanding ourselves as writers. For this reason, whiteness-controlled epistemologies about writing, literacy, and rhetorical education would be taught alongside other ways of knowing (Lee 165) such as Afrocentric or those based in local indigenous communities.

Other models of Afrocentric education such as Freedom Schools and Citizenship Schools situate rhetorical practices as a tool for action towards community development (Cobb; Gillespie; Levine; Perlstein). Under these exemplars, service projects correlate to the enhancement of students' home or local communities. In writing courses, this gives them a sense of responsibility for the language they use as well as the actions that 
language creates. Chapter Two examines these models in more detail to show their relevance to civically responsible approaches to writing curriculum.

\section{Methodology}

To determine the gap created by evading racialized experiences in secondary to postsecondary transition theories, this study works with a triangulated methodology of interviews, narrative, and institutional analysis, superimposed by a racial methodology. These methods and methodologies operate to explore the experiences of Black American students transitioning to college-level writing in the case of the University of Louisville. University of Louisville is a research 1 institution located in Louisville, Kentucky. According the university's diversity plan for 2011-2015, submitted to the Kentucky Council on Postsecondary Education the college-aged ${ }^{5}$ Black American population of the "area of geographic responsibility" was $22 \%$ in 2010 (University of Louisville 2). Yet the Black American base population at the university in same year was $11.9 \%$, leaving a gap of $10.1 \%$ between the representation of Black Americans in the city and the university. Besides underrepresenting the immediate locale it serves, this gap suggests that the university lacks the cultural resources (e.g. instructional, social, and psychological) to retain members of this population. Therefore, I believe that employing methodologies that allow me to examine personal accounts against systemic processes and then also using an overarching methodology which situates race at the forefront of qualitative investigation is the most useful for this project. These methodologies will work to draw conclusions for the overarching research question: in what ways can a first-year writing

\footnotetext{
${ }^{5}$ Per the diversity plan, college-aged includes people 18-24 years old.
} 
curriculum centered on civic responsibility aid in better transitions from secondary to postsecondary academic writing for Black students at a predominantly White institution?

Chapter Three describes the institutional analysis used to examine whiteness and the presence of racialized perspectives in the writing curriculum and institutional practices around transitioning students from high school to college. Institutional analysis allows researchers to observe and analyze which systems function well and which systems fail towards a certain institutional goal, and why these successes and failures occur. Even more, this research method requires researchers to create a plan of action to reform institutions and institutional structures (Lamos) at a level suitable for the needed change (Porter et al.). The institutional analysis used here is primarily archival and ecological. I use rhetorical analysis of institutional documents to show that race is an absent present and racism an absent absence in institutional policies focused on transitioning to college writing, as described by Prendergast, and to demonstrate whiteness as the orienting racial measurement as described by Sarah Ahmed.

To examine where the transitioning experiences of Black American college students at PWIs intersect with the administration of college writing curriculum, this dissertation explores the research question: in what ways can a FYW curriculum centered on civic responsibility aid in smoother transitions from secondary to postsecondary academic writing for Black students at a PWI? The question requires a racial methodology to collect and analyze the findings about transitioning experiences of Black students at the University of Louisville. Asao B. Inoue offers racial methodology as a way to study how racial formations inform our research, theories, and practices in writing studies. A racial methodology applies the critical race framework of racial formation 
theory to the study of writing. Applying a racial methodology to writing studies research helps researchers attend to racialized perspectives throughout research processes, calls attention to how racialized social orders embed institutional and individual research practices, and adds needed complexity to who we include in research and how we represent their knowledge and experiences.

My study utilizes surveys, semi-structured interviews, and oral accounts with Black American first-year and upper-division students to examine the impact of racial formation on engagement with academic writing in the transitional period from high school to college-level writing. In June 2015, I received approval from the Institutional Review Board to conduct surveys, interviews, and focus groups with students and staff at the University of Louisville. Through the Cultural Center's programs, Black student organizations, and contact with students that have taken my FYW courses in the past two years, I gathered a sample of over 30 students from diverse backgrounds and circumstances. It is important to engage the voices of Black students from a range of socioeconomic backgrounds, familial structures, gender identities, high school environments, and local communities to uncover the ways institutional standards of rhetorical education and academic writing have served them. Individual interviews offer the opportunity for both interviewers and participants to consciously take part in constructing meaning (Selfe and Hawisher Ch. 3), but narrative is a method for representing disciplinary knowledge (Journet Ch. 1), in this case knowledge about experiences of transitioning across sites of academic writing. Because so few accounts exist in our field which represent that knowledge, as framed by students in general but 
especially Black students, I believe narrative is the best way to emphasize the personal in this case.

The narrative method of semi-structured interviews and the institutional analysis methods employ the racial methodology. A racial methodology uses racial formation theory to inform every step of any research process, from data collection to conclusion creation; all research procedures in this dissertation are informed by racialized perspectives. A framework of critical race theory supports my racial methodology. Each chapter utilizes some components of the central tenets of critical race theory, as defined by critical race theorist of law Derrick Bell and summarized by critical race theorists Richard Delgado and Jean Stefancic. Those tenets include:

- Racism is the norm, the everyday business, of American society, and therefore appears as the natural way of things to participants in that society,

- Racism advances the social and material interests of the whole American cultural, "materially" and "psychically" (Delgado \& Stefancic 2006), and therefore, is challenging to eliminate,

- Races are shaped and mobilized by social relations for the convenience of those that benefit from such distinctions (see: How the Irish Became White $^{6}$,

- Images and narratives about different racial groups change over time based on the needs of the dominant social group, and

\footnotetext{
${ }^{6}$ Ignatiev, Noel. How the Irish Became White. UK: Routledge Classics, 1995.
} 
- Racialized experiences in a society ordered in part by racial identifications give writers and intellectuals of marginalized races ways to communicate particular perspectives to the dominant White culture that Whites cannot communicate to each other.

With a sociological approach to race and writing, each tenet offers a possible lens to understand how race functions in university writing standards and how it influences the transformation from pre-college to college-level writer. With this lens, I suggest that evolving into a college-ready academic writer has traditionally meant evolving into more White cultural distinction or orienting towards whiteness (Ahmed). Chapters Three and Four more closely detail the use of racial methodology for institutional analysis and interview methods.

\section{Chapter Summaries}

Chapter Two uses the critical race theory principle of counter-story to illustrate models of Black American-centric education from the Civil Rights era as civic responsibility in rhetorical education writing curriculum. I develop a definition of rhetorical education for Black Americans as a counter-story to show how Black American communities have been successful in educating our people for civically responsible purposes of written and oral communication through academic writing practices. These Civil Rights programs of education exemplify ways for first-year writing programs to create culturally responsive curricula of civic responsibility. Chapter Three presents the results of an institutional analysis of policies and curriculum designed for transitioning students. Along with the theory of the absent presence of race in composition studies (Prendergast), the critical race theory tenet of interest convergence 
supports the analysis, suggesting that racial justice is only pursued by the privileged racial culture when it is in its interest. Examining the Composition Program, General Education Written Communication curriculum, admissions materials, and the university mission statement under the categories of race evaded, race implied, and race recognized, this chapter argues that writing programs as well as institutionalized writing standards at predominantly White institutions are major promoters of whiteness-centric academic identities that all students are expected to adopt upon transitioning to the university. Chapter Four "narratizes" (Newkirk) the interviews and surveys I collected about Black American students' transitional experiences at the University of Louisville. This chapter demonstrates the need for race-consciousness and civically responsible curriculum by discussing the qualitative interview responses of nine first-year and upper-division Black American students at the University of Louisville. The case study uses the "unique voice of color" (Delgado and Stefancic) to include these students' perspectives on writing for school, preparation for college writing, and applying academic writing to other situations. Through their accounts, I complement my analysis from Chapter Three by demonstrating the limitations of current transition scholarship in connecting previous written literacy experiences to new college academic writing experiences. Chapter Five exemplifies how a writing curriculum of civic responsibility in FYW programs can create race- and community-conscious transitional experiences for students. This curriculum has implications for counteracting the white privilege in writing curriculum by situating academic writing practices as a tool for social action in Black American communities. 


\section{CHAPTER II}

\section{CIVIC RESPONSIBILITY IN THE RHETORICAL EDUCATION OF BLACK AMERICANS}

"Young black people have always been at the vanguard of re-imagining and re-shaping America's schools."

--Carmen Kynard, "Black Student Protest as the Language and Blueprint of Education"

Writing Studies scholars have dedicated research to studying the literacy practices of Black communities throughout the nineteenth and twentieth centuries (Enoch; Gilyard; Logan; Royster; Smitherman). However, they have not studied how literacy education practices at Civil-Rights-era schools provided models of civically responsible rhetorical education for Black students. Further examination of these models will illustrate the potential for rhetorical education to support civic action among student groups during periods of social strife. For Black American students, rhetorical education has often occurred in community sites outside of formal schooling. Civil-Rights-era programs of education often looked to community teachers such as preachers, farmers, and businessmen to introduce children and adolescents to the social behaviors and language practices necessary to participate in and influence the lives of the community. Thus, rhetorical education toward citizenship performance has remained central to Black communities in the U.S. In this chapter, I apply the critical race theory tenet of 
counter-story, or "the unique voice of color" to historicize the rhetorical education instruction of Freedom Schools, Citizenship Schools, Black Panther Liberation Schools, and independent Black institutions to establish a counter-story about the ways Black Americans have accessed rhetorical education outside of Eurocentric perspectives. By adopting central features of these Afrocentric education programs, college writing programs can create race-conscious and community-conscious writing curricula at the high school to college transition level.

To further establish a case for civic responsibility at the beginning of most Black students' college rhetorical education — the first-year writing sequence, this chapter explains critical race theory's tenet of counter-story and how it can frame historical accounts of American rhetorical education. As a part of critical race theory, the tenet of counter-story or counter-narratives suggests that people outside of cultural norms can best speak to the experiences of those outside of cultural norms. Also called "the unique voice of color," this principle focuses on narratives that counter accepted social myths. "Because of their different histories and experiences with oppression, black, Indian, Asian, and Latino/a writers and thinkers may be able to communicate to their white counterparts" better than Whites can to each other (Delgado and Stefancic 4). Eurocentric rhetorical education instruction has become a central tactic used by the dominant culture to rob students of color, in particular, of the opportunity to use academic discourses as one of many ways to respond to their social, cultural, and political positions (Delpit). This pattern, however, results in part from the divide between the public community and the college or university. In venerating school literacies for the singular purpose of being academic, "such efforts mistake the official purposes assigned to academic knowledge 
and academic discursive and institutional forms for the full range of uses to which these can and have been put" (Horner 169). That divide has historically prevailed within Eurocentric educational models. The counter-story tenet will aid in demonstrating why teachers can use citizenship or civically responsible education practices, such as connecting students' home communities to coursework, in first-year writing courses as a support for transitioning Black students into college-level writing.

The following pages unify some established counter-stories to the prevailing perspective about rhetorical education for Black Americans, elaborate on examples of Afrocentric education models grounded in civic responsibility, and end with a discussion of implications for modern first-year writing courses. This historical perspective expands on what I see as the general definition of rhetorical education: culturally-based instruction in the communication skills and practices essential to participate in society and social processes (Enoch; Glenn, Lyday, and Sharer). More specifically, the education programs described here reveal rhetorical education for Black Americans as instruction in the social actions, civic practices, and language performances in service of advancing Black communities, locally and globally.

\section{Counter-story of Critical Race Theory}

This racialized construction of rhetorical education operates within the infrastructure of critical race theory. One central tenet of critical race theory argues that people of color have a unique voice which can provide vital counter-stories to accepted knowledge about racialized experiences. This tenet suggests that in a society ordered in part by racial identifications, racialized experiences may allow writers and intellectuals of marginalized races to communicate issues to the Eurocentric culture that Whites do not 
have the language to communicate to each other (Delgado and Stefancic 4). By this tenet, racial counter-narratives are essential to providing a complete historical perspective of American social institutions. Aja Y. Martinez argues that critical race theory and counterstory, particularly, can be used as a testimonial method of narrative methodology which brings to light persistent racism in the field of writing studies $^{7}$ and the academy itself (34). Martinez notes that such narrative forms are necessary as the field faces a "demographic shift" in the students it serves (34).

Counter-story has been used as a research methodology that allows researchers to challenge the "humanizing" of "empirical data" (Martinez 37) that propagate deficit narratives about people of color (Solorzano and Yosso 4) and the privilege of the dominant cultural way of being (Solorzano and Yosso 33). Critical race researchers see "counter-story [as] also a tool for exposing, analyzing, and challenging the majoritarian stories of racial privilege" (Solorzano and Yosso 32); I apply it here as a theoretical frame to expose and challenge accepted mainstream accounts about Black American students' engagement with rhetorical education. In theories about transitioning from high school writing to college-level writing, moving outside the dominant narratives about academic writing in college rhetorical education creates fuller accounts of experiences and new knowledge for writing programs, especially. I am focusing on writing instruction as one part of rhetorical education, because it is at the center of college-level assessment methods. Across the curriculum, students write to prove their disciplinary knowledge. Since the overall goal of this dissertation is to argue for stronger support of high school to college writing practice transitions, understanding college-level writing as one way of

\footnotetext{
${ }^{7}$ Martinez uses the designation rhetoric and composition for the field title, but I am using the field title applied throughout this document.
} 
building rhetorical language behaviors for social and civic life is essential to making its curriculum relevant to all students' language practices.

Two critical works in writing studies and rhetorical studies have detailed the connection of Black Americans to secondary and postsecondary rhetorical education in America (Royster; Logan). Traces of a Stream: Literacy and Social Change Among African American Women by Jacqueline Jones Royster and Liberating Language: Sites of Rhetorical Education in Nineteenth Century Black America by Shirley Wilson Logan provide counter-stories for what American rhetorical education has looked like for Black Americans, one of several groups typically marginalized in education histories. Elsewhere, Royster and Jean C. Williams describe the consequences of excluding selected perspectives from the history of a discipline like writing studies. The most accepted Eurocentric narrative about the successful entry of Black Americans into higher education asserts that Black American students entered colleges en masse in the late 1960s and throughout the 1970s. This tale about the mass migration into historically White sites of higher education ignores the history of Black American-centric education in Black communities, constructing Eurocentric education as the ultimate key to social mobility for Black Americans. Drawing inspiration from the ways that Royster and Williams "counter mythologies about African American presence" in the history of writing studies (579), the following sections counter perspectives that emulate the "majoritarian racial privilege" within American rhetorical education.

\section{Counter-stories to American Rhetorical Education}

For a long time, White America crafted the official accounts of Black Americans' acquisition of literacy and rhetorical education through formal higher education. Yet as 
far back as 1903, W.E.B. Du Bois' The Souls of Black Folk offered a counter-story about the formal education of Black Americans. In "On the Wings of Atalanta," Du Bois distinguishes Atlanta University's exceptionality from other, distinguished universities:

Not at Oxford or at Leipsic, not at Yale or Columbia, is there an air of higher resolve or more unfettered striving; the determination to realize for men, both black and white, the broadest possibilities of life, to seek the better and the best, to spread with their own hands the Gospel of Sacrifice, -- all this is the burden of their talk and dream. (Souls)

Du Bois sees Atlanta University as "the organ of that fine adjustment between real life and the growing knowledge of life" (Souls). Contradicting the principal narrative of Black Americans and higher education, this period-based description of an $\mathrm{HBCU}$ conveys an opportunistic perspective.

If one central goal of higher education is liberation through assimilation into culturally dominant ways of knowing and being, then writing in rhetorical education, as it is most generally accepted, is central to this goal. Counter-stories have been central to Black communities owning their identities and creating meaning. The Literacy Narratives of the Black Columbus Project, developed out of The Ohio State University with community partners, presents excellent examples of stories that complicate the dominant narratives about Columbus, Ohio and its history. ${ }^{8}$ The counter-story told in this chapter begins with the work of scholars that have already challenged the official narrative of how Black Americans historically acquired rhetorical education (Enoch; Gilyard; Kates; Logan; Richardson; Royster and Williams; Smitherman). Studying the rhetorical

\footnotetext{
${ }^{8}$ For further details about The Literacy Narratives of Black Columbus Project, please see http://blackcolumbus.osu.edu/theProject/default
} 
education practices of Black Americans prior to inclusion in Eurocentric sites of education may have proved complicated since much of the education happened in nonacademic settings (Kates; Logan; Royster). On the other hand, plenty of instruction in rhetorical education for Black Americans happened in what would be considered formal institutions today. Yet because of second-class status during particular historical moments, it takes the efforts of dedicated researchers to locate the records of these institutions. Along with accounts of informal instruction in rhetorical education, details of rhetorical education through formal Afrocentric instruction crafts counter-stories to the dominant narrative about the history of rhetorical education in America.

Rhetorical Education in America provides a broad scope of approaches to defining and applying rhetorical education in American classrooms. The contributions inquire into the institutional policies around rhetorical education meant to uphold the status quo but also propose rhetorical education practices that empower traditionally subjugated groups wishing to overturn the status quo (Glenn, Lyday, and Sharer xi). This chapter focuses on the latter. While many composition and rhetoric scholars have examined various aspects of literacy education and rhetorical education for Black Americans, most have not focused on the efforts of this education during the Civil Rights Movement era (Smitherman). Further, none have explicitly addressed the relationship between civic responsibility and rhetorical education in the four models of schools outlined here: Citizenship Schools, Freedom Schools, The Black Panther Liberation Schools, and independent Black institutions (IBIs). Writing studies offers little in the way of focus on rhetorical education during this period and within these sites; the majority of information stems from interdisciplinary literature. Two key texts, Teach Freedom: 
Education for Liberation in the African-American Tradition and Education as Freedom:

African American Educational Thought and Activism, provide grounding for this exploration.

The collection Teach Freedom provides essays and primary texts related to the educational institutions discussed in this chapter. From historical analyses of Afrocentric education, just around the Civil Rights Movement, to proposals and firsthand accounts from those who were there, this book supplies crucial perspectives on the dissemination of education to Black Americans. Education as Freedom complements Teach Freedom by illustrating how oppression and liberation have constituted two sides of the same coin for Black American education throughout history. The collection brings together authors who exemplify the objectives around social progression of Civil-Rights-era rhetorical education for Black Americans as well as perspectives on alternatives to the mainstream instruction provided by Afrocentric education.

\section{Types of Formal Afrocentric Rhetorical Education}

Several embodiments of formal education for Black Americans have sprung from community education models. These formal education forays succeeded in granting Black students access to pre-college and higher education for transformative purposes. This chapter outlines Afrocentric models from the 1960s and 1970s that succeeded in transforming the ways of thinking about social status for Black community members and that rhetorically educated a wide range of Black community members. Education programs for Black American students of the Civil Rights era have a number of predecessors. 
Particularly for Black American students, rhetorical education, or training in the ways of using behaviors, language practices, and social skills for social influence, often occurred in community sites outside of formal schooling (Enoch). Black communities have a history of utilizing rhetorical education as a tool of civic engagement and civic responsibility. After all, "[1] ooking to the past for models and uses of rhetorical education $\ldots$ [g]iven that rhetorical action is initiated in response to mediated exigencies, few Americans have had a greater need to respond than have African Americans nor a greater desire to respond effectively" (Logan 37). For many Black individuals, even today, our introduction to the practices of language and power as a tool of social action is through the church or community centers. Schooling forms of rhetorical education often undermine rhetorical education conferred by our communities.

Readers will be familiar with civically engaged institutions of higher education such as Fisk University, Tuskegee Institute, and Atlanta University, all of which serve as forerunners to the programs of education highlighted in this chapter. Among the schools produced by goals of civic responsibility was Mary McLeod Bethune's Daytona Educational and Industrial School for Negro Girls, established in 1904 with a mission to promote racial uplift for young Black girls through education, in order to help them "earn a living" (Bowie qtd in McCluskey 67). Having modeled the school somewhat after Booker T. Washington's legacy, The Tuskegee Institute, Bethune followed the model of vocational education. The curriculum put students in a position where they could use education to transform their lives by applying their learned knowledge and skills to gainful employment in service to themselves and their local communities. 
Normal schools for teacher training are probably the clearest ancestor of Citizenship Schools and Freedom Schools, because they maintained the specific purpose of serving the Black American community through educating future teachers as a resource for social change. Any of the remaining normal schools started by, and for, formerly enslaved Blacks during Reconstruction and post-Reconstruction are now historically Black colleges or universities (HBCUs). Teacher education held a significant role in growing Black communities, as long established debates questioned whether students were better taught by Black teachers or White teachers, southern teachers or northern teachers (Du Bois; Morris). One aim of this educational experience became to produce politically and socially conscious teachers. In The Mis-Education of the Negro, Carter G. Woodson argues that vocational training, like teacher training, should help teach Black students how to make a living (38-40). Not just a living for the students themselves, but to make a living for the community. Along with the legacy of service to Black American communities provided by HBCUs, these archetypes of institutionalized rhetorical education for Black students setup the foundation for the Civil-Rights-era Citizenship Schools, Freedom Schools, and Black Panther Party community schools. From the spirit of these institutions, independent Black institutions rose as a way for parents and community members to counter the hidden curriculum of White supremacy offered in traditional schools.

\section{Civic Responsibility in Models of Black American Rhetorical Education}

\section{Citizenships Schools and the Citizenship Education Program}

The literacy and political education of older community members became central to Civil-Rights-era Black communities in the South and prompted the creation of 
Citizenship Schools in 1957 Tennessee. Citizenship schools and citizenship education offer a counter-story to the histories about the available means of literacy education for Black American communities. These counter-stories also provide a Black American perspective of the range of uses for rhetorical education in community affairs. Along with Freedom Schools, Citizenship Schools developed within the Black communities and taught formal writing education to enhance citizenship practices as well as service to the community. Citizenship Schools served mostly adult students with a second to third grade education and worked to "improve[e] their literacy skills and civic knowledge, expan[d] their problem-solving abilities, and challeng[e] the unjust social order of the segregated South" (Levine 25). Citizenship Schools made education work in critical ways for the students and their lives, as

[s]ome wanted to learn to read the newspaper, some the Bible, others to fill out mail-order catalogues and money orders, and to pass the voter registration test. Some hoped to read and write their own letters, so they could communicate with relatives and not depend on a White to read their incoming correspondence to them. (Levine 27 emphasis mine)

In this way, Citizenship Schools came out of a need for "an explicitly political approach to education assertively linked to the acquisition of knowledge with collective efforts to overcome racism" (Levine 25-26).

The civically responsible curriculum of this education model became "directly responsive to the learning interests and needs of these mature students" (Levine 27). The curriculum at Citizenship Schools often included literacy instruction in reading and spelling, math, civics, and a discussion of voter registration (Levine 31). A key goal with 
both Citizenship Schools and Freedom Schools was creating more Black voters, particularly in the South. Part of the literacy curriculum helped students prepare for voter registration tests by learning words and terms from the test (Levine 31). Other pedagogical practices aimed to give students control over their daily community lives. For example, another part of the literacy curriculum included a Citizenship School teacher who "traced money orders onto pieces of cardboard so that all the students could practice filling them out" (Levine 31). Even the mathematics curriculum utilized artifacts from the students' daily lives, such as supermarket ads (Levine 31). Just as important as the knowledge being delivered were the teachers who had an influence on the students learning that knowledge.

The selection of teachers reflected attention to civic responsibility, as "the most effective teachers would be the peers of the students, rather than credentialed educators who might consider themselves superior to their pupils" (Levine 35). In the case of Citizenship Schools, teachers were only required to have minimal high school education along with legible writing skills, and take a vow of service to the community (Levine 35). Citizenship School policy proposed that "the successful teacher balanced ... the interests and aspirations of students with their own beliefs of what knowledge, actions, and values should be promoted by the learning experience" (Levine 35). Students look to teachers as a resource for guidance but not control over their civic actions and goals, as this would diminish the social and political empowerment goals of Citizenship Schools and citizenship education. As Deanna M. Gillespie suggests, Citizenship Schools' teachers did not see among their responsibilities to lift up the race but rather to inspire and help the students "“lift' themselves" (45). 
Citizenship Schools, eventually, took the form of the Citizenship Education Program (CEP) in 1961, when the Southern Christian Leadership Conference took responsibility for the schools. Under this renamed adult education program, teachers "created a space where they and their students performed first-class citizenship, sowing the seeds for collective action and political empowerment" (Gillespie 42). With a similar mission to increase the registration of Black voters through successful literacy education, the rhetorical value of the CEP served an explicit need related to the students and the larger community. In teaching literacy fundamentals, teachers "also needed to create an environment that encouraged participatory democracy" (Gillespie 45), and the adult students needed to see themselves as key contributors to this democracy and its processes.

Part of the work of responding to the needs of adult students included teaching in the homes of students whose work schedules would not allow them to make the regular sessions of the program. The CEP also expanded its reach through collaboration with community organizations, especially Black churches. The church was allowed to perpetuate its mission of helping to liberate the Black communities it served, and the CEP gained faith-based respectability in the eyes of many community members (Gillespie 49). These examples of flexibility on the part of the educators reinforce the student-centered, community-focused approach of Citizenship Schools and the CEP.

The Citizenship School and the CEP deviated from the White American education perspective "that Black students were capable of little learning" and in doing so developed a participatory student body where such an opportunity did not exist for these students before (Levine 37). Moreover, "[i]t gave ... teachers the conviction that their 
students could achieve great things, if properly inspired by high expectations and the lofty goal of acquiring "first-class citizenship"' (Levine 37). The goals of prevailing rhetorical education have effectually worked to assimilate cultural, economic, and political outsiders into the dominant culture's values and customs. By contrast, these citizenship programs of education invoked rhetorical education for Black Americans as they upheld social justice ends through helping their adult students put their rhetorical education towards the betterment of their overall community life.

\section{Freedom Schools}

Under similar objectives around social justice, Freedom Schools developed as a derivative of the civil rights goals established during Freedom Summer, 1964. The schools aligned with the overall Freedom Summer objective " $[\mathrm{t}] \mathrm{o}$ create a truly representative political party [from] the vast majority of disempowered African Americans" by "develop[ing] the self confidence [sic] and organizational skills required of active citizens" (Emery, Braselman, and Gold 5). Freedom Schools counter ideas that integrated public education was the only viable option for adolescent Black Americans, of the 1960s, to battle social inequities. This model shows that equal access does not mean equity in education. For most Black American students in the Civil-Rights-era South, educational experiences in integrated schools continued to marginalize them (Cobb). One prospectus for a Mississippi Freedom School states that it aimed "to implement a curriculum based on the asking of questions whose answers were sought within the lives of the students" (5). Many influential citizenship responsibilities, such as registering to vote, were seen by southern Black community members as something only White people did. Freedom Summer activists aimed to change such a perception, 
believing their "main challenge was getting Black people to challenge themselves" (Cobb 70). The Freedom School model of civically responsible education produced formal education as a resource for preparing students for social action of multiple kinds: for example, to teach others and organize boycotts.

In encouraging Black people to "make decisions about and take charge of the things controlling their lives" (Cobb 69), Freedom Schools targeted tenth and eleventh graders. Using this target population helped to fill gaps in their poor public education and give them intellectual tools for social action to take back to their high schools after the summer (Emery, Braselman, and Gold 40). The overall consensus by Black people in the 1960s South was that White educational opportunities severely surpassed Black educational options, and "the idea of ideas, thought, and creativity among Black people was ruthlessly suppressed" (Cobb 71). In response to the Mississippi state-sanctioned destruction of "“smart niggers"” so that the state's "Black classrooms remain intellectual wastelands," Freedom Schools saw their "responsibility to fill an intellectual and creative vacuum in the lives of young [Black] Mississippians, and to get them to articulate their own desires, demands and questions" (Cobb 67). The everyday reality of Black students that Freedom Schools aimed to upset included "[n]ew brick school buildings built to give the illusion of 'separate but equal' [but] contained virtually bookless libraries and science labs with no equipment" (Cobb 71) and teachers removing Black students from class for questioning about voting and organized freedom rides (67). Thus, one concern of Freedom Schools was to inspire students to brave their public-school classrooms to ask critical questions of their teachers (Cobb 67). Part of this rhetorical education included preparing students for participation within the mainstream education programs. 
Freedom Schools helped their student challenge the oppressive nature of mainstream classrooms by instituting three civically responsible objectives:

1. supplement what they aren't learning in high schools around the state.

2. give them a broad intellectual and academic experience during the summer to bring back to fellow students in classrooms in the state, and 3. form the basis for statewide student action such as school boycotts, based on their increased awareness. (Emery, Braselman, and Gold 40) Situated with models of civic responsibility, the most prominent facet of the total curriculum surrounding these goals was "political and social science, relating their studies to their society" (Emery, Braselman, and Gold 41). Along with drama and music, the curriculum included writing as part of the cultural program. The creators understood the importance of having "the art of effective communication through the written word be developed in Mississippi students" (Emery, Braselman, and Gold 41). Action projects included student newspapers, forums for student opinions, or the planning of a statewide student conference, in addition to the central goal of voter registration. Each of these required writing in helping "the student as a force for social change" (Emery, Braselman, and Gold 41) so that they had the power "to battle institutions" by first altering their own ways of acting (Guyot qtd in Cobb 70).

The Freedom Schools' organizers battled racist institutions in a territory in vital need of social change, and they saw "education as an approach to community organizing in and of itself" (Cobb 72). Influential figures in the efforts included activists for the United Federation of Teachers, participants in the Southern Christian Leadership 
Conference, associates of the Highlander Center, ${ }^{9}$ and a writer of citizenship curriculum (Cobb 72). They imagined the curriculum, pedagogy, and student outcomes of these schools to produce "self-actualizing learners [who] defined and shaped their world" (Perlstein, "Live" 138). The organizers and teachers maintained this goal even in light of detrimental realities. In one case "in the Mississippi Delta, the fall school term was delayed while cotton was picked"10 (Cobb 71), and in general the education system remained entirely void of academic freedom, placing students in a space where teachers suppressed their ways of thinking and intellectual curiosity (Cobb 67).

With its civically responsible goals, "the essence of [Freedom] [S]chools was that Black people could begin to rethink in their own terms the ways and means of shaping and controlling their own destiny" (Cobb 73). Reflecting Black American rhetorical education practices, the instruction prepared students to both perform their own social action for helping Black communities and to teach other community members to do the same. Both Citizenship Schools and Freedom Schools operated on the premise that education held the capacity to bring about significant change in the lives of the Black citizens and in their communities. Similar to Paolo Freire, the organizers viewed traditional pedagogy as a dehumanizing project which keeps oppressors in a position of authority (Freire 44). "[S]haped by a liberal faith that America's democratic institutions could fully accommodate the Black aspirations for equal citizenship" (Perlstein, "Live" 137), Freedom Schools and Citizenship Schools placed the oppressed among the developers of the pedagogy for themselves (Freire 54). Other Afrocentric models of

\footnotetext{
${ }^{9}$ The Highlander Center was a form of the Highlander Folk School, a Tennessee school based on equal opportunity began by Myles Horton and others in 1932.

${ }^{10}$ Since cotton was picked by Black children in the fall while White children were in school, Black children attended school in the summer (Cobb 73).
} 
education expanded on the idea of giving oppressed Black communities control over their rhetorical education.

\section{Black Panther Liberation Schools}

The Black Panther Party's Liberation Schools built upon and enhanced this model with a resolute political approach to the education of young Black Americans. Liberation Schools reflected a distinct connection between politics and pedagogy, an approach that counters philosophies to keep politics out of the classroom. The Black Panther party sought to counter the educational values of mainstream White public education, and they, in turn, more adequately prepared Black American adolescents with culturally relevant rhetorical behaviors. Disgruntled with the education of Black children in state-owned public schools, the Black Panthers aimed to illustrate the class struggle to students but as it related to Black history specifically (Perlstein, "Live" 149). Where Citizenship Schools emphasized literacy education as a vehicle for democratic participation and Freedom Schools worked to create informed, "self-actualizing" youths to take control of their own lives, Liberation Schools offered revolutionary education (Perlstein, "Live" 150). The schools operated on the premise that meaningful change required radical thought and a radical approach, and that education is, and has always been, political. The organizers saw revolution as inevitable, and their rhetorical education practices embodied this vision.

Their vision for creating young revolutionaries addresses Logan's central question in "To Get an Education and Teach My People': Rhetoric for Social Change" which is "Rhetorical education for what?" (36) The rhetorical education at Liberation Schools taught students the history of socio-political conventions including "racism, capitalism, 
fascism, cultural nationalism, and socialism" (Perlstein, "Minds" 262). Their ideological approach to the curriculum was explicit, contradicting the implicitly ideological curriculum Black students received in Eurocentric schools. Like Citizenship Schools and Freedom Schools, Liberation Schools rejected notions of rhetorical education as preparation for full civic and social engagement (Enoch 8), and they reflect the construct of rhetorical education for Black American students. Demonstrated in point five of the party's Ten-Point Platform, Liberation Schools sought to deliver "education which teaches us our true history and our role in the present day American society" ("A Huey P. Newton").

This revolutionary rhetorical education was based on lived experiences of revolutionaries who students would recognize and encouraged students to work together towards revolutionary goals (Perlstein, "Minds" 264). The Black Panther Party deemed American society as "decadent" (Perlstein; Wei), and the revolutionary education provided at Liberation Schools worked to prepare students for eradicating that decadence. From the standpoint of the party, this massive change would come through "the destruction of the ruling class that oppresses and exploits the poor [,] ... the destruction of the avaricious businessman[,] ... the destruction of the lying, deceiving politicians, and most important of all, the destruction of the racist pigs that are running rampant in our communities" (Wei 12). Some Liberation Schools worked to instill this revolutionary epistemology in students with a Black Child's Pledge as a part of the curriculum. Children recited

I pledge allegiance to my Black people.

I pledge to develop my mind and body to the greatest extent possible. 
I will learn all that I can in order to give my best to my people in their struggle for liberation.

I will keep myself physically fit, building a strong body free from drugs and other substances that weaken me and make me less capable of protecting myself, my family, and my Black brothers and sisters. I will unselfishly share my knowledge and understanding with them in order to bring about change more quickly.

I will discipline myself to direct my energies thoughtfully and constructively rather than wasting them in idle hatred.

I will train myself never to hurt or allow others to harm my Black brothers and sisters for I recognize that we need every Black man, woman, and child to be physically, mentally and psychologically strong. These principles I pledge to practice daily and to teach them to others in order to unite my people. (Williams qtd in Wei 12)

Rather than teaching reading, writing, and other fundamental subjects as detached from social contexts, teachers urged students to confront and question the entire gamut of school-related practices (Perlstein "Minds" 264), including the "Pledge of Allegiance." Not unlike Freedom Schools, the educational system itself became a topic of study within Liberation Schools.

Along with Citizenship Schools, these educational models stem from a critical moment in American history where the education of Black Americans was either a source of oppression or progression. For many areas of the country, this binary within educational institutions still exists for Black people and other subjugated populations. 
The next section considers a modern-day construction of Afrocentric rhetorical education practicing civic responsibility.

\section{Independent Black Institutions}

First established in the early 1970s, IBIs have gained increasing popularity over the last thirty years. These schools use an Afrocentric program of education to teach relevant curriculum and values to preschool through high school-aged students (Lomotey 455). They come in the form of "home school collectives" and "African-centered schools" (Changa), where they hold a more encompassing view of success than mainstream schools (Lomotey 456). Similar to the schooling models discussed thus far, IBIs provide a counter-story about the most effective curriculum to help Black Americans prepare for active community life. This counter-narrative to traditional rhetorical education practices responds to Enoch's argument that rhetorical education "is always a form of politicized acculturation, because it teaches students how to communicate inside a culture" (176), Logan's question “[r] hetorical education for what?” (36) and Royster and Williams' call for "a systematic commitment to resist the primacy of 'officialized narratives"' (582) about rhetorical education. The IBI definition of success for students includes students" "attitudes toward school and the nature of the relationships between school personnel, students, and families" (Lomotey 456). According to a Facebook post citing Kalonji Jama Changa on the page for the Council of Independent Black Institutions, these institutions are "growing everyday [sic], not as an alternative to public school, but as our own paradigm for academic excellence, cultural awareness, and the quintessential foundation for Black self-sufficiency and sovereignty for African people" 
(Council of Independent Black Institutions). Their community-based approaches to curriculum, pedagogy, and administration exhibit an emphasis on civic responsibility.

Community education is a central aspect of IBIs, as it has been with each of the types of schools discussed thus far. Yet for IBIs, this community connection is embedded within the Afrocentric institutional philosophies. These philosophies originate from various principles based in African Diasporic ways of being. For example, some are based in "Maat" or "ancient African principles of ethical character development" (Lee 166). ${ }^{11}$ Others share values with the seven Kwanzaa traditions: Umoja (unity), Kujichagulia (self-determination), Ujima (collective work and responsibility), Ujamaa (cooperative economics), Kuumba (creativity), Nia (purpose), and Imani (faith) (Lee; Lomotey). Maulana Karenga, founder of the academic discipline Pan African Studies and the Kwanzaa holiday, established these Nguzo Saba, or "Seven Principles of Blackness" as part of the Kawaida doctrine (Lomotey 458). By grounding their curricular and pedagogical approaches in this philosophical perspective, IBIs deliver rhetorical education that "develops in students a communal and civic identity" (Enoch 7) relevant to who they are and their social positions.

Taking the definition of rhetorical education for Black American students proposed in this chapter, these schools aim to develop communicative and behavioral practices based on the students' cultural and community histories. The pedagogy underscores social action and civic practices relevant to Black people. Among the eight goals for Afrocentric pedagogy within these schools, four center on the progress of community life (Lomotey 165-66). These include having teachers amplify support while

\footnotetext{
${ }^{11}$ Maat is a concept described in what most Westerners know as The Egyptian Book of the Dead but which title actually translates as The Book of Coming Forth by Day.
} 
serving students' multiple local, cultural, and world communities as well as championing the belief that individuals and communities are producers instead of simply consumers of knowledge (Lomotey 166). The other goals for pedagogy build on an Afrocentric consciousness, including consciousness of language performance which "[e]xtend and build upon the indigenous language" (Lomotey 165). Lomotey does not elaborate on what "the indigenous language" is, but I take it to mean the student's "mother tongue" (Elbow) or what IBIs often call home language. The intention is for teachers to expose students to both the progress of community life and Afrocentric critical consciousness as early as possible. In doing so, IBI educators help ensure that these values and ways of knowing influence students' overall engagement with education. For this reason, IBIs provide effective rhetorical education in many Black American communities.

IBIs continue to steadily prosper today, even with limited financial support. However, they are built on the tradition of Citizenship Schools, Freedom Schools, and Liberation Schools, and they use rhetorical education as a means for community engagement. Each of the schools detailed here operates on the premise that all children deserve to receive a curriculum relevant to their worldview and therefore the lives they face. Rather than inculcating Eurocentric ways of knowing and acting through rhetorical education, these educational models demonstrate how academic knowledge can serve purposes outside the academic setting. It allowed the students of these schools to take accountability for the advancement of their communities, or it gave them the tools for civic responsibility. To conclude this chapter, I reinforce the need for the counter-story that IBIs, Citizenship Schools, Freedom Schools, and Black Panther Liberation Schools give to rhetorical education in America at the college level so that we, as writing 
instructors and program administrators, may understand rhetorical education relevant to all of our students.

\section{Significance of Rhetorical Education Counter-story to Inclusive Curriculum Design}

The counter-story to Black students' engagement with rhetorical education in America that I have provided shows a missing link in the ways educational institutions understand the civic purposes of this education. While traditional approaches to rhetorical education have centered on civic participation, this participation identifies primarily with the dominant culture's way of being civically responsible. Rhetorical education, in general, attempts to make clear the influential capacity of "language practices, and ... social behaviors" (Enoch 7). However, conventional definitions — and most revised definitions - do not account for the political-rhetorical ways of being that construct how individuals put that education to work in everyday life. My definition of rhetorical education for Black Americans expands on the definition advocated by Enoch which "complicates the idea that rhetorical education leads to full engagement or that it maintains the status quo" (8) and the approach recommended by Logan, "a rhetoric of social change" (39). The counter-story provided by the four Afrocentric education models postulates that educators must consider, in addition to "rhetorical education for what," rhetorical education in service of whom.

Long before Citizenship Schools, Freedom Schools, IBIs, or Liberation Schools, educational psychologist Inez B. Prosser studied the effects of non-academic social and psychological factors on Black American schoolchildren. The study compared the experiences of these children at segregated and integrated schools. Prosser concluded that that "the teacher-pupil relationships in the mixed schools are not as satisfactory as those 
in the segregated schools" (178). Still, even among teachers in segregated schools, Prosser suggests that they "strive to rid pupils of definite personal inferiority feelings unless such feelings are warranted" and recommends "teacher re-education in newer aspects of mental hygiene" (186). Using Prosser's research into "certain attitudes and interests, the emotional stability, and the personality adjustment of two groups of Negro pupils... in the two types of schools commonly called mixed and segregated" (1), pedagogues of rhetorical education might better serve their Black student populations by understanding the non-academic variables that influence them inside the classroom. My study urges rhetorical educators to take notice of the nonacademic factors that students bring into the classroom by connecting their academic work to community consciousness. One of these nonacademic factors might be the psychological undertow that Black students feel that they "live and work in a world built up largely by and for someone else" (Prosser 30).

Since "counterstory [sic] functions as a method for marginalized people to intervene in research methods that would form master narratives based on ignorance and on assumptions about minoritized peoples" (Martinez 33), countering White savior narratives about Black students in rhetorical education can help reduce systemic ignorance about the purposes of this education. The counter-story of the CEPs, Freedom Schools, IBIs, and Black Panther Liberation Schools gives authority to marginalized perspectives in the history of rhetorical education. The civic responsibility promoted by the Afrocentric schools here demonstrates how academic writing as one component of rhetorical education can be used to teach public engagement and civic practices that challenge prevailing methods of civic participation. Rather than focused on using 
rhetorical behaviors for sole engagement with dominant society, this counter-story emphasizes how Black Americans applied the rhetorical education they gained from school to respond to the needs of their oppressed racial community. For example, reciprocity is an African principle expected of IBI teachers and one that they instill in students. This African principle long precedes mainstream, predominantly White universities' community-based work and writing studies community literacy research. It puts forth that the teachers are symbolically connected to the success of the students, and the students are symbolically connected to the success of their communities, and therefore, communities are symbolically connected to the success of both the teachers and students (Lomotey 165, 168). Such a privileging of the tripartite relationship between community, teacher, and student answers Woodson's call to help students learn to work in service of their communities.

This goal of serving Black communities stands in contrast to what many see as the central goal of institutional rhetorical education. That goal has been to assimilate Black American students out of the "black ghetto" (Smitherman 202) by "inculcating the values of the dominant society and eliminating the cultural distinctiveness of Black America" (203). That purpose of rhetorical education for Black Americans is the accepted narrative. It is happily accepted by mainstream higher education. One purpose of rhetorical education at Liberation Schools, to prepare students for "the art of survival" (Wei 12), correlates to Michelle Hall Kells' definition of rhetoric as "the art of survival" (377). Kells views this as a more relevant meaning of rhetoric than the art of effective communication, particularly when attempting to understand rhetoric in the lives of ethno 
- linguistically diverse students and communities (377). ${ }^{12}$ Kells focuses on situating rhetoric as a means to survive the navigation of multiple human relationship networks (377), and the Black Panthers focused on creating curriculum to survive oppression from certain human relationships (Wei 12). Privileging this narrative for Black Americans reframes the purposes of institutionalized rhetorical education in order to better serve the lives of more of our students.

In the next chapter, this stronger understanding of the affordances of Afrocentric rhetorical education practices allows me to present the outcomes of an institutional analysis of race consciousness in curriculum and institutional policies surrounding the transition to college-level writing. The analysis speaks to and circumspectly examines the college writing curriculum as a producer of facets of whiteness and Eurocentrism within institutional identity at one predominantly White research university. In analyzing the ways in which writing programs at predominantly White universities and colleges ignore the conditions of racial injustice in students' past rhetorical education experiences, I will argue that this works against the successful college writing transitions of many Black American students.

\footnotetext{
${ }^{12}$ This designation of ethnolinguistic diversity is from the perspective of predominantly White institutions rather than the communities practicing the linguistic variations.
} 


\section{CHAPTER III}

\section{WHERE WE BELONG: \\ THE ABSENT PRESENCE OF RACE IN INSTITUTIONAL DOCUMENTS THAT GUIDE TRANSITIONING}

"It is not just that there is a desire for whiteness that leads to white bodies getting in.

Rather whiteness is what the institution is orientated 'around', so that even bodies that might not appear white still have to inhabit whiteness, if they are to get 'in.",

--Sara Ahmed, “A Phenomenology of Whiteness”

One tactic colleges and universities use to reinforce the supposed intrinsic value of whiteness involves equating whiteness with academic intelligence. I, along with many Black American children, noticed this link long before I entered a college campus. While I saw, in the earlier phases of the public school system, the link between standardized testing requirements and the lack of students who resembled me in honors and advanced courses, as a college educator, I continue to see the whiteness/academics connection in program and general education outcomes. Since higher education, in its many forms, exists to prepare students for well-informed professional, social, or civic life, its correlation of intelligence with whiteness can have detrimental consequences on the success of transitioning Black American students. The absent presence of race and the orientation along whiteness in institutional documents related to transitioning can hinder Black American students' immersion in college-level academic writing practices. This chapter presents an institutional analysis of whiteness representations in transitioning 
practices that result in an absence of race at the University of Louisville. I begin with a discussion of my methodology including how issues of race and college academic writing reflect the critical race theory tenet of interest convergence. This tenet proclaims that the privileged racial culture in a society — White in the case of American society—will only strive for racial equality as long as the privileged members can keep their status. I follow this discussion by detailing the institutional analysis I applied to analyze the documents and then present the results of the analysis. I conclude by proposing the need for the presence of race-conscious perspectives inthe local writing program, and in writing programs in general.

\section{Methodology}

This chapter employs a critical race theoretical framework to present an archival institutional analysis of documents directly or indirectly shaping transition experiences of college students at the University of Louisville. While the research process for this analysis also included semi-structured interviews with institutional agents in advising and admissions, the primary units of analysis in this chapter are the institutional documents that shape what comprises successful transitions to college and college-level writing at the University of Louisville. The input from the advising and admissions staff supplements the document analysis to show how established institutional processes influence advisors' interactions with new students entering from high school. My ultimate purpose is to illustrate the ways that the wider institutional practices of the university mark the writing program curriculum and resulting transitional experiences of Black students in first-year writing. In the next chapter, I include what Black American 
students at the university have to say about how they navigate the high school to college writing transition.

\section{Theoretical Framework: Interest Convergence and the Absent Presence of Race}

The critical race theory principle of interest convergence guides my analysis of the institutional policies and their influence on the success of scaffolding Black students' transition to college-level writing. This principle allows me to observe when and why mentions of race are recognized, evaded, or implied in the institutional documents and what that concludes about the purpose of those documents in institutional practices. Interest convergence leads me to examine the institutional benefits of maintaining race as an absent presence, and I demonstrate how these benefits potentially rupture transitional experiences of Black students. Law professor, activist, and critical race theorist Derrick Bell developed the theory of interest convergence to explain the limits of racial justice in American society. I contend that the same theory can be applied to smaller institutions, particularly those that aim to reproduce the values of the larger society.

Higher education institutions have a duty to play to the interests of their stakeholders, and these interests often represent those in the meritocratic White middleclass, capitalistic world. Since interest convergence establishes that "the interest of blacks in achieving racial equality will be accommodated only when it converges with the interest of whites" (Bell 523), I will show how the institution is limited in the support it can provide relevant to many Black students' lives, since that support often does not converge with the interests of stakeholders. Self-recognition of interest convergence by the institution may be why, in one of the country's most segregated cities and with such a 
high rate of poverty especially among Black citizens, race holds a mostly absent presence within the policies which guide transitioning processes.

I am utilizing the work of composition scholar Catherine Prendergast in examining race as an absent presence. Prendergast argues that

if race has been an absent presence, racism has been an absent absence.

Even when the subject of a study is identified by race or ethnicity, the legacy of racism in this country which participates in sculpting all identities--white included--is more often than not absent from the analysis of that writer's linguistic capabilities or strategies. (36)

The failure to examine race results from the norm of racism in society, but Prendergast attributes it specifically to Victor Villanueva's notion of "colonial sensibility" (37).

Following Villanueva in suggesting that this sensibility most frequently and most intensely affects people of color, Prendergast urges composition teachers with scrutinizing the absent presence of race (37). This colonial sensibility is what allows both those oppressing others with literacy practiced and those being oppressed by institutionsanctioned literacy practices to perceive that oppression as the norm. While "the implications of critical race theory for writing and writing research are not immediately evident" (Prendergast 37), by framing my institutional analysis of policies about transitioning with interest convergence and the absent presence of race, I am able to determine the effects of denying racialized experiences in transitioning at the institutional level. 


\section{Eurocentric Epistemologies and Academic Writing Standards}

Denying the value of racialized experiences may come as a result of norming Eurocentric epistemologies about literacy and writing. As described in Chapter Two, these epistemologies have worked, historically, to invalidate Black American experiences with rhetorical education that happen outside of White-invested spaces. Additionally, these epistemologies of academic writing nullify language behaviors that do not conform to Eurocentric ways of knowing. Eurocentric, or White-invested, epistemologies are ways of evaluating knowledge that has a stake in proliferating White-centric ways of being (Collins 271). For example, these epistemologies situate other knowledge bases, such as Afrocentric, women, or queer ${ }^{13}$ experiences, as specialized rather than normative.

Under this system, the discourse of whiteness is most highly valued in linguistic and rhetorical practices. Whiteness as a discourse has distinct features including “[h]yperindividualism -- self-determination and autonomy," an "[i]ndividualized, [r]ational, [c]ontrolled [s]elf," "[r]ule-governed, [c]ontractual [r]elationships," and "[c]larity, [o]rder, and [c]ontrol" (Inoue). These features signify what Eurocentric ways of knowing privilege about discourse as well as what they hold in low esteem. Asao B. Inoue suggests that while "[i]ndividual rights and privacy are often most important and construct the common good[,] [and] [t]he truth is always good to hear, no matter how painful, good, or bad it may be" according to the discourse of whiteness, qualities of altruism, decency, and service for the sake of service are seen as counterproductive and irrational. Similarly, being positioned as the dominant way of knowing and being in culture overall allows those who value whiteness as a discourse to situate political values

\footnotetext{
${ }^{13}$ I use the term "queer" here to represent the value of all non-heteronormative experiences as denoted by studies in Queer Theory.
} 
as less important (Inoue). Interrogating the political nature of things is only critical to those who do not hold stations of power. Since the individualistic quality of whiteness as a discourse places "[1]ittle emphasis on connectedness, relatedness, feeling, interconnection with others," this discourse dismisses social connections that influence it (Inoue).

Timothy Barnett analyzes the presence of whiteness-invested discourses in English studies. With an analysis focused on American universities in the late 1960s and the early 1970s, Barnett suggests that the power of whiteness in academic writing discourses comes from its position as natural, unraced, neutral, and objective (10). My institutional analysis examines the institutional and writing program policies that keep whiteness-invested discourses in the position at University of Louisville, and I consider the impact these policies may have on Black American students new to the university.

\section{Institutional Analysis Process}

Institutional analysis allows researchers to better understand the activity in institutional spaces in order to effectually modify problematic practices. Even more, this research method requires researchers to create a plan of action to reform institutions and institutional structures (Lamos 2012) at a level suitable for the needed change (Porter et al. 2000). To stay within the racial methodology, I analyze the documents by considering questions about racialized aspects of the university's institutional identity. Broadly, I attend to questions concerning transitioning from high school to college in general and more specifically from high school academic writing expectations to college-level writing expectations. The institutional analysis considers the intent and power of action-based documents at the classroom, program, and university-wide levels. 
Within this analysis, I use institution ecology to study the "set of institutional relationships and practices that surround" curriculum development in the Composition Program as well as policies and procedures regarding community engagement at the university (Sackey and DeVoss 196). Thus, I will examine the "variables that institutions bring to" the rhetorical situation of the writing classroom (Sackey and DeVoss 199) and how those variables create a narrative about transitioning to college-level writing.

Rather than looking at student perspectives alone, the institutional analysis narrates how the university, as a culturally informed institution, mythologizes the processes and outcomes of transitioning. In analyzing the manifestations of whiteness in the institutional identity, the general education curriculum, and writing program, this chapter exposes how whiteness permeates the interconnected networks that guide transitioning from high school to college.

Embedded within institutional agents are constructions of dominant cultural assumptions about rhetorical education, and acceptable writing practices, which racially underrepresented students must face. Specifically, this analysis helps further understanding of how transitioning across institutions as an academic writer operates through multiple networks at multiple levels outside the student and outside the classroom.

The next section critically analyzes instances in which institutional texts evade, imply, or recognize racial identity as a factor of student experiences. Each of the described texts guide practices around transitioning to postsecondary writing from secondary environments. Institutional documents used in this analysis, including the Office of Admissions recruiting materials, the university's mission statement, the 
general education curriculum written communication requirements, and the

Composition Program student learning outcomes (SLOs), construct a tradition of what

being a college student means and how academic writing practices contribute to the performance of that identity. Table 1 briefly outlines how these texts approach race.

Table 1. Presence of Race in Institutional Documents

\begin{tabular}{|l|l|l|l|}
\hline & Race Recognized & Race Implied & Race Evaded \\
\hline Mission Statement & $\checkmark$ & $\checkmark$ \\
\hline Recruiting Materials & & $\checkmark$ & $\checkmark$ \\
\hline $\begin{array}{l}\text { General Education } \\
\text { Requirements }\end{array}$ & $\begin{array}{l}\checkmark \text { (Cultural } \\
\text { Diversity } \\
\text { Competency) }\end{array}$ & $\checkmark$ & $\checkmark$ \\
\hline Composition SLOs & & $\checkmark$ & $\checkmark$ \\
\hline
\end{tabular}

My analysis of how, when, and why race gets discussed in high-school-to-college transition-based documentation helps measure the influence of these policies and procedures on students whose identities have not been normalized. It examines the ways college administration, at both institutional and departmental levels, gives attention to everyday social differences among their campus community members. If the orientation along whiteness (Ahmed) propagates without being interrogated, the reality of racialized experiences is evaded. Bronwyn Williams proposes that, when acclimating to the culture of higher education, students, professors, and researchers must choose whether to accept the cultural identities of institutions, or resist and negotiate new identities that serve both purposes (1). Particularly within formalized education, literacy practices are one way to perform identity (B. Williams, Identity 4). The higher education institution expresses this, in part, in its approach to writing curriculum. As Black American students at this predominantly White institution —in appearance and cultural values—are on their way to performing college-educated identities through writing, the evasion of racial identity in 
institutional texts can indicate that non-privileged racial identities are trivial among the greater college community. Similarly, implying the possibility of Black racial identity through code terms such as diversity, underrepresented, and minority reifies constructs of whiteness. Rather than validating students' histories, caused in part by the societal impact of racial identity, as suggested by Prendergast, evading and implying race in the texts works to colonize these histories (37). The documents used in my analysis demonstrate how implying racial identity and evading racial identity in policies related to transitioning to college and college writing might influence learning outcomes.

\section{The Documents}

My analysis is primarily archival, provided by the racialized ideas about its identity that the university has established through its printed materials. The genres of these materials may shape their actions regarding race. For instance, the mission statement is a governing genre. According to Norman Fairclough, "genres of governance" are those that sustain "structural relations between local government, business, universities, the media, etc." (32). They include genres created for "regulating or managing some other (network of) social practice(s)" (Fairclough 32) such as the way mission statements govern how the university as a whole should function. The SLOs and general education requirements are teaching and assessment genres. Recruiting materials are a part of promotional genres. If genres work as "forms of social action" (Collin 78; Miller) and "ways of acting" (Fairclough 26) with texts, the way the documents under analysis work within the university's institutional structure can dictate how they address racial identity in students, as well as how changes can be enacted for those that evade race entirely. 
The primary archival material that directly influences the academic lives of firstyear students is the general education curriculum written communication requirements. ${ }^{14}$ The requirements of the various learning outcomes of this curriculum are listed on all general education course syllabi. The written communication area requirements include

1. Understand and use writing processes, including invention, drafting, organizing, revising through multiple drafts, and editing;

2. Write clear and effective prose in several forms, demonstrating an awareness of audience and purpose;

3. Understand and use appropriate academic textual conventions of presentation, at sentence level and beyond;

4. Employ critical thinking processes, such as abstracting, synthesizing, and representing ideas, and developing complex structures for them;

5. Collect, select, and integrate material from a variety of sources into their writing, citing it appropriately. (General Education Program)

Students are assessed on their ability to meet the requirements and, therefore, how they perform college-level work in the content areas.

The Composition Program student learning outcomes ${ }^{15}$ influence the academic lives of the transitioning students referenced in this project. The first-year composition sequence of English 101 and English 102 has specific criteria "intended to provide instructors and students with a sense of what kinds of knowledge students should be

\footnotetext{
${ }^{14}$ You can view the general education requirements for Written Communication courses here: http://louisville.edu/provost/ger/ger-preface

${ }^{15}$ You can view University of Louisville Composition Program student learning outcomes here: http://louisville.edu/english/composition/101-and-102-outcomes.html
} 
expected to acquire and demonstrate by the end of each course" (Department of English, "Composition Student Learning Outcomes"). The knowledge areas of these outcomes include "rhetorical knowledge," "critical thinking," "critical ... reading," "processes," "conventions," "confidence and ownership," and "community issues and cultural diversity" (Department of English, "Composition Student Learning Outcomes"). Outlined in detail on the English Department's website, these knowledge areas represent the base of college-level writing habits expected at University of Louisville, and composition instructors evaluate students on their ability to meet these criteria.

Before students are even exposed to the student learning outcomes or the general education requirements, they are bombarded with recruiting materials. These include print and electronic texts that intend to attract potential students to the university. To supplement high school visits, ${ }^{16}$ the Office of Admissions distributes brochures, infographics, and emails and maintains a Facebook page and Twitter account to keep interested high school students in the know about University of Louisville. Its job also includes projecting a cheerful, confident image of the institution. The university also produces promotional videos to attract students. These materials are the opening narratives that introduce students to the institution's identity.

Each of these documents and their policies are based on the university's overarching mission statement. The mission statement can be thought of as the controlling document for all activity at the university. The document received a recent update in January 2016 to reflect a revised institutional identity which appears more

\footnotetext{
${ }^{16}$ The Admissions Office is also responsible for recruiting transfer students, particularly from local twoyear colleges. Those efforts are not the subject of this analysis.
} 
invested in issues concerning inclusion and diversity. The previous mission statement read,

The University of Louisville shall be a premier, nationally recognized metropolitan research university with a commitment to the liberal arts and sciences and to the intellectual, cultural, and economic development of our diverse communities and citizens through the pursuit of excellence in five interrelated strategic areas:

- Educational Experience,

- Research, Creative, and Scholarly Activity,

- Accessibility, Diversity, Equity, and Communication,

- Partnerships and Collaborations, and

- Institutional Effectiveness of Programs and Services. (University of Louisville "Mission Statement")

On the other hand, the university adopted the current mission statement in January 2016. It reads,

The University of Louisville pursues excellence and inclusiveness in its work to educate and serve its community through

1) teaching diverse undergraduate, graduate, and professional students in order to develop engaged citizens, leaders, and scholars,

2) practicing and applying research, scholarship and creative activity, and 
3) providing engaged service and outreach that improve the quality of life for local and global communities.

The University is committed to achieving preeminence as a nationally recognized metropolitan research university. (University of Louisville, "Mission Statement)

Such a brief text conveys the institutional identity in a concise form for university patrons, community members, and stakeholders.

Several other documents ${ }^{17}$ could be included in this analysis and would provide meaningful perspectives on how ideas about transitioning, race, and writing are mythologized. These documents might include college entrance exams, the advanced placement English exam, admission applications, and high school advanced placement and honors English curriculum. Due to the scope of this analysis, I have not included these documents. However, a more long-term, extensive institutional analysis project should take account of the ways that standardized tests and pre-college curriculum contribute to narratives about becoming an advanced academic writer.

\section{Race Implied}

In the case of the documents described here, when a policy or university practice implies race but does not mention race, it recognizes the possibility of difference due to cultural distinction. However, the policy does not indicate the significance of those differences in affecting how learning experiences occur. Terms such as diversity, minority, underrepresented and even culture and ethnicity will be used. A number of critical race theorists have noted the complications of equating race to ethnicity

${ }^{17}$ I reviewed additional documents including the Undergraduate Catalog, The 2020 Plan, the University of Louisville Diversity Plan, and the Community Engagement Glossary of Terms. 
(Brubaker; Wacquant; Omi and Winant) in a culture that places so much emphasis on racial formation (Inoue; Omi and Winant). Most of the past racist experiences with education that some students carry with them into their first year in college did not include individuals concerned with the students' ethnicities. To imply the presence of racial difference through the terminology of ethnicity ignores the distinction.

Additionally, diversity and culture fail to grasp the sociocultural construction of race. Although many types of diversity exist at University of Louisville-sexual orientation, gender identity, religious, disability, age, race, and ethnicity among othersthe appearance of a specific image and caption on the page designated as "Diversity" on the university's website homepage demonstrates the association of diversity with racial difference. I discuss this image and text further in an examination of the admissions recruiting materials, but Figure 1 shows the image.

UNNIEERSIIYY OOF

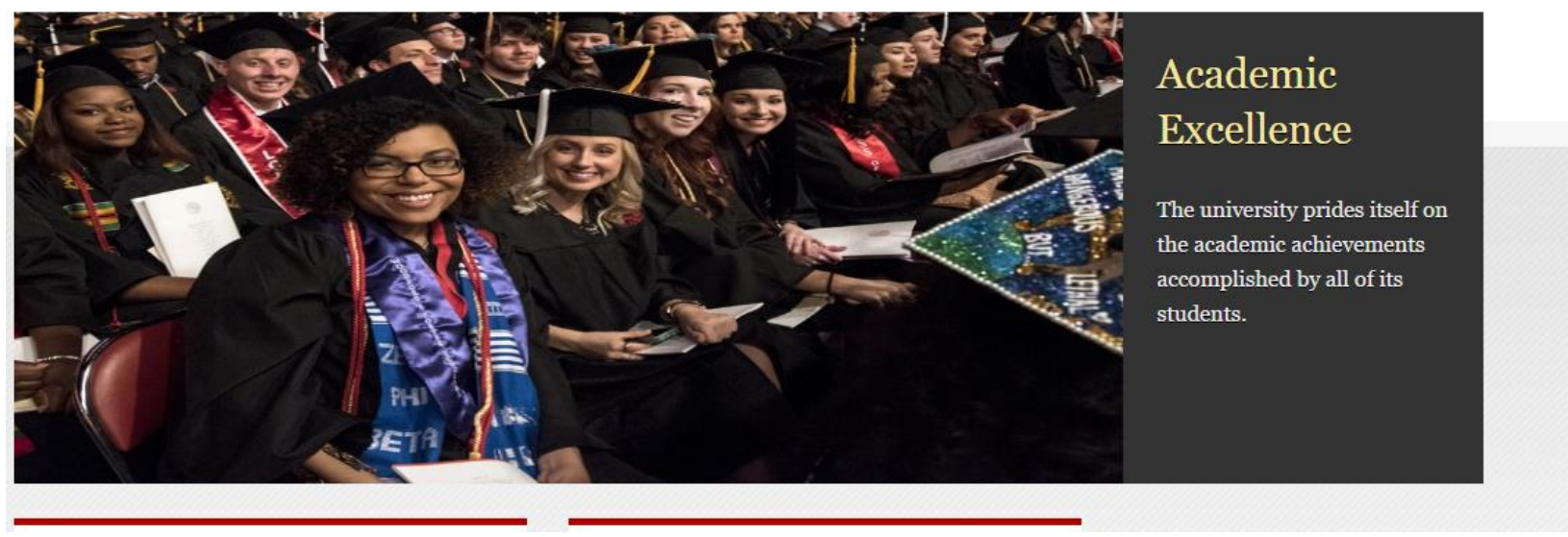

Figure 1. Image on Office or Diversity and International Affairs website home page. 
The University of Louisville further links diversity with "international affairs" which indicates diversity as part of genealogical and cultural identifiers. Similar to marking race with diversity, race includes the other distinctions of ethnicity and cultural traits, but it does not end there. While science has generally agreed that race contains no biological component, phenotypical and genealogical features remain significant to establishing a racialized social system. This significance is so critical that racial distinctions change based on the political and social interests and needs of dominant cultural group (BonillaSilva; Delgado and Stefancic; Omi and Winant).

\section{Admissions Recruiting Materials}

The lack of race consciousness in recruiting materials is certainly intentional. While a portion of the Admissions Office is dedicated to diversity recruitment, the majority of recruitment is focused on the general student population for which White is the predominant racial identity group. For example, one two-sided recruiting infographic sent to area high schools is titled "Check Out Ways to Visit UofL Today" (Figure 2) on one side and "It's Never Too Early to Plan for College" (Figure 3) on the flip side. 


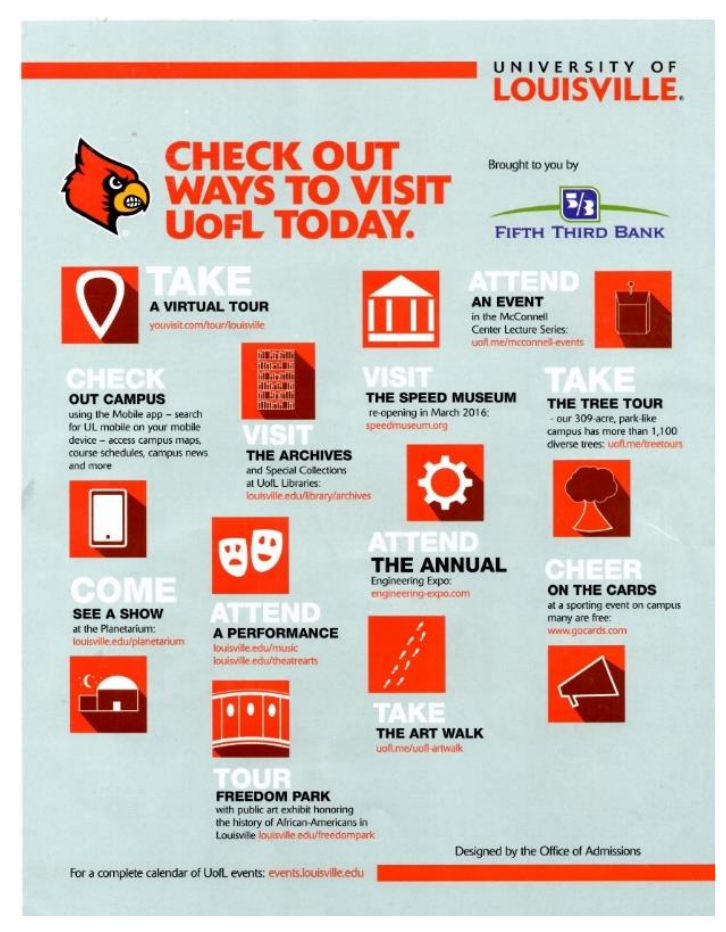

Figure 2. Office of Admissions High School Recruitment Flyer, side 1.

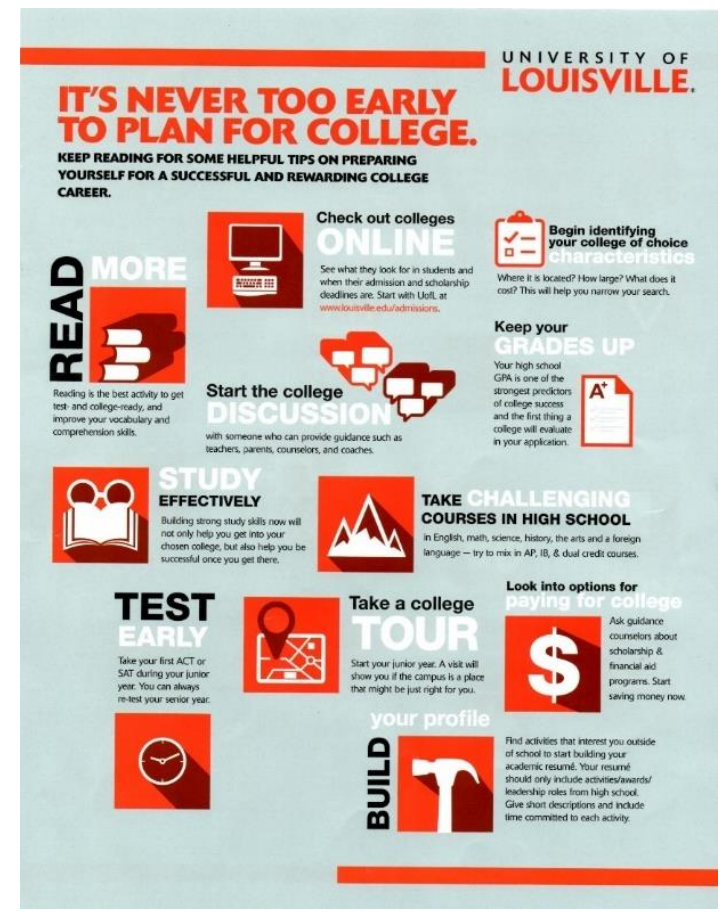

Figure 3. Office of Admissions High School Recruitment Flyer, side 2. 
Where the document mentions racial identity, it does so in an exhibitionist fashion. Inviting potential students to "[t]our Freedom Park with public art exhibit honoring the history of African-Americans in Louisville" represents a type of academic multiculturalism that "can be an invitation to 'cultural tourism' or 'cultural voyeurism,' rather than to genuine multicultural engagement or education" (Edelstein 18).

The document, in fact, misses an opportunity to highlight such engagement such as the Theatre Arts Department African American Theatre Program. According to its mission statement,

Founded in 1993, the African American Theatre Program is committed to staging works by new and established African American dramatists, developing a broad audience for African American theatre, and offering an in-depth curriculum that focuses on the theory and craft of acting, directing, and designing for Black Theatre. (UofL Theatre Arts Department)

This program performs plays for community audiences all year around, and it is but one opportunity for recognizing the importance of racial experiences at the university. Since "[h]ere you will learn training not only for William Shakespeare and Tony Kushner but also August Wilson, Pearl Cleage and Wole Soyinka" (UofL Theatre Arts Department), it is an opportunity for transitioning students to see how the university can productively engage them in inquiries of culture and racial identity. Other opportunities for such engagement include programs with the Cultural Center, student organizations, and archives available in university libraries. 
Reducing the presence of racial difference to historical art in this document implies these differences are less meaningful in the current university context. The insignificance of racial identity to transitioning to college life is even more apparent in the side of the document which contains "helpful tips on preparing ... for a successful and rewarding college career" (Office of Admissions). Among the advice to "study effectively" and "take challenging courses," potential students are directed to "find activities that interest [them] outside of school to start building [their] academic resume" (Office of Admissions). Even as cultural awareness is one of the competency areas the university expects students to build upon in its general education program, the infographic lacks any mention of that awareness.

The promotional videos, which give potential students who may not be able to visit the campus a 360-degree perspective of the campus and its offering, lack any recognition of cultural awareness regarding racial identity within the campus. So, for example, they do not reference registered student organizations which support racially marginalized groups and they do not show performances from the African American Theatre Program. The student life campus tour video begins by showing the Thinker statue and soon after flashes the Shumaker Research Building across the screen (University of Louisville, "UofL Campus"). Even though the target audience of the film may not know that nanotechnology research takes place in this building, they will no doubt note the contemporary, sleek look of the building - a look associated with progress. The composition of this promotional video furthers the ideal of traditional, Eurocentric research practices. It even includes an image of a Black female student participating in these research practices as she studies intently on the floor in between the stacks. Patricia 
Hill Collins describes traditional, Eurocentric research practices as based in individual idea development and recognition and representative of White heterosexual male validation of knowledge (271). If transitioning students want to be successful academically at University of Louisville, this video tells them that they must adopt these practices.

Transitioning students are shown that the outcome of embracing these practices is successful matriculation and graduation. On University of Louisville website's homepage, "Diversity" is its own tab. This tab carries visitors to the webpage for The Office of Diversity and International Affairs. Here, the first image and caption is a Black female smiling brightly in graduation attire next to the text "Academic Excellence." Underneath the text reads the additional message, "The University prides itself on the academic achievements accomplished by all of its students" (The Office of Diversity and International Affairs). While high school students "check out colleges online" and "start the college discussion" (Office of Admissions), the university website is one of the first means of gathering information.

These documents represent some part of the institutional identity which all members of the university community are expected to embrace. An institutional identity indicates the culmination of an institution's values and culture. What these recruitment texts convey about University of Louisville's institutional identity is “academic excellence is valued above all else." That is no surprise; it is an R1 research university, after all. However, the quality of being raced is either specialized or nonexistent in the recruitment process. When implied, rather than recognized, racial identity becomes just another feature of no consequence. Race is represented as significant as the clothing a 
student wears - worth noticing sometimes, but not influential to the college social or academic experience. By priding "itself on the academic achievements accomplished by all of its students" (The Office of Diversity and International Affairs), the university conveys the message that all of its students begin on the same field of opportunity. While race — often complicated further by gender identity, disability, linguistic variation, or sexual orientation - is just one factor that makes this assumption irresponsible, it is a critical factor for many Black Americans at a predominantly White institution.

Still, a dedicated group of admissions counselors carries out diversity recruitment tasks, implying that issues of diversity, including racial diversity, are outside of the norm. Programs like the Woodford R. Porter scholarship program ${ }^{18}$, Cardinal Covenant ${ }^{19}$, and the Martin Luther King scholars program ${ }^{20}$ provide great opportunities for students of color to engage with the university community. However, the message these specialized opportunities might convey about their racial identity tells many students, particularly those students whose racial identity correlate anti-White and therefore anti-academic (Ladson-Billings), that they are abnormal to the operations of the university. They, and people like them, overall do not belong in this space which is oriented along whiteness (Ahmed).

One central socialization goal of higher education is to liberate those outside norms through assimilation into culturally dominant ways of knowing and being. The recruiting and admissions process begins this process. As a part of the process of assimilation, factors of race are business-as-usual in daily operations of higher education

\footnotetext{
${ }^{18}$ Find out more about the Porter Scholars Program here: https://louisville.edu/culturalcenter/retention/porter

${ }^{19}$ Find out more about Cardinal Covenant here: http://louisville.edu/financialaid/cardinal-covenant

${ }^{20}$ Find out more about the Martin Luther King Scholars Program here: http://louisville.edu/admissions/aid/scholarships/mentored-scholarships/mlk
} 
institutions, as they are in all American social institutions. Due to this normative practice of racializing the nature of things, race often maintains an absent presence in higher education institutional identity, and this practice is remarkable in University of Louisville's institutional identity.

\section{Mission Statement}

In an attempt to resist against its own nature as an institution invested in whiteness, as part of becoming a community-engaged $21^{\text {st }}$ century university, the University of Louisville recently updated its mission statement to strengthen its diversity and community engagement objectives. In both recent versions of University of Louisville's mission statement, the concept of racial identity and difference is implied, again, by the term "diverse." I separate this from other categories of diversity such as sexual orientation and disability which are more traditionally associated with "inclusiveness" and "accessibility." Jennifer Clary-Lemon finds "diversity" to be among the most common terms that composition scholars have used to designate race (W6). In researching 20 years of writing about race in the journals College Composition and Communication and College English, Clary-Lemon notes 28 occurrences of the term diversity associated with racial identity (W6). As I have indicated, by substituting the concept of racial difference with culture, diversity, or ethnicity, Clary-Lemon concurs that "using words like 'culture' or 'diversity' to discuss racialized ideology may be limiting or reductive" (W9). The mission statement demonstrates such a reduction, simultaneously indicating race while not recognizing its significance.

The governing genre of the mission statement acts as the engine driving policies and administrative actions on behalf of all university representatives. Placed on the 
institution's website, in the course catalog, and in some recruiting documents, the mission statement is broad, yet unread by so many of the people it influences, namely students. Based on its mission, vision, and other strategic statements, University of Louisville portrays its identity, in order of significance, as community-centered, diversity-driven, and research-focused. These attributes influence what activities, and what ways of being a university, are valued. While the previous mission statement emphasized the academic nature of the university with the distinction of "a premier, nationally recognized metropolitan research university with a commitment to the liberal arts and sciences," the current statement underlines commitment to "its community" and equally prioritizes "inclusiveness" with "excellence" (University of Louisville, "Mission Statement"). The university proclaims to value diversity through inclusive curriculum; racially, ethnically, and otherwise culturally diverse faculty; and community engagement practices. The prominence of the university's status as a premier metropolitan research institution takes less precedence as it has been moved to the final sentence of the statement. This rearrangement also reforms the institutional identity.

For transitioning Black American students, a renewed focus on "teaching diverse undergraduate ... students" for engaged citizenship, scholarship, and leadership (University of Louisville, "Mission Statement") seems welcoming. And it is, generally speaking. However, like the Office of Diversity and International Affairs' image and caption, the implication of racial difference, without the recognition of it, denies the impact that various forms of difference have on social and academic engagement. These difference variations affect student learning outcomes in dissimilar ways as they attempt to transition to college-level academic work. Still, I am not suggesting that a document as 
brief as the university mission statement encompass every form of social difference available at a large institution such as University of Louisville. I am, however, proposing that the mission statement gives recognition to how different forms of diversity drive engagement with the academic and cultural life of the university.

\section{General Education Written Communication Curriculum}

The general education curriculum represents one manifestation of the institutional identity taken up by the mission statement. The General Education program (Gen Ed) consists of courses and required outcomes for learners across the curriculum. Because every student must either complete Gen Ed curriculum at University of Louisville or transfer Gen Ed credits in, this represents a key component of the institutional academic identity. To say that racialized perspectives exist in the central curriculum within an institution invested in whiteness might seem redundant. In fact, to say that race-based cultural interests remain within mainstream public education curriculum is also old news. The hidden curriculum has been a critical aspect of education research. Zeus Leonardo has considered the factor of "white investment" in the curriculum, or how it intentionally or unintentionally teaches white supremacy to White students (144). According to Leonardo, "The hidden curriculum of whiteness saturates everyday school life and one of the first steps to articulating its features is coming to terms with its specific modes of discourse" and critical educators should work to unpack white supremacist "discourses in particular school places" (144). Gloria Ladson Billings suggests that "critical race theory sees the official school curriculum as a culturally specific artifact designed to maintain a White supremacist master script" (21). Accepted manifestations of knowledge are mandated by this script. 
Overall, the Gen Ed curriculum for written communication does not imply or recognize the impact of race. In fact, "Understanding Cultural Diversity" is a separate competency area in the Gen Ed curriculum which allows any aspects of cultural influence to be removed from the content areas such as written communication. The competency area "encourages an appreciation of the realities of a racially and culturally diverse world" (The General Education Program), and I discuss this in more detail while emphasizing where race is recognized in institutional documents concerning high school to college transitions. On the other hand, the cultural diversity competencies require students to "[c]ommunicate an understanding of the ways in which race, ethnicity, and/or gender are socially constructed" and to "[c]ommunicate an understanding that different cultures may hold different views of the same issues" (The General Education Program); written communication practices can be an avenue for exemplifying these skills. These will be discussed more as I consider how the Gen Ed curriculum recognizes racial identity.

The Composition Program student learning outcomes expand on the Gen Ed curriculum, adding more specificity as well as opportunities to imply the influence of racial difference on writing. In examining what knowledge about writing is privileged in University of Louisville Composition Program outcomes, I considered each individual criterion with specific questions for analysis. I question whether it reflects an investment in whiteness or white supremacy, which of the sanctioned rhetorical strategies intersect with Black rhetorical traditions, and how that criterion tries to shape the ways that students develop as writers. While the orientation along whiteness may not be deliberate within the writing program, it is persistent. In other words, the influence of whiteness 
values in our society makes their presence in the writing curriculum purposeful, but those teaching these values may not recognize them as aligning with a particular racialized perspective. The mission to infuse the curriculum with diversity-oriented practices may appear altruistic or, in the very least, forward-thinking. However, in examining the objective more closely, Eurocentric epistemology is expressed by several criteria in the student learning outcomes.

In the English 101 Introduction to College Writing outcomes, race is implied in criteria related to rhetorical considerations about audience and purpose and critical thinking about multiple points of view. English 102 Intermediate College Writing, however, more directly addresses the possibility for racial community consciousness as "Community Issues and Cultural Diversity" are one of the learning outcomes students are expected to grasp. Outcomes related to these criteria do not specifically mention race or any identity factors. While this open, universal approach to audience, perspectives, community, and culture allows for instructor adaptability of these criteria, it also provides the opportunity to reinforce racial and cultural dominance in the curriculum. Audience and purpose in predominantly White universities will always be defined by those who represent epistemologies privileged by academia. As Patricia Hill Collins argues, "Because this enterprise [of academia] is controlled by elite White men, knowledge validation processes reflect this group's interest" (271). Like in other types of knowledge, "new knowledge claims" about writing and rhetoric "that seem to violate this fundamental assumption are likely to be viewed as anomalies" (Collins 272). Therefore, even as first-year writing instructors teach students to give critical attention to various audiences and purposes, those students whose social, professional, and civic lives might 
lead them to compose for racially subjugated, or less accessible, groups in the academy are expected to learn to write for more apparently privileged audiences. These practices are useful since "a culturally relevant [Afrocentric American] education" in first-year writing includes incorporating content from European and African knowledge bases (Richardson 119). On the other hand, students who hail from privileged rhetorical and literacy traditions have no expectation of learning to communicate with underprivileged audiences.

Specifically, referring to racially varied audiences, to "[a]nalyze and respond to the needs of different audiences" (Department of English) implies a possibility to address the needs of racial difference in particular situations. For example, in my English 101 course, we analyze how different racial upbringings—-socially dominant and oppressedmight influence how we receive the rhetorical appeals of Black Lives Matter and All Lives Matter arguments. However, the expectation for communicating with ethnolinguistically diverse students is contradicted by the outcomes "Choose evidence and detail consistent with purpose and audience" and "Employ a tone consistent with purpose and audience" (Department of English). Most students and teachers at predominantly White institutions have no experience writing for or with ethno-linguistically diverse communities. These limitations of instructors and peer audiences prevents students from such communities the opportunity to learn to compose eloquent texts in their home or native linguistic varieties. Writing teachers at the University of Louisville have the autonomy to interpret these student learning outcomes to teach rhetoric, writing, and literacy as racialized. Some faculty employ this autonomy. Although, by not making this a part of the expected outcomes, some transitioning Black American students miss the 
opportunity to link academic discourses to other discourses for the purposes of resistance and liberation (Delpit; Fox). Moreover, writing program administrators and writing instructors fail to become mindful of how the inherent power of white supremacy marks their curriculum and pedagogy (Olson 216).

More attuned to the nuances of cultural difference, the outcomes "[q]uestion existing assumptions about culture and community" and "[a]ddress concerns of diverse audiences" (Department of English) open up more opportunity for discussions of race consciousness and writing. In fact, some cultural rhetoric scholars (Anzaldua; Matsuda; Perryman-Clark; Powell) have taken on much of this racialized work in writing studies and rhetorical studies.

Race is implicated more directly in these outcomes, but as with the recruiting materials, reducing race, ethnicity, religious faith, gender identity, or other identities to "culture," "diversity," or "community" alone ignores the complexities of these identities. Regarding race, "question[ing] existing assumptions about culture and community" only operates critically if students understand how racialized experiences shape cultural and community practices. As Black American students transition into performing college academic identities through writing, only loosely exploring the ways culture impacts written communication results in continuing to normalize hegemonic rhetorical behaviors.

The investment in these hegemonic practices is not only cultural, but also material, as Bruce Horner suggests. Horner explains that "the institutional form of the [freshman composition] program is treated as a commodity" (172). Since the institution is invested in the exchange-value of composition work, the interest with issues of race must 
converge with larger institutional issues. For the institution, and the writing programs that represent institutional values, teaching students outside of privileged racial groups to act discursively within the traditions of dominant racial groups is more meaningful than teaching the rhetorical traditions of underprivileged racial groups. Some writing programs and writing instructors insist that this "discourse stacking" is a mode of access to upward mobility (Delpit 165), or used as a way to misrepresent the literacy as a freedom trope from Black American history (Richardson). However, introducing transitioning Black American students to the process of privileging academic discourses, through this manner of implying race, risks that they will perceive their own rhetorical practices as meaningless in academic situations.

In shifting into college academic identities, these students are transitioning into an additional way of representing themselves. Transitioning into these new ways of representing as a member of a lower order group in the American racial hierarchy has its own complexities. Therefore, institutional policies which imply race consciousness, but do not fully recognize its workings within academic social systems, dismiss how those complexities around race can shape academic engagement. To suggest that something may exist as a dynamic, race in this case, is to leave for doubt of its existence; that doubt is dangerous. Even for Black American students who have not wrestled with the high school to college institutional-cultural transition, being physically marked as other places them in a susceptible position. Teachers, administrators, and other students, who are part of the majority, will perceive them as out of orientation. These Black Americans have made a choice to adopt or rent the property of whiteness, at least in terms of education, so that they might accept membership into this predominantly White institutional 
community, "not only to join, but ... to inhabit it by turning around as a return of its address" (Ahmed 158). As the signatories of the Racial Contract ${ }^{21}$, those in control at the institution come from a legacy which establishes their "white" race (genealogy, phenotype, and culture) as a superior moral status. "Non-white" others have been deemed with an inferior station in all civil and social arenas (Mills 11), so the standards set by the American education system were set by those who have access to particular types of knowledge that others do not. This control, based on the Racial Contract, means that "audience" in the writing curriculum refers to primarily White, middle-class, academic audiences. Genres and their rhetorical purposes reflect the social needs of audiences and authors invested in cultural whiteness.

Therefore, even when Black American students successfully adopt and practice the customs of whiteness, their otherness at a predominantly White university shapes their engagement with the university. Writing program student learning outcomes remain one circumstance in which their marginalization is reinforced. Hence, the time and space of academic writing practices have been designed to drive out representations of blackness. Inoue ("Racial Methodologies") and Carmen Kynard suggest that such violent acts against Black racial consciousness happen, most often, through writing assessment practices. Due "to limited notions of academic writing" these students often get reprimanded for their intellectual, rhetorical choices (Kynard 5). Some might argue that those rhetorical choices limit the readership of the text, but such arguments reinforce the

\footnotetext{
${ }^{21}$ Charles Mills defines the Racial Contract as a "set of formal or informal agreements... between the members of one subset of humans, henceforth designated by (shifting) 'racial' (phenotypical/genealogical/cultural) criteria... as "whit[e]" ... to categorize the remaining subset of humans as "nonwhite" and of a different and inferior moral status, subpersons, so that they have a subordinate civil standing in the white or white-ruled polities the whites either already inhabit or establish" (p. 11).
} 
point that rhetorical knowledge, pertaining to audience and purpose, which students are expected to build upon is limited. Since race is only implied as a recognizable experience in the student learning outcomes, its significance to written acts of language remains in doubt by the institution.

\section{Race Evaded}

When an institution's policy document evades race consciousness, it negates all recognition of racial identity. By doing so, it delegitimizes the influence of racial social systems (Bonilla-Silva) on the responses to the institutional policies. Racialized perspectives represent no position in the policies' objectives or plans, and such a text situates student identity, as has been described in this chapter, as universal. Rather than signifying legitimate experiences, these texts are designed to guide experiences. These documents exhibit what the institution would like to see; not what, in fact, exists.

\section{Recruiting Materials}

In the case of the Office of Admissions general recruiting materials, it would seem that racial identity has no influence over a high school student's decision to attend University of Louisville. Since the objective of the Office of Admissions is to recruit all eligible students, regardless of identity, it takes an amalgamation approach (Castagno) to recruitment. Focusing on "amalgamation ... emphasizes commonalities across groups in an effort to reduce prejudice and improve intergroup relations" (Castagno 45). The infographic "It's Never Too Early to Plan for College" (Figure 3) encourages extracurricular activity involvement, but not cultural competency and certainly not difference competencies. This document exhibits the amalgamation approach in that it demonstrates tolerance and acceptance—-sometimes one or the other-over cultural 
responsiveness or relevance. The infographic indicates that all qualified people can meet the standards of preparing for college, if they are of merit. While "educating for amalgamation" recognizes individual cultural differences, and might even recognize the influence of racial experiences on academic merit, its ultimate purpose is to erase these differences to create another culture that represents all cultures' contributions (Castagno 45).

Most of the university programs developed for the purpose of helping Black Americans make the transition from high school to college ${ }^{22}$ are not referenced on the Office of Admissions' website or general recruiting materials. Unlike the mainly White fraternities and sororities mentioned in the "No Better Time to be a Louisville Cardinal" brochure, these specialized programs for racial others are either promoted by word-ofmouth or by the diversity recruitment staff. So, in fact, they, and the students who use them, are both present and absent. By not naming these programs to the mainstream students, staff, and faculty, the message that the needs of the students for which these programs were designed are effectually not present is sent (Royster and J. Williams 568). Recruitment brochures and general high school visit days highlight the universal race absent programs and services. For example, as shown in Figure 4, the Office of Admissions distinguishes "Campus Visit for High School Students" from "Diverse Student Visit Opportunities.”

\footnotetext{
${ }^{22}$ Transition-based programs from Black American students at University of Louisville include the Early Arrival Program (also includes other racially underrepresented groups), C.O.N.E.C.T., AVIATOR, the African American Male Initiative, the Association of Black Students, and Student African American Brotherhood.
} 


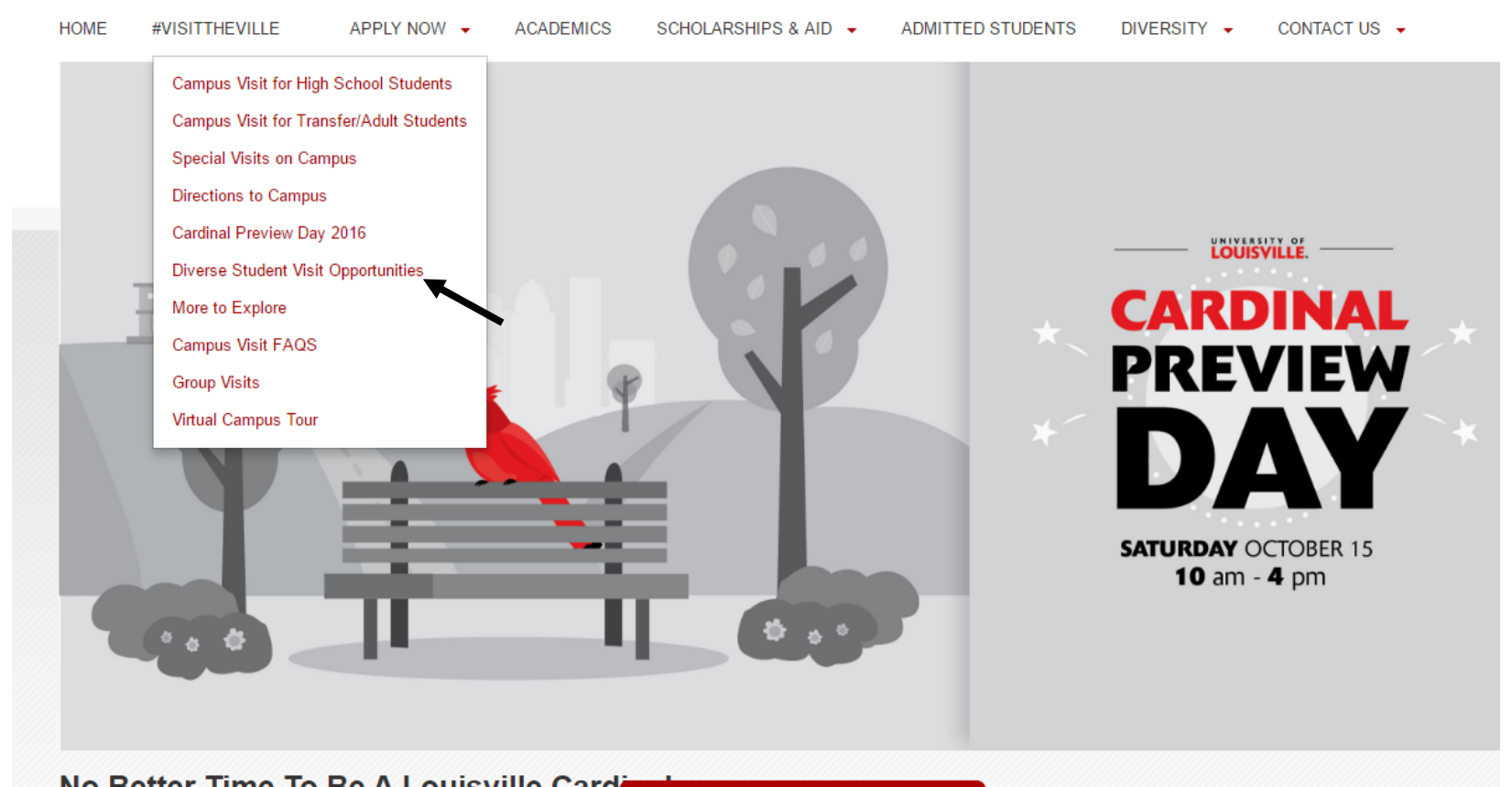

Figure 4. Office of Admissions Campus Visit Website Menu.

Again, while categories of diversity vary at University of Louisville, in this case it clearly signifies racial diversity as the page "Diverse Student Visit Opportunities" boasts, "We are proud to be the most diverse university in the state of KY, with students of color representing $25 \%$ of our student population" (Office of Admissions). By making this distinction, the university suggests that, by evading race, its general recruiting practices cannot meet the essentials of all of its students. This narrative evades race in the institutional recruiting norms. Rather than making diverse students' needs a part of the standard, those needs are specialized. Therefore, it must separate these practices even as it claims inclusion.

In addition to the evasion of racialized perspectives in academic spaces, University of Louisville evades racial difference when promoting the city of Louisville. Such a lack of recognition can disrupt Black American student experiences, since many students of color who attend the university come from lower funded districts, with less 
academic resources than predominantly White high schools and districts. As they are developing in their academic identities - taking on new roles and new measures of achievement - their engagement with the surrounding communities becomes even more important. The promotional video, "The Total Package: UofL and the City of Louisville" focuses on the Eurocentric, middle-class angle of Louisville. The video describes Louisville neighborhoods and what they offer residents. After a brief introduction by a young, non-threatening White American male representation of the traditional University of Louisville student, the video opens with images of downtown Louisville, the historic Belle of Louisville steamboat, and Waterfront Park with the Big Four Bridge overlooking the Ohio River. The neighborhoods and venues highlighted in the video include Bardstown Road, a local hotspot of upscale and trendy shops, restaurants, and bars; Fourth Street Live, a touristy collection of eateries, shops, bars, and clubs in downtown Louisville; St. Matthews, an affluent suburb east of Louisville; Churchill Downs, the racetrack of The Kentucky Derby; and some of the city's parks. Each person giving testimony in the video is a young White American student, save one male student of East Indian or Middle Eastern descent, symbolizing the presence of brownness, and, therefore, inclusiveness.

This video is far from inclusive. Louisville consists of more than majority Whitecentric, hip, trendy, touristy areas. In fact, Louisville remains one of the top most segregated cities in the U.S. (Kent and Frohlich, "America's"), with 31.1\% of its Black population impoverished, and $61.7 \%$ of its highest earning population living in nearly allWhite zip codes. While materials meant to promote University of Louisville and its compassionate city may not want to advertise this fact, evading race in promo videos 
such as "The Total Package" undermines the history, culture, and community of Louisville and its complete makeup of residents. More specifically in terms of the university, it undermines the experiences of students whose personal histories hail from the snubbed areas. According to this video, University of Louisville embraces its investment in whiteness, middle-class values. Students who are more interested the Portland neighborhood ${ }^{23}$, Jefferson Mall ${ }^{24}$, or Smoketown ${ }^{25}$ do not share the values of the university community and, in a sense, do not belong. This message extends beyond this one text.

Both the "No Better Time to be a Louisville Cardinal" brochure and a pamphlet titled "A Visitor's Guide to Campus" highlight what University of Louisville considers noteworthy destinations in the city. In addition to the ones named in the video, these destinations include:

- Old Louisville

- Museum Row

- $\mathrm{NuLu}$

- Frankfort Avenue

- Louisville Zoo

- KFC Yum! Center

As with the promo video, the brochure and pamphlet make no mention of predominantly Black spaces or the collaboration between the university and the residents of these spaces.

\footnotetext{
${ }^{23}$ Portland is a working-class, predominantly Black borough in Louisville's west end.

${ }^{24}$ Contrasted with the more affluent Mall St. Matthews and Oxmoor Mall, Jefferson Mall consists shopping for the common person.

${ }^{25}$ A historically Black American neighborhood in Louisville's southeast end.
} 
The "No Better Time to be a Louisville Cardinal" brochure has two opportunities to emphasize, for example, collaborative projects completed by the Kent School of Social Work and the department of Education and Human Development with local underserved communities. The career development list on page 1 of the brochure might name opportunities for education and social work students to acquire experience contributing to community development projects in Louisville's west end. Page 5 of the brochure, named "Experience More," includes categories of committed to sustainability and diversity among others, but, again, efforts to improve the sustainability of segregated communities are absent. Moreover, neither the documents nor the video mentions the extensive community development efforts of the Cultural Center or The Muhammad Ali Institute for Peace and Justice at University of Louisville. Some of these projects include partnerships with local Black Lives Matter advocates and the National Black Family Conference. The evasion of race and dependence on amalgamation of racial identities standardizes the whiteness-invested version of the university to transitioning students, while upholding the façade of inclusion.

\section{General Education Written Communication Outcomes}

Perhaps the clearest example of whiteness-invested standards of transitioning to college-level academic identities is the makeup of Gen Ed written communication outcomes. The written communication requirement for the Gen Ed competency areas requires students "to develop and express ideas, opinions, and information in appropriate written forms" (The General Education Program). This description is vague and even out of context, signifying a removal from social, cultural, or political constructs attached to literacy and rhetorical education. To gain an understanding of how the written 
communication curriculum invests in whiteness, I analyze each of the five criteria.

Relating to Inoue and Barnett's conception of whiteness as discourse, I pinpoint where the Gen Ed curriculum for written communication encourages this discourse. Finally, I compare this to the features of Black rhetorical traditions (Gates; Gilyard and Richardson; Smitherman), African American literacies (Richardson), as well as rhetorical education practices for Black Americans.

"Understand and use writing processes, including invention, drafting, organizing, revising through multiple drafts, and editing." This outcome dismisses where racialized experiences in previous writing education scenarios influence student writers' writing processes. For some Black American students, their blackness has been policed in writing classrooms just as it is policed in public life. The difference in writing classrooms is that the policing comes under the pretext of best practices literacy. In "Writing While Black: The Colour Line, Black Discourses and Assessment in the Institutionalization of Writing Instruction," Kynard suggests that a "continued colour [sic] line in higher education" (4) results in the penalizing of "students who consciously employ rhetorical and intellectual traditions of Black discourses" (4-5). This literacy color line extends well beyond higher education into secondary and elementary education. If students are expected to learn to use specific writing processes, writing program administrators should, and should help instructors, be conscious of how the students' processes have been controlled based on race prejudice in the past. Such prejudice possibly influences even beginning the invention process for many of these students. However, as demonstrated by the Freedom Schools, Black Panther liberation schools, and independent Black institutions described in Chapter Two, Black American 
communities have historically privileged the collaborative development of communicative ideas. Discourses of whiteness, on the other hand, encourage "hyperindividualism" in writing processes where ordered, controlled, and rule-governed “consistency [is] valued highly" (Inoue, "Whiteness as a Discourse).

\section{"Write clear and effective prose in several forms, demonstrating an}

awareness of audience and purpose." The second outcome, as emphasized by race implied in the discussion of student learning outcomes, disregards the implied audiences and whiteness-invested purposes at predominantly White colleges and universities. Staci Perryman-Clark notes that even with the advent of Students' Right to Their Own Language, Black American students in college writing courses must still negotiate the language choices they make, particularly in established curriculum using whiteness as a discourse. As Perryman-Clark notes, "the pressures for students to adapt Standard English in academic writing while adapting alternative language varieties outside of the academy can add complexity to how language rights choices are often affected and contingent upon audience expectations" (480). Black American students at predominantly White institutions are asked to write for presumably well-educated White American audiences, because those audiences have become the default. "Awareness of audience and purpose" may vary based on the influence of racial-cultural histories. Afrocentric rhetorical attributes, for instance, consider the wisdom of proverbs, aphorisms, and even Biblical verses for use in formal, even academic, documents. So, the features may be more rhetorically effective for a primarily Black American audience or an audience familiar with the rhetorical features. While such features are likely well-known by nonBlack Americans, their usage in academic texts may be discouraged or penalized. Not to 
mention, without the permit of "ethnolinguistic idioms" or "verbal inventiveness" (Gilyard and Richardson 41; Smitherman 13) in academic writing tasks, students transitioning to the university may believe they are limited in crafting their versions of reality-commonly influenced by their lived experiences as members of a subjugated racial group - through written texts, because of the limitations of their implied academic audiences.

"Understand and use appropriate academic textual conventions of presentation, at sentence level and beyond." Many of the sixteen features of Black American discourses described by Geneva Smitherman as well as Keith Gilyard and Elaine Richardson contradict what Eurocentric or whiteness-invested epistemologies consider "appropriate academic textual conventions." For example, "sermonic tone," “ethnolinguistic idioms," "rhythmic, dramatic, evocative language," and "verbal inventiveness, unique nomenclature" (Gilyard and Richardson 41-42; Smitherman 12-13) are common properties Black American discourse, which often challenge whitenessinvested epistemologies. The capability to understand and practice the textual conventions of academic discourse limits the availability of rhetorical resources. Perryman-Clark proposes that for all students, perhaps Black Americans especially because of intense linguistic prejudice against their dialects, the ability to manipulate “Ebonics” or Black American discourses, Edited American English, and other dialects may be more rhetorically purposeful for students learning college-level academic writing practices.

“Employ critical thinking processes, such as abstracting, synthesizing, and representing ideas, and developing complex structures for them." Critical thinking, 
synthesis, and other practices for representing ideas are not universal. Where whiteness acts as a discourse, "[m]eaningful issues and questions always lie within the self; individuals have problems and solutions are individually-based" (Inoue, "Whiteness as a Discourse"). On the other hand, Black American discourses demonstrate these practices in other ways. Abstracting may occur through structural call/response, in which the "[w]riter returns repetitiously to the prompt as a structural device, checking for constant connection with the question or text at hand" (Gilyard and Richardson 42). In an analysis of Black American student essay responses to a university-wide assessment, Kynard notes where critical thinking in representing ideas takes the form of selecting appropriate metaphors and the rhythmic, dramatic language (29-31) described by Gilyard and Richardson, and Smitherman. This vague outcome description may assess Black American rhetorical moves such as narrative sequencing ${ }^{26}$ and topic association ${ }^{27}$ as failing to develop complex structures for ideas.

\section{"Collect, select, and integrate material from a variety of sources into their} writing, citing it appropriately." Similar to the previously listed Gen Ed outcomes for written communication, this final outcome does not explicitly denounce racialized perspectives on academic writing. However, when considering what "citing it appropriately" constitutes on paper, particular standards abide. These standards reflect Eurocentric validation of knowledge. Whether MLA, APA, or Chicago Style, academic citation practices "[f]ocus on the individual in a contractual relationship with other

\footnotetext{
${ }^{26}$ According to Gilyard and Richardson, narrative sequencing takes place either a "dramatic retelling of a story implicitly linked to topic, to make a point," the "reporting of events dramatically acted out and narrated," or the "relating of facts and personal sociopsychological [sic] perspective on them" (42).

${ }^{27}$ Topic association includes "a series of associated segments that may seem anecdotal in character, linked implicitly to a particular topical event or theme, but with no explicit statement of the overall theme" (Gilyard and Richardson 42).
} 
individuals" (Inoue, "Whiteness as a Discourse") and continue to protect official knowledge. In most cases, this knowledge has been "designed to represent and protect the interests of powerful White men" (Collins 271). Moreover, this "community of experts [has] maintain[ed] its credibility as defined by the larger population in which it is situated and from which it draws its ... taken-for-granted knowledge" (Collins 271). The way people "collect, select, and integrate material" from outside sources preserves the epistemology of a subject or field. In most cases, the methods of preservation consist of those validated by the dominant group. As a result, ways of referencing borrowed knowledge that do not meet these standards are not supported by this outcome. I am not suggesting that all students should not learn traditional citation practices, especially those that are common to their field of study. However, as a field and as writing program administrators, we should be conscious of how students might use the Black discourse features of signifying, testifying, and call/response to cite the work of others. Signifying, for example, relies on readers' collective understanding of a topic, or common knowledge, to overstate, understate, or "apply oppositional logic" to a piece of information (Gilyard and Richardson 42). This practice can include an indirect use of sources, which is uncommon to academic discourses, but it still demonstrates a writer's ability to integrate material from several sources.

The written communication outcomes evade the possibility of racial identity influencing communication practices. This approach does not expose students to the many voices they need access to (Delpit) in order to survive networks of human relationships (Kells), including those in the academy. As Black American students transition out of high school, they are moving from an academic culture focused on 
standards and graduation statistics for the most part. While the creative approaches of many dedicated teachers can challenge this trend, overall institutional differences between high schools and colleges can create hindrances to transitioning into collegelevel curriculum (Conley). While contemporary high schools make little effort to connect curriculum and institution cultural identity to student individual identity, at most universities and colleges in the U.S., this connection is expected. More precisely, students are expected to connect to the institution's cultural identity.

\section{Composition Program Student Learning Outcomes}

While not stated as such, the university uses the Composition Program student learning outcomes as a principal strategy to teach first-year students to perform the rhetorical behaviors that the institution values. By evading racial identity and its significance on communication practices, first-year writing outcomes essentially require students to assimilate into the institutional culture. This culture is invested in whiteness, so, as suggested by Sara Ahmed, when bodies enter the institution, they either line up with whiteness or they do not (159). Values of whiteness must intersect with other institutional lines to be truly in line with institutional identity (Ahmed 159). When the outcomes require students to consider culture and community it is part from an outsider perspective, as the objective researcher not from the position of the practitioner. Overall, the student learning outcomes are race anti-conscious.

The rhetorical knowledge and critical thinking skills, which the program expects students to gain, are decontextualized from the students' personal vernacular histories (Anson 23). Considerations of genres and their purposes make up a central aspect of the rhetorical knowledge outcomes for the first-year writing sequence, and rhetorical genre 
studies scholarship (Bazerman; Miller; Wardle) has demonstrated the cultural influence of genres. Within a critical race theory frame, the dominant White American culture gives particular genres more power over others in White spaces, like the predominantly White university classroom. Those more privileged genres, such as the academic essay and objective reports, take higher positions on a sociolinguistic scale (Blommaert 6). Sociolinguist Jan Blommaert details how space, such as higher education institutions or classrooms, can act as an "agentive force" in assessing sociolinguistic competences (2). Therefore, the performance of higher scale genres, such as analytical essays, in college writing courses are assessed by different means than those genres in community writing spaces, for instance. If "[a]rticulate, multilingual individuals could become inarticulate and 'language-less' by moving from a space in which their linguistic resources were valued and recognized into one in which they didn't count as valuable and understandable" (Blommaert 2), Black rhetorical traditions may allow communicators to "adapt genres" or "adapt an argument to a variety of genres" (Department of English) in different ways than conventional academic discourses.

In addition to demonstrating rhetorical knowledge, students are asked to illustrate their ability to think critically in University of Louisville's first-year writing sequence through traits of whiteness as discourse. In the first semester course, English 101, students show critical thinking if they

- Summarize argument and exposition of a text accurately

- Demonstrate awareness of the role of genre in the creation and reception of texts 
- Provide an understanding of knowledge as existing within a broader context, including the purpose(s) and audience(s) for which a text may have been constructed

- Incorporate an awareness of multiple points of view

- Shows basic skills in identifying and analyzing electronic sources, including scholarly library databases, the web, and other official databases.

In the second course of the first-year sequence, English 102, students are said to be critical thinkers if they

- Use evidence that responsibly represents other research and communities in and beyond the classroom

- Demonstrate an understanding of a text as existing within a broader context, with a distinct audience and purpose

- Represent and respond to multiple points of view in research and across community and cultural issues

- Select academic and nonacademic sources with discernment

This approach is deeply invested in "a belief in scientific method, discovery, and knowledge [and] deductive logics" (Inoue, "Whiteness as a Discourse). These practices are considered "timeless" and "widespread," a part of higher scale "semiotized TimeSpace” (Blommaert 5). Blommaert describes the sociolinguistic scales of semiotized TimeSpace as the social, cultural, political, ideological, and historical control people try to take over semiotic practices, which become sociolinguistic patterns and norms (5). Demonstrations of critical thinking that involve subjective or personal connections sit on 
lower scales of the sociolinguistic norms, the semiotized TimeSpace, of the college classroom. They serve little purpose to the critical thinking student learning outcome. Certain aspects of Black discourses that connect directly with the personal and subjective may seem to lack the deductive critical thinking valued in Eurocentric epistemologies. According to Gilyard and Richardson, the discourse feature of "field dependency" requires analyzing the writer's connection to an issue or phenomenon (42). This feature has the markings of subjectivity and interconnectedness (Inoue, "Whiteness as a Discourse") in that it "lack[s] distance from topics and subjects" and "personaliz[es] phenomenon" (Gilyard and Richardson 42), but understanding how to employ these features to drive an argument and represent multiple perspectives is a process of critical thought. The use of cultural references relies upon the interconnectedness of the writer, topic, and culture as well, since it involves the writer's choice to "[r]eference ... cultural items/icons that usually carry symbolic meaning in the [African American Vernacular English] communities" (Gilyard and Richardson 41). The selection of when to use these references for effective communication requires strong critical thinking. Yet these practices within Black discourses are disregarded in whiteness-invested academic settings.

When scaffolding Black American students' transitions to college-level writing, it is critical that teachers and WPAs understand the effects that sociolinguistic norms in the classroom space have on students who have had negative literacy education experiences related to their racial-linguistic identities. If colleges and writing programs reduce critical thinking representations to only "abstracting [and ]synthesizing ... ideas, and developing complex structures for them" (General Education Committee), they eliminate a space for 
community-conscious and civically responsible representations of critical thinking. For example, more than predominantly White American, middle-class academic audiences, Black American audiences might connect with signifying and misdirection which requires abstracting but is generally not encouraged in academic writing scenarios.

Writing processes, on the other hand, are encouraged in most academic writing scenarios. The University of Louisville composition program's processes SLOs value what Bonnie Williams calls Western rhetorical strategy. The processes SLOs for English 101 and 102 include

- Reflect a recursive composing process across multiple drafts

- Illustrate multiple strategies of invention, drafting, and revision

- Show evidence of development through peer review and collaboration

- Use sources to discover and develop research questions and/or projects

- Reflect recursive composing processes and strategies across multiple drafts and research assignments

- Show evidence of research development through peer review and collaboration

- Evaluate the credibility and relevance of both print and digital sources Williams compares common writing processes of "African American vernacular tradition" (412) to writing processes of dominant rhetorical traditions. This comparison suggests that while dominant Western rhetorical writing processes include "prewrite/write/re- write," teachers might better create spaces for Black American rhetorical writing processes by utilizing DeJoy's RAIDS strategy of "revision, invention, arrangement, delivery, and style" (416). RAIDS relates better to non-dominant discourses, because 
invention is positioned as a process in which reading can be used to "expand our ideas of what it means to be a writer" (DeJoy qtd in Williams 416). Arrangement is also expanded to go beyond the organization of things within the text, but to also include, "how things are being put in relationship with one another" (DeJoy qtd in Williams 416). Revision not only encourages students to make changes within the written text, but also to consider changes that must take place outside of the text, causing students to rethink their own experiences, standards, and expectations. Delivery and style activities explore styles of language and media used to meet the writing expectations for the situation. (B. Williams, "Students' 'Write" "416)

While the Williams' comparison is reductive, the RAIDS process of developing written texts can be used to recognize racialized experiences that happen outside the texts. It demonstrates just how much accepted process practices represent discourses of whiteness in their objective dependency on research and the text rather than on the writer as well.

These programmatic student learning outcomes and the others, including understanding of conventions, confidence and ownership, and cultural and community issues align with national recommendations for first-year writing outcomes. Hence, the curricular investment in whiteness exists not as a local institutional phenomenon but as a widespread Institutional phenomenon found in national curricular recommendations and scholarship on composition theory. The scope of my study examines the case of race as an absent presence in local institutional policy, but the coordinating national recommendations can be found in the Council of Writing Program Administrators' 
Outcomes for First Year Composition. The reflex to maintain cultural norms of whiteness is so much a part of the institutional cultural practices that even when the writing program attempts to challenge these norms it reinforces them. As a result, whiteness is coded as non-raced, as expected, through the student learning outcomes. Transitioning Black American students, seeking to be evaluated as successful within this system, must continue to suppress their linguistic cultural identity and racially-influenced rhetorical traditions at predominantly White institutions as they have for the entirety of their educational lives.

\section{Race Recognized}

The considerations of racial identity's significance on linguistic traditions and, therefore, rhetorical behaviors show up in one institutional document that guides transitioning. To be clear, other documents discussed in this chapter mention racial identity. However, those references act as descriptors rather than recognizing race as social influence. Besides documents by race-centric programming, such as those offered by the cultural center, the Gen Ed curriculum cultural diversity competency is the only document to recognize the impact of racialized experiences on behaviors and choices. According to the "Understanding Cultural Diversity" competency area developed by the General Education Program,

Understanding cultural diversity means students will have a broad exposure to a variety of social systems, cultures, and subcultures, both within the United States and the rest of the world. This portion of the curriculum encourages an appreciation of the realities of a racially and culturally diverse world. 
Here, the university accounts for the ways that not only cultural differences but racial differences shape worldviews and constructions of reality. When applied effectively, this competency area has the potential to help transitioning Black American students use writing as a pipeline for personal engagement and transformation (Tatum 10). The objectives of the competency area also have the possibility of interrogating the racialization of whiteness in a productive way for all students. If students should "[c]ommunicate an understanding of the ways in which race, ethnicity, and/or gender are socially constructed" (General Education Program), inquiring about the standard position of whiteness in culture fulfills this requirement. Moreover, "[r]ecogniz[ing] that social and cultural systems develop out of adaptation to environmental and historical circumstances" (General Education Program) includes examining the cultural-historical relevance of literacy practices and rhetorical traditions.

Examining these practices and traditions can work to make the first-year writing sequence at University of Louisville a general education cultural diversity course, which it is not, as of summer 2016. Even with these possibilities for productive race-conscious curriculum and pedagogy, the cultural diversity competency area outcomes are limited. Cultural diversity in writing is defined by awareness and recognition of various cultures, not by the incorporation of marginalized discourses. If language use — syntax, style, genre, and discourse - is one way “the structuration of America's racialized society began ... with the growing signification (interpretive rules) of whiteness" (Guess 664), limiting the ways a language is used to align with that structuration remains a subtle but powerful way higher education has maintained White dominance. Excluding the use of 
particular written communication practices not only exclude cultural expression, but it can also limit creativity.

One deterrent to developing more race-conscious or antiracist SLOs relates to issues of assessment. Writing programs must use learning outcomes to assess students' writing proficiencies, and these assessments serve the multiple divisions within the university. At the University of Louisville, the SLOs are approved by the Composition Committee but receive input from parties in university administration. As Inoue suggests, antiracist assessment practice "provides for the complexity and holistic nature of assessment systems, the interconnectedness of all people and things, which includes environments, without denying or eliding linguistic, cultural, or racial diversity, and the politics inherent in all uneven social formations" (77). Inoue describes these assessment practices as ecologies, because "[ $\mathrm{t}]$ he classrooms, dorm rooms, homes, workplaces, coffee shops, computer labs, libraries, and other environments where students do the work of a writing course have relationships to those students as they work" (78). I expand on how a WPA might assess antiracist, race- and community-conscious outcomes at the University of Louisville in my concluding chapter, but some examples of these outcomes include:

- Recognizes how racial culture and other identity factors influence reception of a text

- Can critically read and analyze the rhetorical practices of multiple cultures through content and genre

- Understands how rhetorical traditions are formed and practiced 
- Includes research source perspectives from three or more cultures, both domestic and international, including academic peer-reviewed, non-academic community knowledge, and primary lived experiences

Like the current outcomes, these have enough flexibility to allow for pedagogical latitude, but they require writing instructors to reflect on how race is related to rhetorical knowledge, research processes, writing style, and writing conventions.

Writing style and conventions are two of the most difficult outcomes with which to address aspects of racial identity and language practices. In "How Writing Rubrics Fail: Toward a Multicultural Model," Valerie Balester recommends the use of multicultural rubrics for assessing usage and mechanics, because with them, "the writer is empowered to use all available resources to create a text rather than to master ... a narrowly defined linguistic code" (71). Balester provides examples of usage and mechanics criteria using multicultural rubrics, including the competent level of the 2008 James Madison University Writing Rubric as "is generally free of errors in mechanics, usage, grammar, or sentence structure ... Problems do not compromise meaning” (72). The "A" paper designation from the 2008 Sacramento State University Writing Rubric “displays evidence of careful editing with superior control of grammar and mechanics appropriate to the assignment" (qtd in Balester 72). While a note about multilingual writers in the Sacramento State rubric adds that "occasional imprecision in word choice and usage may occur" (qtd in Balester 73), this note 1) often does not include Black American student writers choosing to use Black discourses as "multilingual" and 2) does not account for "imprecision" in various discourse and language practices outside of academic discourses. I suggest the following outcomes for conventions: 
- Effectively applies the chosen discourse to the writing task

- Shows understanding of rhetorical purposes of paragraph structure, sentence length, sentence variety, and punctuation marks.

- Recognizes the fluidity and changing of writing conventions

- Gives attention to the influence of style and usage on composing effective communication

These outcomes recognize the complexity of writing conventions as well as the "vernacular histories" (Anson), "discursive resources" (Denecker), the linguistic values (Kells), and the literacy education histories that students bring with them to college-level writing practices. As indicated by some of the student interviewees in the next chapter, they often struggle with presenting their ideas and constructing their thoughts in the rhetorical ways of academic discourse.

\section{The Need for Race Presence in the Writing Program}

By pinpointing the absent presence of race consciousness and orientation towards whiteness in University of Louisville's policies in this chapter, I intend to show why factors promote a colonial sensibility when acclimating Black students to college-level writing practices. Revisiting the discussion from Chapter 2, if institutional rhetorical education has always maintained colonizing purposes, the history of first-year writing as freshman composition has been central to executing those purposes. By their very nature, Composition Studies and composition courses instill the values of whiteness through teaching, and therefore valuing, the discourse most highly valued by dominant racial cultures. Historically, composition courses, like most English language education in American, have seldom, if ever, had the goal of teaching students of color to use 
academic discourse for purposes of social or political critique (Smitherman; Delpit). In its goal to inculcate the customs of whiteness, academic discourses become the ends, not the means in first year and advanced composition courses.

In some respects, new curricular initiatives by the Composition Program, and determined efforts by composition instructors, work to challenge the norms of institutional whiteness. Most notably, the recent induction of the Concept in 60 digital composition assignment recommendations potentially disrupts the Time/Space limitations of sociolinguistic norms in the academic writing setting. Unlike the academic essay, and the personal letter, digital writing and rhetoric transcend sociolinguistic scales. While the academic institution can co-opt digital writing genres into Eurocentric practices, students practicing alternative rhetorical traditions can designate the genres for themselves. The Concept in 60 assignment asks students to report on cultural or community issues in a 60-second digital format, such as a video or audio file. While the possibilities for this assignment vary widely, the opportunity to interrogate issues around racialized perspectives abound.

Examples of this interrogation of racial identity are one student's 60 -second video, "The Effects of Skin Tone" 28 and another's "This is Me"29 about a biracial perspective. These student videos exemplify how the student learning outcomes can be interpreted to address racialized perspectives. In addition to "[q]uestion[ing] existing assumptions about culture and community" and "[d]escribe[ing] actions being taken to address cultural and community issues" (Department of English), students can think critically about how to effectively present their experiences to an audience of

${ }^{28}$ Video is found here: https://www.youtube.com/watch?v=I6vyzwqrjIk

${ }^{29}$ Video is found here: https://www.youtube.com/watch?v=jirP7zmXevg 
predominantly White peers and teachers. They have to use rhetorical knowledge to make the best use of the video genre to convey their messages. As meaningful as these interpretations of the outcomes are, in terms of critiquing the racialized social system of academic writing, they are limited.

If college classrooms are considered community sites in the larger society of higher education, then the model of academic writing can be held as a racialized social system. Eduardo Bonilla-Silva contends that "all racialized social systems are hierarchical" although "the racial practices and mechanisms that have kept Blacks subordinated changed from overt and eminently racist to covert and indirectly racist" (470) Writing studies scholars should consider the privileging of particular discourses in academic society as one of these practices. This frame aids in a better understanding of how the academy actually suppresses particular forms of written expression associated with non-White communication practices.

To further the capacity of the Concept in 60 assignment to challenge whitenessinvested norms, students should be encouraged to compose, speak, and otherwise communicate in the discourse practices that best present their ideas. Now, I am not suggesting that all, or even most, Black American students at University of Louisville will consider Black American discourses best for presenting arguments and reports on issues in Black American communities. However, they should be given the option to apply "sermonic tone," "verbal inventiveness," "ethno-linguistic idioms," "cultural references," "signifying" (Gilyard and Richardson; Smitherman), and other attributes of Black American discourse, if it fits the rhetorical purposes of the Concept in 60 
assignment. Teachers can stretch the assignment possibilities by asking students to research and critique language practices of multiple language communities.

Besides the excellent work of developing and promoting the Concept in 60 assignment, some first-year writing instructors at University of Louisville have worked towards creating more race consciousness in the curriculum. One section of English 101 offered in the fall 2016 semester draws on

African American rhetoric as a conceptual approach ... [to] study various modes of [rapper] J. Cole's musical, artistic, and intellectual expression alongside a survey of multi-genre compositions that challenge our understandings of mobility and its influence on how we compose, what we compose, why we compose, where we compose, and for whom we compose.

A prologue statement on the course's syllabus reads, "This space is a community where racial and cultural connections are consciously uplifted," where "we can inspire social change and continue to transform our communities and the world." The instructor specifically designed the course as a space for first-year Black American male students, especially, to recognize their histories, racial culture, and rhetorical traditions in the collegiate academic and social community. Other courses in the program endeavor to disrupt norms about academic writing practices by requiring students write in and for community-based settings. In the concluding chapter of this dissertation, I draw connections between race-conscious and community-conscious writing curriculum in the first-year writing sequence to propose a writing curriculum of civic responsibility during this transitional period. 
For students in the contingent space of their first year- from which they can continue or exit - they may view their experiences and ways of being through the eyes of the institution only relevant in particular moments. The following chapter offers narratives, from Black students, about some experiences transitioning from high school writing to college-level writing. Collected through interviews and email exchanges, these narratives provide personalized perspectives of how these students engage with writing courses at both the secondary and post-secondary levels. They also explore the participants' personal histories with in-school literacies to show how those histories and new institutional expectations mark transitioning across academic writing spaces. 


\section{CHAPTER IV}

\section{TRANSITIONING COUNTER-STORIES: BLACK STUDENT ACCOUNTS OF TRANSITIONING TO COLLEGE-LEVEL WRITING}

"How can you have your mission statement say you strive for diversity and inclusion but most of the content that is taught say the opposite?"

--Interviewee NF2

Student experiences of transitioning across the high school-college writing threshold are difficult to find. For the most part, research and theory focuses on pedagogy and curricular infrastructure from the institutional side of things. The approach suggests that before bringing in student voices, the masters need to get their houses in order. If, as suggested by Tinberg and Sullivan, we practitioners cannot even agree on a clear definition of college-level writing, a certain trepidation toward hearing student experiences probably exists. However, our theories and praxes likely lack a dimension of insight by dismissing student accounts from academic writing transition research. In particular, to develop more community- and race-conscious, anti-racist pedagogies that constitute Black American students' social rhetorical needs, writing programs at predominantly White institutions need to investigate the transition experience accounts of these students. In this chapter, I chronicle some accounts of Black American students transition experiences to widen the scope of writing studies knowledge about transitioning from high school to college-level writing. For these students who have transitioned from one predominantly White academic space to another, upwardly mobile 
predominantly White space, examining their voices gives authority to their experiences in this space, and that authority counters common conceptions of students of color as underprepared and underdeveloped in academic writing practices. My description of these students' accounts begins with a discussion of low general student presence in scholarship on the high school to college transition and then moves to a discussion of the absence of Black American students in this scholarship. I will then explain my methodology for collecting interview data and constructing the student accounts. I follow this by presenting the accounts as part of personal histories of literacy education, conceptions of transitioning and meaning of college student identity, and impacts of whiteness on college success in writing. I close the chapter by examining how the critical race theory principle of the "unique voice of color" can speak to the racism is businessas-usual experience of transitioning from academic writing expectations in one predominantly White educational space to another.

The accounts of Black American students transitioning across sites of academic writing in this chapter offers a unique voice of color that may guide WPAs and writing instructors towards more culturally sustainable and life-relevant curriculum early in the college years. James M. Gentile analyzes high school to college transitions from a programmatic perspective, but does not include student accounts. This perspective paints a nice image of what transitions look like within an institution-wide context from a WPA's eyes. College students offer perspectives on transitions through literacy narratives in one section of Patrick Sullivan's and Howard Tinberg's What is "College-Level" Writing? Comparably, William Carpenter and Bianco Falbo analyze "the written literacy narratives of students working as undergraduate Writing Associates at Lafayette College" 
to consider how well-prepared students construct identities through literacy (92).

Christine Denecker offers an additional perspective by interviewing students in a dual enrollment program. These firsthand accounts illustrate the significance of including students in our scholarship on secondary to postsecondary transitions. I further these efforts by emphasizing the accounts of students whose experiences are ordinarily diminished within predominantly White spaces such as majority White research universities.

Most transitioning studies scholarship overall does not take up sociocultural forces such as gender, race, or ability. Addressing issues of identity and cultural ideologies embedded in literacy and writing education has not been at the forefront of high school to college transitioning scholarship. Several reasons might exist for this lack of recognition. For example, Carmen Kynard suggests that the link between the social order behind academic literacies, teaching labor, and racial ideologies is difficult to discern (7-8). Many of these links start long before the first-year writing (FYW) courses that many of us teach. As Kynard elaborates,

The organizational structures of teaching and schooling, like in K-12 spheres, thus, becomes an integral part of the historically-loaded and ongoing structural inequalities maintained via schooling, of which composition studies is not exempt. To put it most bluntly and simply: working/poor Black and Latino students have seen inexperienced and un/der-trained teachers most of their (schooling) lives as part of the structuring of the colour [sic] line. (6) Furthermore, Jacqueline Jones Royster and Jean C. Williams explain that composition studies has a history of erasing Black American presence from pedagogy research in 
particular. I see the trend of equating American blackness to basic, remedial (Royster and Williams 571) and less-than writing carried into transitioning studies research by eliminating Black students' transitional experiences from disciplinary conversations and critical spaces.

\section{Methodology}

My project aims to explore some marginalized student experiences by using critical race methodology to centralize Black American student perspectives of transitioning into college-level writing. In conjunction with racial methodology, which I use to interrogate the role of race in our research practices around institutional transitioning, critical race methodology marks racially underprivileged or underrepresented narratives as central. I use the term central rather than dominant, because critical race theory and methodologies critique racial dominance. Trading the dominant standing of one racial identity for another would go against the social justice curricular efforts I am proposing in this dissertation.

Instead, the critical race methodology applied here comes out of education research and works to frame these accounts through the critical race theory principles of racism is business-as-usual and the unique voice of color (Delgado and Stefancic). The unique voice of color principle has been discussed in Chapter Two, but, rather than constructing a counter-story, I use it here to emphasize how underrepresented racial identities can shape educational experiences in predominantly White spaces. In conjunction, the principle of racism is business-as-usual implies that "a regime of white supremacy and its subordination of people of color have been created and maintained in America" (Crenshaw et al. xiii). Some accounts by interviewees express this principle 
through discussions of stereotype threat and curriculum design. These two principles complement the critical race methodology that frames the responses that I collected through semi-structured interviews to "challeng[e] the traditional research paradigms, texts, and theories used to explain the experiences of students of color" (Solórzano and Yosso 24).

For my project, I used semi-structured interviews, because I considered that my participants would be more at ease with the slightly guided format. Interviews allow participants to share their thoughts, ideas, and experiences through a frame constructed by the researcher. Using interviews, researchers can collect specific qualitative knowledge based on personal experiences and reflection. Cynthia L. Selfe and Gail E. Hawisher claim that interviews situated as semi-structured conversations can help researchers understand the "powerful, vernacular sense of what social change looks like from the perspective of individuals in their own experiences and lives" (Ch. 3). In this way, the interviews are about exchanging knowledge instead of extrapolating information (Selfe and Hawisher Ch. 3). Applying a racial methodology gives me the tools to attend to the race evasion, or the lack of attention to a student's racialized experiences, discussed in the previous chapter. I applied this methodology from my selection of participants through my data analysis and conclusions.

The primary method to select interview participants included surveying students in the University of Louisville Cultural Center's Early Arrival Program. The Cultural Center's website describes that the program was “created to help ease the transition of incoming students of color including African American males, Latino students and Woodford R. Porter Scholars, from high school to college and to teach them the tips and 
tricks of prospering in their first year of college." Students arrive at the University of Louisville a week before courses start to learn where their classes are, where they can access important resources, and how they can increase their chances of becoming active, informed college students. I sent a survey through the web application SurveyMonkey.com to all students in the program—about 150 - and received 37 viable responses. ${ }^{30}$ My original goal included interviewing 30 students of various racial identities; however, of the 30 participants I contacted, 15 responded, and 6 scheduled interviews. All of the self-selected participants identify as Black American or as more than one race including Black American. To gather more participants, I expanded my selection process.

Another step in my interviewee selection process included contacting composition program faculty whose students would be willing to participate as well as contacting my previous students - those from Black American, White American, and Latinx racial identities. While some of my past White American-identifying students initially agreed to participate in interviews, each of them withdrew or did not show up to interviews.

Therefore, the available data does not allow for a comparison between experiences based in part on racial identity. The lack of a White American perspective in my study does provide an opportunity to further centralize Black American student perspectives about transitioning. Furthermore, some scholarship has potentially ${ }^{31}$ already detailed the high school to college writing transition for some White American students (Carpenter and Falbo; Nelson; Winalski).

\footnotetext{
${ }^{30}$ Responses that were not blank and included all contact information.

${ }^{31}$ The racial identity of the students in these studies is not identified.
} 
The nine Black American student perspectives in my study were shared through semi-structured interviews with all nine participants and in-depth interviews with two of the participants. The descriptions of participants and the semi-structured interview questions are located in Appendix A, and the initial survey questions asked of potential participants are listed in Appendix B. In the next section, I begin by discussing the participants' past experiences of academic writing. I then provide student accounts of how transitioning to college-level writing connects with college student identity and I follow that with a discussion of the impact of whiteness-invested writing curriculum on connecting with writing practices as part of the college student identity.

\section{Personal Histories of Literacy and Academic Writing}

Present writing practices are informed by previous writing experiences (Lunsford). The connection between practice and experience transitions with students into first-year writing courses as they begin to establish understandings of what a collegelevel writer does. My interview participants also considered how the academic writing experiences in their time at the University of Louisville mimicked and differed from their high school experiences. I examine the students' literacy education and academic writing histories by considering their thoughts on how they believe college writing compares to past writing experiences, both in and out of school, and then discussing their confidence and insecurity in writing for school.

\section{How College Writing Compares}

With the study participants, I wondered what stories about college-level writing from high school teachers and administrators influenced their perceptions. Extended from this, I questioned how they approached previous academic writing tasks and why. One 
key component of transitioning includes shifting perspectives and ways of doing things. Some participants detailed how they approached writing for college courses differently than writing for high school. Second-year student, MM1, explains that "in high school, I would just start writing, and that usually helped me out. But with college courses, they're a little more complex, so I can't just start writing without a focus on where you're going before you start." Denecker explains this night-before-the-due-date practice of drafting major assignments in high school courses results from the report makeup of the assignments (33). On the other hand, drafting the night before does not coincide with the research and argument expectations of most college-level writing. First-year student, FF1, expressed a similar attitude. "I make sure I understand what's being asked of me," she says, "and then I always always make an outline--it doesn't matter what I'm writing." She explains that writing research papers in high school was less challenging.

Considering the types of writing and intensity of writing, FF1 told me, "In my [high school] history class, it was just that research paper. But in my English class, we did responses, we did essays. The final was a research paper. And then like a few writing assignments for homework, just like reflections and stuff." Compared to the college writing expectations, she adds, "Since I've been in college--I've only been here one semester--and I've written six research papers and a whole bunch of essays." Participants suggested that, in addition to intensity and volume, their preparation for writing assignments in college has changed. Compared with college, MM1 explained, "With college courses, they're a little more complex, so I can't just start writing without a focus on where you're going before you start." OM1 noted how his approach to college papers changed but also extended from practices he learned in high school. "Usually I read the ... 
grading rubric," he said. "Then I look at the question. And in high school, I was taught to do some type of pre-writing, so it doesn't have to be elaborate, but I usually just write my main points on a piece of paper." For OM1, the invention and pre-writing practices he learned in high school transitioned with him into college-level writing tasks. Both JF1 and FM1 noted the importance of outlining as part of their invention practices for college writing assignments. Each conveyed how this practice has become even more important as college students than as high school students, suggesting that they must give more thought to the process of invention itself.

The significance of invention leads to understanding, from the participants' perspectives, one of the greatest tales of the difference between high school and college writing practices includes the variance in their rigidity. Secondary juniors and seniors are often told by their teachers that college professors want very particular form and structure in their writing (Strachan; Mosley; Van DeWeghe; Farris; Denecker). They emphasize three-point-five or three-point-eight essay structure and thesis statements. Perfection in style and mechanics takes precedence over analysis and description. One of the instructors participating in Denecker's study suggests that “an emphasis on format is a distinctive element of high school writing instruction and explains that since a fiveparagraph essay has typically allowed students to pass" standardized graduation exams (34), students and teachers have difficulty moving past this format. Many students need less preparation to perform those approaches to academic writing. However, the emphasis on structure and form rather than inquiry, research, and exploratory analysis gives some students a false impression of what college-level writing will entail (Farris). OM1 shared that his senior English teacher told him "it was going to be a lot longer and a lot more 
writing, and more papers and things like that." By comparison, FF1 said she heard that “college writing's a lot harder than high school and my English teacher tried to prepare us." These narratives of college writing preparation are common.

Though common, Jordan et al. questions their truth. Upon hearing an alumnus of her class, Mike, report that he never wrote a research paper in college, Jordan et al. muses,

I turned to him, shocked. I knew what he was saying was not true for a typical college experience. Or could it be? I thought that research-based writing was the foundation of academia. I had just dedicated six weeks of junior English to guiding (okay, maybe dragging) my students through the process by promising them that for college they needed to learn how to research, to evaluate the validity of sources, and to document their sources using MLA format. I coerced them into taking the project seriously because developing an original thesis and supporting it with evidence was critical to success in college and beyond. Now my former student returns and says he never wrote a research paper after he graduated from high school. (36)

As most of us reading this know, Mike's experience is atypical. Even as a creative writing major with a certificate in information technology, I wrote several research papers through my senior undergraduate year. Still, Mike's experience does challenge the emphasis we place on norms in secondary and postsecondary education. For instance, three of the nine participants noted that the writing requirements in their high school English courses felt more demanding than their college writing courses. NF2 also 
detailed an experience that counters the common rigor myths. Responding to meeting the writing standards expected of her, NF2 said,

In high school, they're [stricter] on how your paper's supposed to be. You know like the 3.5. I hated it! I was like, why do we have to do all this? But it was different, because you know here, I don't think professors care about the format or the method that you do, as long as you have the information there. So that's one thing I do like about college. I just feel like if you have all your information there, and it's like in a good range, you got an A basically.

Similarly, one of my former FYW, FM1 detailed that "we did really rigid format for research papers, but of course it turns out not to be true at all" of college writing assignments, and OM1 noted that "it turns out my high school teacher gave us a lot more work than my class now." Other accepted norms about transitioning to college writing remain true, per my participants.

Several of them described a change in their prewriting practices from high school to college. JF2 explained her goal for less procrastination. "I just don't like writing, so I just power through," she said. "I try to stay on top of it, because I will procrastinate." DF1 made a similar account of her invention approaches. "I always try to pick something that I'm at least semi-interest in," she explained. "Like, [when] we had to pick a time period, I try to pick the one that I'm most kind of interested in. And I usually just make an outline." She clarified that this approach differs from what she did in high school, because "I feel like I take my education more seriously in a college setting." This alteration might be attributed to Steve Fox's notion about the differing literacies required 
for high school and college. Fox writes, "[I]nstead of asking how to make high school writing prepare for college writing, let's ask what literacy looks like, and we will have a better chance of developing a writing curriculum that fosters lifelong literacy" (80).

Discussing these literacy acts by looking at the paradigmatic differences across secondary writing, Denecker asserts that

the current "report" versus "research" binary leads to the argument that, although high school and college-level writing instruction may each strive to equip students with the abilities to write strong essays-essays with thesis and structure - the goals behind these essays may be inherently different. (35)

In particular, when it comes to students from marginalized literacy backgrounds, thinking of writing transitions in terms of literacy practice transitions could be especially effective.

Both those participants who identified with marginalized literacies, and those who did not, recognized the shift in literacy practices at the college level. OM1 described the themed course, a phenomenon more common to higher education than secondary English courses, and how he had to shift his thinking about writing to succeed in it. "Like for my English class right now, the whole class is based on music, and I'm not very musical," he explained. "I have no rhythm in my body in any way. So, writing about how much I like music is really hard." He described his solution as "I ended up having to like, I don't want to say lie my way, but I had to stretch a few things."

\section{Self-Confidence and Insecurity in Writing for School}

Farris suggests that the ways that secondary teachers and college teachers ask students to think about how writing contrasts across institutional contexts. Add to this 
difference the fact that for many students of color or ethnolinguistic other-ness, "limited notions of academic writing" result in penalties for use of non-academic rhetorical traditions and discourses (Kynard 5). Further, Elaine Richardson contends that "unlike most other American groups, African Americans' experiences ... have established a history of mistrust of American institutions" which has led to "oppositional attitudes and behaviors, because their upward mobility" in whiteness-centric American society has required them to intentionally exterminate their linguistic histories (32). Many current college writing professors recognize these complications, but the college academic literacy expectations can be a rough transition for Black American students with closeminded professors.

More than just discussing how writing in high school and college courses differs, I wanted to know how students' psychological connection to academic writing influences their transitions. Participants described in-school writing situations that made them feel confident and insecure. According to writing studies scholar Andrea Lunsford, in regards to relationships to writing, "In some instances, prior knowledge and experience are necessary and often helpful; in others [sic] they can work against writers" (Ch. 3). Because people are more likely to repeat practices that make them feel good and least likely to repeat practices that make them feel anxious, examining the psychological relationship between students and writing can help FYW teachers understand some of the choices their students make in writing. As Lunsford suggests, prior experiences contribute to these relationships, and "[f]or many people ... prior experience with writing had been negative, and this attitude and these feelings went with them throughout their 
lives" (Ch. 3). In the case of Black American students, the insecurity is often linked to the irrelevance of the curricular content to their lives and lived experiences.

OM1 explained that he feels most insecure "when I have no connection or relation with the topic at all." However, he feels most confident with "argumentative writing. Ones where we pick sides and you defend that side--I think that usually caters to all. Because then if you disagree, you can switch to another topic--then whether you disagree or not, rather than writing about just disagreeing when you don't really disagree." Novice college writers are more comfortable composing argumentative essays than analytical essays, because it closely relates to the kinds of writing they performed in high school. As Amy Winalski, a former first-year student at Temple University, details, in high school, "the student's ability to communicate effectively (and not to effectively communicate) had precedence over the raw quality of the ideas" (304). Since "[i]n high school, students often assume that a thesis sentence guarantees a passing grade" (Winalski 304), argumentative essays are ideal. Winalski notes, however, that this veneration of the thesis statement alone can set new university students up for failure (304). In "Challenges in the Transition from High School to College," David Conley ${ }^{32}$ describes learning to perform college-level writing as "important because it forces a certain cognitive development to occur, one that requires logical and orderly reasoning" (96). Even though OM1 continues to write argumentative essays in college, as he did in high school, the type of argumentative papers he has to compose for college-level courses will include more attention to not only "understanding how to construct and use a thesis

\footnotetext{
${ }^{32}$ Conley is a professor of educational leadership and policy at the University of Oregon as well as founder
} of the Center for Educational Policy Research and the Educational Policy Improvement Center (EPIC). 
statement" but to "knowing how to be persuasive and expressive without abandoning logic" (Conley 96).

Still, OM1's experiences and preferences for connecting with his topic reflect the Black discourse features of community consciousness, cultural references, and field dependency, which writing professors should build upon. When we consider the multiple discourses that students use to compose, we must think beyond morphology, tone, and style. Field dependency, for example, helps writers connect content between their own experiences and new information. While these connections are important for all students, Black Americans' historical relationship to American dominant culture makes it especially necessary to develop culturally relevant curriculum. Per Richardson, many educators continue to neglect culturally appropriate curriculum, because "[f]or the most part, America continues to teach us to accept the status of lower achievement for Black students as the norm" (8). In addition to the discourses of whiteness identified by Asao B. Inoue and Timothy Barnett discussed in the previous chapter, Richardson describes White supremacist literacy practices as "consumption, consent, obedience, fragmentation, singularity (as opposed to multiplicity), and positivism” (9). For example, traditional writing assessment practices encourage student obedience, not only to the instructor's standards but to institutional standards which often prize these White supremacist practices. These values privilege meritocracy and falling in line, which a key assimilationist approaches applied through literacy and rhetorical education. Therefore, when students engage in common Black American literacies such as resistance and survival literacy they may be penalized. 
With these factors in mind, the writing situations that made participants feel insecure make sense:

- JF2: It's mostly myself. Everyone else is pretty encouraging I feel like. Because I usually start my papers the day before. So, I'll just be like oh my gosh why do I do that to myself?

- MM1: I know a lot of times teachers, professors, will give you the option to do a free write about whatever you want. And sometimes I would have topics but at times, I found that to be more difficult.

- FF1: In school writing, I'm getting a grade for that, and I'm essentially paying for that, so it's like I need to make sure that what I'm writing in school is top notch as opposed to Twitter and Facebook and social media.

NF2 admits to rejecting her natural writing voice for academic writing tasks, or "fronting" (Canagarajah qtd. in Richardson 17). This practice is common to Black students in order to "make the grade" (Richardson 17). As suggested by NF2, this "offshoot of acting White" requires students to "fil[1] the 'academic essay' with emptiness" (Richardson 17). DF1 did not mention an issue with accommodating academic voice, but she did concur with NF2 about page length requirements. "I just had to write a seven-page paper," she said. "I was, like, this is ridiculous. My argument is just diminishing, because I'm just putting stuff in there so I could get to seven pages.”

Similarly, the interviewees' reasons for feeling self-confident are clear:

- MM1: I like to have structure and kind of have someone help me out--guide me-and then once I push towards the topic, I find the passion and write about it. 
- JF2: Like for something creative, because you can't really grade that, so I feel more confident with that. Because they can't grade it harshly.

- FM1: When I'm given a rubric that's not so picky or you have to have perfect grammar or each paragraph needs to be this long and ... more it has to be MLA format and has to be this length, I kind of like that.

The pressures of assessment, evaluation, and general judgment seem to shape the students' response to insecurity and confidence in academic writing practices. The participants often feel more comfortable being assessed when they related to or had some passion for the topics they were assigned. This connection to community, social, and personal interests is especially essential for Black American students, whose life experiences and perspectives remain excluded from much of college curriculum.

This analysis is not to suggest that all Black American students have complications with academic writing expectations or that their complications are any more intense than the White American students in college courses. The honors, dual credit, and AP high school English status of most of the interview participants matches the academic resources accessed by many middle-class White American students entering the university. As OM1 noted about his experience of being in a predominantly White high school preparing him for a predominantly White university, "I haven't really thought about it. My English teachers have always been extremely nice to me, so I don't know. They were really good teachers." The complexities surrounding the transition from one whiteness-invested academic space to another often involve general socialization aspects involved in rhetorical education. 
However, several interviewees discussed how school affects their personal relationship to writing and how this difference became more pronounced in the move to college-level writing. JF2 described how writing outside school comes more naturally than writing for school, "because when I do write, it's because I have an idea. If somebody gives me a prompt, I don't have an idea right then. I've have to read it and research.” OM1 explained how the struggle with writing for school becomes more pronounced as education progresses. "I think for school writing, the teacher should set less boundaries just to explore the creativity of the student," he recommended. "But making someone--making a group of people--write about the same thing is kind of challenging for some of the people in that group, because someone might have a background in that writing," which gives them an advantage and others a disadvantage. He stressed the need for choice in academic writing, because "if it doesn't connect with you, you're obviously not going to put a lot of research or anything like that.” FM1 concurred, stating, "It's kind of weird of that someone asks you to write a long paper about something you probably didn't even pay attention to." He described a preferable situation as "if ... you kind of get to choose your own direction, then maybe I'd be a little more interested, but it's hard to keep focus." As shown previously regarding what makes him feel insecure in writing, MM1 agreed with the necessity of choice but discussed its limitations. He would rather be guided through the options, which he found does not always happen.

By the time students reach our FYW and other writing intensive courses, they already have a toolbox of discursive instruments for composing academic writing. Some of these instruments for Black Americans include the rejection of their home or non- 
academic linguistic practices. For example, NF2 noted "I like to write how I talk. Even though I know that may not be academic voice. Sometimes I feel like when I write in my academic voice, it's not me." In the shift to becoming a college writer, students use their discursive resources to shape how they enact their college student identities.

\section{Conceptions of Transitioning and Meaning of College Student Identity}

When things transition, they partially alter their ways of being while keeping a bit of their previous identities. As suggested by Jan Blommaert in the previous chapter, space and time can control the construction of identities, especially in places where sociolinguistic competences are assessed. Students perform the identity of academic institutional culture, in part, through academic writing, so transitioning to college-level writing means that the space of the university and the university classroom help construct college student identity. The participants in my study made numerous connections between writing with college student identity. DF1 noted, in her response, "I think writing helps you clearly communicate what you're trying to say. I feel like if I didn't go to college, that skill would diminish because I wouldn't be writing as much." DF1 sees college-level writing as a key factor in learning to communicate clearly and effectively, while FM1 believes the written communication practices he has learned thus far have made him a more critical reader. FM1 clarified,

Some of the social issues we were writing about [in English 102], it's kind of like you know what social is and why it's happen, but the page length requirement kind of made you have think a little further. So that's cool, and you can kind of use that a lot more. Whenever I read an article on the internet now, I'm not just reading it; I'm reading it and kind of analyzing it 
and think deeper about points. Otherwise, I would just read an article and directly take it as it is.

Some participants, like JF2, connected their identity as a college student to writing for other situations. JF2 stated, "I know with my career, I'm going to have to write research papers, so just knowing how to communicate your thoughts effective through writing I think is important." Both of these examples illustrate how writing practices are key to transitioning. I examine the interviewees responses to conceptions of transitioning by presenting how they perceive the connection between writing and the college student identity, what they emphasize about the teacher-student relationship, and what they reveal about the relevance of writing curriculum.

\section{Writing and College Student Identity}

The college institution requires students to represent academic ways of being through numerous acts. In particular, as a metropolitan research university, the University of Louisville encourages these ways of being through research activity, community partnerships, and the specific writing practices outlined in the General Education curriculum presented in the last chapter. Being a longer-term student at the University of Louisville, NF2 added a different perspective to the connection between writing and college student identity. She said, "Writing is necessary so that we can grasp all the material that we're trying to learn and so we can let the professor know that we understand what we're talking about." Still, she noted, "The only problem I have with college writing is the amount of pages that we're given. If the topic I'm given is something I could put out in five pages, but I'm supposed to expand it into 10, I feel like I can get redundant." Perhaps, transitioning into college-level writing is learning to look 
for ways to expand your ideas without using what NF2 called "just filler words." OM1 suggested a similar relationship to some of his college writing. "Your writing develops as you grow as a college student," he explained. "At least, it should.” JF2 emulated this view that "as you continue with your education, [writing is] bound to get better. If you just keep practicing it.”

The difficulty of transitioning to college coursework from secondary curriculum comes from more than intellectual aspect of the work. The obstacle often relates to the overall overwhelming feeling of the new college experience. One the University of Louisville academic advisor for STEM disciplines explained that in the first semester of their first year,

I ask them about things they've gotten involved in so far as what they're doing. Most students tell me, well I just wanted to get used to things before I acclimated, you know, I wanted to get used to my classes. I'm like, that's a really good strategy. I say because you don't want to overwhelm yourself. I basically ask them how they're managing their time, you know, how they're spending their time outside of classroom--whether it's working.

She also focuses on basic wellness such as how many hours a week they work, where they work and if they get enough sleep. "Those are all important things--if they're living on campus, or if they are commuting," the advisor detailed. "Basically, I want a whole picture of what their life is like right now and that means inside and outside of the classroom, because everything outside of the classroom is going to affect their experience." According to FM1, "Because my English 101 was pretty open, but the first 
essay led to the next one, and there was a little bit more direction, going to English 102, I kind of freaked out for just a second," because "school has always been like 'here's a question, write about this' or 'here's the book, talk about this very specifically."' The changing "contact zone" of not only the classroom but the college campus also places Black American students in close contact with unfamiliar members of the dominant culture. While all of the participants in my study transitioned from predominantly White high schools, those spaces contained people that they at least knew, if not trusted.

This new space puts higher stakes on adopting whiteness-centric rhetorical behaviors. Even though OM1 remarked that he never felt mistreated by his White teachers in high school, he also explained, "I actually have to think: what can I say, what's the teacher going to think of what I say? I didn't want to jeopardize my scholarship.” Minority scholarship programs have become one way for predominantly White institutions to assimilate students of color into whiteness-centric rhetorical behaviors. Gloria Ladson-Billings and William Tate IV argue that teachers and educational institutions have been conditioned to reward "conformity to 'white norms' or sanctioned cultural practices" (59), which scholarship programs promote with their focus on meritocracy. Since many Black American college students at the University of Louisville receive acceptance through programs such as Porter Scholars, TRIO, and others, these programs shape their approaches to coursework. This added pressure means that their relationship to course curricula has a different dynamic from their relationship their high school curricula. Transitioning requires learning the difference between high school and college-level coursework as well as relationships. 


\section{Teacher-Student Relationship}

NF2 recognized the difference in how the teacher-student relationship emerges on the page. "If I do give [a paper] to them to review, they'll just say 'you need to make it longer,"” she stated. "When I need help, I don't need just 'make it longer;' I need specifics. Give me some ideas or help me jog up some ideas to add into the paper." FYW courses are one of the main spaces where academic relationships are forged, due to the intimacy of the classes and the assignment topics. The resulting connection that students have with their instructors can be critical in shaping college student identities. Kynard discusses the ways that past relationships with English teachers can shape the ways that many Black and Latinx students engage with FYW instructors, especially in the case that they are graduate instructors not actually interested in teaching writing (6). However, when students take FYW courses taught by dedicated teachers, the outcomes become greatly beneficial to how students perceive themselves as intelligent capable students. I found that the link of student-teacher interactions to success as academic writers relates to both the Black American discourse features of community consciousness in writing (Smitherman; Gilyard and Richardson) and the tripartite of teacher, student, and community common in Afrocentric education models (Lee; Lomotey).

Following the tradition of community learning and the mutually beneficial relationship between teacher, student, and community valued by independent Black institutions, several participants emphasized the impact of teacher connection on their learning. OM1 argued that teacher relationships are essential to adequate college preparation. "I think it starts in high school, like how good your teachers taught and how well you learn," he suggested. "It's just about growing, and if you're already a few steps 
behind coming into college, then you're not going to grow as significantly as someone else. You're not going to get the same level as someone else who's had a great teacher." MM1 described relying on professors as a resource for help with writing rather than services like the Writing Center or the Learning Resource Center. "In most classes, if there's a paper and I need help, I'll just go to the professor and ask about the structure," he said. "Because they know how they want the paper to be written, so I just feel like that's why they're there." While a smart attitude, not every participant found their college professors to be as helpful, as indicated by NF2's frustrations with the feedback "make it longer." For NF2, relationships with the Writing Center and out-of-class mentors replaces the teacher-student relationships forged by OM1 and FF1.

These relationships may prove critical to the success of all students, but particularly students who may feel marginalized. In a study comparing the impact of school racial climate on Filipino American and Chinese American students, Robert T. Teranishi suggests that racial and ethnic stereotypes that teachers hold can influence how students perceive the value or purpose of education overall. Whereas JF2 described that in college she plans to use the Writing Center as a central resource for writing help, in high school, she felt "like you could just walk up to a teacher" and ask for guidance. A high-achieving but sometimes minimally motivated Black American student such as JF2 relies on the connection with her teachers, in addition to interest in the subject matter, to keep her engaged. On the other hand, FF1 found she became engaged with the FYW instructor on the page through the instructor's feedback on her work. According to FF1, "A lot of the feedback she gave me--like oh explain here or think about this more and things like that ... is going to help me later on.” These perspectives show that FYW 
teachers must consider the various ways that they build relationships with transitioning students, how the students' identities influence those relationships, and how they shape the students' college student identity.

\section{Relevance of Writing Curriculum}

Teacher-student relationships are often improved through pedagogy that helps students' identities become a part of the curriculum. While constructing cultural knowledge through writing practices has been an interest of composition scholars, as explored in the sub-field of community literacy (Adler-Kassner; Long; Kirsch; Guerra), it has been central to the learning experience Black American communities. JF2 chose her first paper topic for her Honors Composition course at the University of Louisville by writing "about a letter that a doctor wrote to the National Organic Standards Board concerning carrageenan," because as an aspiring scientist she "wanted to research more about the effects of carrageenan and if it is actually as harmful as people were claiming it to be." This link to the material through personal interest and personal values is also part of the value system of independent Black institutions (IBIs) referenced in the previous chapter. By choosing a socially responsible topic, JF2 is demonstrating "KujichaguliaSelf-Determination," "Ujima-Collective Work and Responsibility," and "Nia-Purpose" from "The Seven Principles of Blackness" (Lomotey 458), one of the value guides of IBIs. She also invokes one of the "pedagogical aims" of IBIs, "Promote the vision of individuals and communities as producers rather than as simply consumer" (Lee 166). Through these, JF2 has been able to see herself in the curriculum (Lomotey 459).

In an extended email interview, JF2 discussed how FYW curriculum related to her in the long-term. She wrote, "I think this class has prepared me well for other 
assignments that I will have to complete for the rest of my college career and my career in general." In reflecting on whether or not FYW should prepare her for all writing situations, JF2 suggested, "I definitely think that these types of courses should prepare students for writing in the rest of their careers regardless of whether they are English majors or not because I think that writing is an incredibly important skill." Yet considering that JF2 noted that a self-taught and practiced high-school graduate can write at the same level as many college students, her view on how FYW courses should prepare students is flexible.

NF2 views the necessity of FYW with a different attitude. "When I got here," she said, "you guys talked a lot about using the library like online library sources and stuff to like incorporate into your writing." She uses those skills in her upper-level courses, as she described:

You don't forget. Because even currently in my nutrition class, we have to use the EBSCO and CINAHL searches. We have to find diabetes and hypertension and stuff, and literally write a paper about the stuff. She says we have to use those links and it's mandatory. I don't know how some people don't use it. I mean it does help.

This statement indicates that in addition to the practice of writing itself, the ways academic writers select, evaluate, and report information (Bartholomae 4) should be made relevant as well. FM1, described the relevance to his personal life of vetting sources and reading critically as part of the research process. In this second-semester first-year course, my students had extensive choice in their writing topics, though the topics had to fit within the realm of social criticism. The assignments required them to 
research and explain the history, cultural relevance, and possible solutions for a social issue affecting the many communities they belong to-local, virtual, and national. FM1 explained that, as a result of the class, "I feel like I have more critical analysis about things." He learned that experienced academic writers "have to really research who wrote it. I didn't really ever think about [that]." Perhaps, FM1 found encouragement to followthrough on the research practices that we all try to teach due to his connection the topic and the relevance of the curriculum's content. Even when choice is present in the curriculum, some of my upper-division interviewees noted the impact of race or its absent presence on their experiences as college students and their interaction with the writing curriculum.

\section{Impact of the Absent Presence of Race for Success in College Writing}

Much of the preliminary conversations with the first-year students focused on writing practices and preferences rather than issues of race. However, the second and third year students gave more attention to the connection between their racial identities and the curriculum. MM1, for instance, commented that "as I have grown, I have surely begun to love the fact that I am a black, African American male ... [a part of] the culture that thrives in America despite the racial profiling and blatant racism that still lingers, even on the $\mathrm{U}$ of L campus. I realize the responsibility I have to be unapologetically me, unapologetically black!' Held in conjunction with NF2's challenge in this chapter's epigraph, the absent presence of race is clearly felt by some of the students. LadsonBillings (1998), Richardson (2003), and Smitherman (1977) emphasize the lack of legitimate representation of Black American experiences in the curriculum. As the curriculum acts as artifact of white supremacy (Ladson-Billings 21), institutionalized 
literacy and rhetorical education denies the rich cultural history of Black American discourses and rhetorical traditions (Richardson). Some of my study participants hinted at the invisible influence of racial perspectives on their academic and social engagement as well as the influence of stereotype threat on performing academic writing.

\section{The Invisible Influence of Racial Perspectives}

As I outlined in the previous chapter, race can be an absent presence in transitioning experiences. While most interviewees did not emphasize the impact of racialized experiences directly, some of their responses denoted an invisible influence. For example, FF1 and DF1 discussed grounding part of their success as college writers on their fluency with citation styles and grammar usage. FF1 reflected that her FYW English 101 course "really didn't do a lot of different stuff. It was MLA and that was basically it." She added, "We didn't do APA and Chicago or any of that. I know Chicago's more like history based. In my history class now, we have to write a paper, and we have to use Chicago. And I've never used Chicago before." Similarly, DF1 noted the emphasis on MLA in her AP English course. At the time of our interview, she felt she was a less successful college writer, because "I still have to look up like MLA or I didn't remember how to do in-text citations, and I still make simple grammatical errors." In addition to being typical of new transitioning students, the focus on citation practices and style conventions eliminates recognition of culture on writing practices such as citing. For example, features of Black American discourses linked to citing sources include incorporating cultural references - some of which their instructors are not familiar with, field dependency, and structural call and response (Smitherman; Gilyard and Richardson). Each of these were discussed in the previous chapter, but here, I want to 
signify how the general ignorance of their use and effectiveness in writing creates racially exclusionary pedagogies.

Discussing situations that make her feel confident in writing for school, DF1 said, "My paper that I just turned in as my final for Chinese Studies, I feel really confident about it." She explained her reasoning as, "Because I talked to my professor about the idea about what I wanted to write about, and he didn't agree with me. But he said I could argue it, and then I used some of why he didn't agree with me in the paper and I also quoted him." Her reliance on the relationship and conversations with her professor adds community conscious and field dependency to her writing. It also invokes a type of calland-response between her professor's perspective and her research. In the whitenessinvested discourses and White supremacist literacies which value individuality, consumption, and clarity (Richardson; Inoue), DF1's approach may be undervalued. Like this, most of the perspectives on race in the interviews arose indirectly. MM1 remarked that "I find inspiration from my experiences to direct that towards a paper or assignment, if it's a paper that we can just write about an argument or something." Those experiences include being a Black American male in the American higher education system. He added in a follow-up interview, "As I matured and truly started to find myself in college, which I am still doing constantly, I realized who I was as a black man in America and the pros and cons that go along with that identity."

Other participants confronted race head-on. Regarding the curriculum in writing and English courses at the University of Louisville, NF2 noted that most often "no Black, Latino, Asian, Middle Eastern, gay/lesbian authors ... get brought up nor read" and neither do the worldviews or lived perspectives of these groups. While the English 
department offers courses that focus on these groups and their literary perspectives at the 300 level, chances are that NF2 and her non-English major friends stopped taking the required English courses at the 200 level. They will not have had the 300-level literature courses. She explained her struggles with making connections with faculty and the curriculum and described feeling forbidden to use her authentic voice to show what she is learning. She feels as though her authentic voice will cause others to make negative judgements about her intelligence through writing. Nevertheless, NF2 also indicated that writing in academic voice makes writers "sound smarter" but requires her to lose her authentic voice.

This perception of conveying intelligence through particular writing styles is based in constructions of whiteness. Ladson-Billings describes some of the traditional constructions of whiteness accepted as “'school achievement,' 'intelligence,' 'middle classness,' and 'science"' (9). Loss of a writer's authentic voice can also be linked to the White supremacist literacy practice of obedience that Richardson describes. FM1 additionally questioned this obedience during our interview. In discussing the literary analysis assignments common to high school English courses, he suggested, "Even though it was open, there pretty much was a right answer, so it was a little hard to be creative. And even if you were creative, your teacher would go back and say 'no this is wrong, and this is why."' Most likely, at least some the reasons given for the flaws in FM1's and other students' literary interpretations speak to their failure to meet whitenesscentric values in the curriculum. Whiteness-centric interpretations do things such as fashion Rosa Parks as "a tired seamstress instead of a longtime participant in social justice endeavors" and Dr. Martin Luther King, Jr. as "a sanitized folk hero who enjoyed 
the full support of 'good Americans' rather than a disdained scholar and activist whose vision ... challenged the United States on issues of economic injustice and aggression in Southeast Asia" (Ladson-Billings 21-22). In many cases, students who do not ascribe to such interpretations - whose worldviews have not been shaped by discourses of whiteness-receive negative evaluations on their work.

\section{Race, Academic Writing, and Stereotype Threat}

The connection between race and education, and more specifically race and academic success, should not be considered without the influence of stereotype threat. Stereotype threat has been discussed even less in relation to how academic writing expectations work with students of different racial formations. In "Stereotype Threat and the Intellectual Test Performance of African Americans," Claude M. Steele and Joshua Aronson compare the performance of Black students and White students on GRE verbal test items. The researchers tell the experimental group that "the test [is] ... diagnostic of intellectual ability, thus making the racial stereotype about intellectual ability relevant to the Black participants' performance" (799) in order to test their hypothesis that "whenever African American students perform an explicitly scholastic or intellectual task, they face the threat of confirming or being judged by a negative societal stereotype — a suspicion — about their group's intellectual ability and competence" (Steele and Aronson 797).

Based in negative stereotypes of racial minorities and influenced by socially constructed understandings of intellectual ability, stereotype threat involves a selfcomparison to the intellectual performance of the dominant set, or Whites. Students who suffer from stereotype threat experience a type of double-consciousness, which involves 
them seeing themselves through what they understand to be the eyes of those who make judgments about their academic performance and, consequently, their value as students. For students like NF2, stereotype threat creates an obstacle in transitioning. NF2 explained her stereotype threat experience as,

when we were taking the ACT, you know the high score is a 32 or something, so I used to always compare myself to all the other kids that would do very well and complain about it. They'd be like, oh man, I got a 30. And I got a 20. And because I got 20, and they got 30 and they're saying that sucks. And I'm like, well, that sucks for you. But it made me feel really stupid, and I was like "wow." I try not to, but I compare myself and my intelligence to other people--mostly people that are White. And maybe Asian or something like that.

No other participant expressed such a sentiment, but every participant associated negative feelings with writing for school in general. FM1, for example, described a feeling of "dread" when writing for school, because some of his habits have been discouraged by the English teachers he has had in the past. He explained, "I like to use stream of consciousness a lot. They told me not to do that in high school, but it seems to work the best, pretty much." Stereotype threat emerges as a way to justify the cognitive dissonance of what Black students know to be true about their own abilities from lived experience and what they think others believe based on recycled cultural narratives about academic achievement and race. Knowing that stream of consciousness works for him, but being told it is an incorrect invention technique caused FM1 to doubt himself in some respects. This previous experience with in-school writing led him to believe that, as a student, his 
individual writerly choices would be neither expected nor accepted. In fact, even as a Porter Scholar who is highly capable in math and science and confessed to "play[ing] music" and "writ[ing] short little poems," transitioning into new academic writing contexts in FYW caused him to "kind of frea[k] out" due to the amount of choice he received from the pre-writing through editing phases of his writing.

The emphasis other participants made on feeling most confident when a grade or judgement is not involved can be linked to stereotype threat and feeling in comparison to other students and the teacher's perception of good writing. The academic standards for achievement constructed by the American education system continue to be established by those who have access to particular types of knowledge that others do not, to resources others do not, and to the shaping of what counts as knowledge that others certainly do not. Historically, the ways in which teachers respond to Black students differs from their White students of the same writing ability (Smitherman; Royster and Williams; Richardson; Young; Kynard). This response possibly results from, as asserted by scholars Jacqueline Jones Royster and Jean C. Williams, “[t]he conflation of basic writers with students of color . . . becom[ing] deeply embedded in the literature, despite lengthy histories that demonstrate other realities" (571). The composition studies scholarship that Royster and Williams reference here has often misunderstood non-White, male, heterosexual worldviews and, therefore, has misrepresented these worldviews. As a result, pedagogical theory and praxis continue to underserve students that embody marginalized racial and gender identity experiences. Since the 1970s, literacy studies scholars (Smitherman; Gilyard; Royster; Richardson; Logan) have brought attention to the dearth of honest representations of Black American students' literacies and rhetorical 
practices. Richardson remarks on the limitations of Mina Shaughnessy work in basic writing that "it appears that Shaughnessy took the path of least resistance" in part because "other thinkers in language education ... put more weight on the language and cultural background of the learner than did those who followed Shaughnessy's error approach" (13). In part, as well, because Shaughnessy's approach failed to resolve or even address Black American students "general underachievement in literacy," as did other approaches that lacked attention to the discursive resources that students carry with them into the classroom.

Because their experiences with standardized tests, past assignments, and the school system in general have denoted that academic writing is but one measure of their intellectual ability, transitioning to new academic writing situations imposes unfamiliar assessments of their intellectual ability. If they fit the stereotypes-incompetence in reading and writing, in this case - then they will fall into the mainstream culture's narrative about them, and they must be inferior, unworthy of a college education. Furthermore, they will have disgraced their own racial group and reinforced the collective understanding about them by the dominant group.

By understanding more completely personal histories of literacy education, conceptions of transitioning and meaning of college student identity, and impacts of the absent presence of race on college success in writing, instructors, WPAs, and institutional administrators may develop the methodological resources to understand how students understand and engage with the curriculum standards and what sociocultural factors influence this engagement. I end this chapter by discussing how exploring these students' perspectives further through critical race methodology can add a "unique voice of 
color"- similar but different from the counter-story given in Chapter Two- to collective knowledge about the high school to college transition.

\section{Adding a "Unique Voice of Color" to the High School to College Writing Transition Tales}

The preliminary interviews with my participants focused on writing-based transition experiences, and follow-up interviews, which only three participants gave, discussed some issues of race. Rather than any particular commentary on race itself, the accounts shared in this chapter reveal an added understanding to commonly accepted perceptions about crossing the threshold from high school to college-level writing. This understanding is tied to the students unique voice as members of one of the most historically subjugated racial groups in American social institutions. Coming from the voices of Black American students gives authority to their perspectives. Solórzano and Yosso argue that "[i]t is within the context of racism that 'monovocal' stories about the low educational achievement and attainment of students of color are told" (27), and excluding their perspectives from research on transitioning maintains this "monovocal" storytelling. In a space, such as a predominantly White higher education institution like the University of Louisville and similar colleges, foregrounding the voices of Black American students who physically embody anti-Whiteness provides more critical knowledge about transitioning. Aja Y. Martinez describes counter-story in writing research as a rhetorical method for investigating dominant racialized ideologies in the field. These ideologies represent the influence of institutional racism on our research, pedagogy, and administrative practices. 
Excluding the literacy narratives of Black American students and other students of color from transitioning demonstrates how writing studies adheres to the principle of racism is business-as-usual. Again, the point of this principle is not to blame individuals or certain institutions for specific racist beliefs or intentions, but instead, to shed light on the embedded racism within society and its institutions. That embedded racism compels researchers to, for example, omit racialized experiences from transitioning studies. This study references the unique voice of color in transitioning accounts and affords us profounder insight into how race and institutional whiteness might shape transitions from high school to college. The accounts given by my interview participants disrupt the common association of Black and Latinx students, most often, with basic or remedial writing curriculum. I give attention to the transition experiences of Black American students to show the limitations of the diversity and inclusion efforts presented in the previous chapter's analysis. MM1 explained that race played a significant role in making the transition to college life, because "the awareness of my racial identity has become more prevalent" in college. He continues,

In high school, when around white people, I found myself conforming to the way they acted and, in a sense, acting the way that they expected me to act when in an environment with them. Now, in my junior year of college, I look back and realize that I need to be myself in all aspects of my life, whether someone accepts me or not.

While this response is not specifically about writing, it illustrates that racial identity is an important part of who MM1 is and that it does not cease to exist because he is in the writing classroom. 
Most of the interview participants in this study did not recognize the influence of race on their academic success in writing, because it had never been discussed. I also left this topic out of preliminary interviews. When asked whether he thought attending a predominantly White high school with only one Black American teacher prepared him for the social environment at the University of Louisville, OM1 said, "I mean, I think ... it might have prepared me, but I haven't really thought about it. My English teachers have always been extremely nice to me, so I don't know." In most cases, we are taught that school success has more to do with hard work, individual merit, and intelligence rather than social factors such as racial identity or the weight of previous experiences. The mainstream school system, from pre-K through college orients along constructions of whiteness. These constructions manifest in perceptions of intelligence and perceptions of how to be a student, so there is no doubt that students bring expectations and trepidations about these constructions into their college-level writing practices.

The contentious history of Black students' relationship with formal school literacies reinforces stereotype threat, as described by a few of the participants in this study. African American Studies and English Studies scholar Geneva Smitherman reminds us of Carter G. Woodson's summation from Mis-Education of the Negro that Black students had most commonly been taught in their language education to devalue their home dialects as incorrect and inadequate (203). Referring to equal education movements of the 1960s, Smitherman notes, "It was argued that since education correlates with economic and social success in America, the way out of the black ghetto was through enhanced educational achievement" (202). In this case, like most cases even today, "enhanced educational achievement" denotes standards of White middle class 
educational achievement. Thus, neither deficit nor difference language instruction programs for Black students had been designed "to teach black students critical thinking and analysis, nor, above all, to give them tools to righteously examine the socioeconomic workings of America" (Smitherman 203). Some of us American citizens of color may not be aware of how usual it is because, as suggested by Catherine Prendergast and Deborah Brandt, it is so a part of the way society functions. As I have demonstrated here, racism is also the way society does education.

The experiences of these Black American students at the University of Louisville provides a new perspective on collective knowledge about secondary to post-secondary transitioning processes. With the continued disciplinary interest in writing and transitioning, these student perspectives work towards eliminating dominant narratives about bridging, crossing, and minding the gap. The responses of these students disrupt many of the common myths about what happens in high school and how students approach college writing in their first year. Because critical race methodology "strategically uses multiple methods, often unconventional and creative, to draw on the knowledge of people of color who are traditionally excluded as an official part of the academy" (Solórzano and Yosso 37), this chapter and this study can act as a catalyst for bringing student voices in general but, even more specifically, for bringing marginalized student voices into critical dialogues on transitioning across sites of academic writing. In the conclusion to this dissertation, I discuss how these voices are critical to understanding the value of a curriculum of civic responsibility in FYW courses. 
CONCLUSION

\section{GUIDING RACE-CONSCIOUS TRANSITIONS WITH A CURRICULUM OF CIVIC RESPONSIBILITY}

In the previous chapters, I connect the complications of institutional whiteness and racism at the secondary and post-secondary levels with students' transitioning experiences. I do this to show what is missing from scholarship in writing studies on "minding the gap" (Hoffman et al.; Farris) between high school and college writing. By taking the critical race theory approach to this disciplinary conversation, I mind a few of the gaps in transitioning studies scholarship. I support my theory that racial identity has remained absent from writing studies research at a fundamental level as well as from resulting pedagogies concerned with transitioning new high school graduates to collegelevel academic writing. I argue for a curriculum of civic responsibility in first-year writing (FYW) to create inclusive, culturally relevant curricular practices. A curriculum of civic responsibility in FYW courses presents an effective model for helping Black American students transition to college-level writing, because it connects academic writing standards of college curriculum to community development purposes and connects non-academic rhetorical behaviors to academic situations as they begin to develop their identities as college students.

Several critical race theory (CRT) principles validate the claims that I make about transitioning as a racial minority to FYW curriculum. For example, in Chapter Three, the principle of interest convergence suggests that universities give attention to racial identity 
in policies related to new students most often when that attention serves majority whiteness-invested interests. Likewise, in Chapter Four, I rely on the CRT principle of the unique voice of color to interject disciplinary perceptions about secondary to postsecondary transitions. Similar to the counter-story given in Chapter Two which gives authority to Black American histories of rhetorical education in America, Chapter Four helps give credibility to Black American experiences of transitioning to college-level writing. Applying the CRT lens to college and high school writing curriculum led me to examine what institutional, programmatic, and pedagogical approaches could reduce the investment in whiteness at predominantly White institutions. As a result, I emphasize to the benefits of a curriculum of civic responsibility in FYW courses.

Civic responsibility involves some of the aspects of community literacy and community-based writing curriculum. Scholars who research community literacies study the many ways people perform community actions through literacy acts. Another way to understand community literacies is to consider how communities circulate their work in public spaces toward social change. Similar but taking place in classrooms, communitybased writing education teaches writing through texts centered within communities, whether those be professional, academic, or civic communities. In the case of incorporating both community literacy and community-based writing into the curriculum, the impact of students' racial formation is seldom considered. Just like with transitioning experiences, I examine community-based writing curriculum with CRT to examine the investment in whiteness in this curriculum. Much of the scholarship about topics such as service learning, community service, and community engagement in writing courses details students from predominantly White middle class colleges volunteering or 
providing services to working-class or working-poor neighborhoods. Often, these communities are over-represented by people of color while the university students are underrepresented by people of color. I aimed to show how one form of community-based writing curriculum, when used effectively, gives attention to the ways that racial identity shapes students community engagement experiences. Civically responsible curriculum in FYW is race-conscious, because it relies on students' multiple community identities, including those identities which have been politically oppressed by society. Specifically, in the high school to college transition for Black American writers, a curriculum of civic responsibility acknowledges the racial and linguistic culture of these writers' various communities.

To conclude this project, I provide recommendations based on my research for transitioning — minding, bridging, and crossing the gap — from high school- to collegelevel academic writing expectations. I follow this by discussing suggestions for research in race and college academic writing in general, rather than only at the secondary to postsecondary transition level. This discussion includes remarks on the limitations of racial and critical race methodologies for studying student experiences in particular. Following implications for race and academic writing, I discuss the third and broader research suggestions in community-based writing pedagogy. I close by providing a plan for applying this research to create race-conscious and civically responsible writing programs. 


\section{Implications for Minding, Bridging, and Crossing the Gap from High School to College-Level Writing}

This study enhances the primary research area of the high school to college transition for writers. The research area applies to both writing studies and writing program administration. Situated by The Framework for Success in Postsecondary Writing, research in this area has seldom connected community-conscious or raceconscious curriculum to transfer-level writing. Community-engaged courses continue to proliferate within FYW curriculum, but my project lays a path for further examining the affordances of these courses for helping with transitions.

The community literacy to transitioning link deepens with my project's focus on racialized perspectives and experiences. I highlight the impact of the cultural racialized hierarchy in historical and current society because, as Gloria Ladson-Billings and William F. Tate IV suggest, “Class- and gender-based explanations are not powerful enough to explain all of the difference (or variance) in school experience and performance" (51). As demonstrated by stereotype threat (Steele and Aronson), "there is some evidence to suggest that even when we hold constant for class, middle-class African American students do not achieve at the same level as their white counterparts" (LadsonBillings and Tate). Looking at key disciplinary documents around the high school- to college-level writing transition shows no mention of identity factors - race, class, or otherwise - that at least partially influence transition experiences. Neither The Framework, nor The WPA Outcomes for First-Year Composition or the CWPA Position Statement on Pre-College Credit for Writing discuss race or its intersections with gender, 
class, disability, linguistic practice, or nationality and how they have the potential to shape a student's engagement with writing curriculum.

A critical text in this subfield, College Credit for Writing in High School: The “Taking Care of" Business," evades issues of race and language difference as well. By centering on race, I invite writing studies researchers to examine in what ways the social hierarchy of racial identity emerges in critical ways in the transitional writing moments our FYW students face. Ladson-Billings and Tate suggest that similar considerations about social hierarchy can come from distinctions of social class (51). However, the distinction between resources available to poor White schools and poor Black and Latinx schools varies enough to make the social system of race more influential on educational experiences than the social system of class. My study addresses the question of how students' experiences with institutional racism travel across educational institution boundaries.

I suggest that WPAs, especially, think about ways that the unique voice of color and counter-story can create more extensive knowledge than exists today about racialized experiences with transitioning. While I focus on student experiences and institutional policies primarily, the critical race methodology and racial methodology applied to secondary to postsecondary transitions is useful for examining teacher training, curriculum objectives, assessment practices, and other accounts regarding these transitions. This dissertation critically analyzes issues of race in FYW curriculum at the classroom, programmatic, and institutional levels. It demonstrates the ways that CRT presents opportunities for researchers to trace institutional racism and institutional 
whiteness through "networks" of students' academic experiences (Kells). Tracing these networks proposes new directions for research on race and academic writing as well.

\section{Implications for Research on Academic Writing and Race}

Racial methodology and CRT allow researchers to study academic writing transitions while analyzing the effects of "the hidden curriculum" (Leonardo) on students. While racial formations make up but one factor of identity that might influence how students engage with academic writing, these formations' cultural history and broader social stratification in today's society makes their impact critical to examining Black American students at predominantly White institutions and within the larger system of higher education in general. Recently, scholars such as Aja Y. Martinez, Frankie Condon and Vershawn Ashanti Young, and Asao B. Inoue have offered perspectives on the role of racial identity on teaching, assessing, and administrating college academic writing standards. My study adds to these critical works by using racial identity as a way into studying the overlap and conflict between institutional policies and student experiences.

Both Martinez and Inoue trace institutional acts such as assessment and curriculum development in relation to dependence on certain racialized perspectives. However, I illustrate how principles specific to CRT are useful in studying institutional policies at universities and colleges. Moving beyond, Martinez's 2014 article on using counter-story in rhetoric and composition to create a scholarly and methodological space for giving authority to marginalized voices, I employ interest convergence and racism "is business-as-usual" to show how institutional practices around transitioning students to college-level writing relies on whiteness as a discourse and Eurocentric epistemologies of knowledge about writing. In Chapter Three, I applied an institutional analysis by using 
the interest convergence principle and the absent presence of race in composition studies theory to critique the General Education Written Communication criteria and Composition Program learning outcomes.

I recognize that outcomes should be flexible enough to meet a wide range of pedagogical approaches, even race- and community-conscious outcomes. However, as proven by other institutional policies, placing rhetorical acts in written record gives them power. If governance genres "regulat[e] or manag[e] some ... [networks of] social practice" (Fairclough 32), the outcomes govern the ways that teachers design their courses and expectations for what students should learn about writing. Making these governing documents race-conscious, culturally sustainable, and civically responsible creates a foundation for these values in writing programs. Also, let's face it: many teachers will not make antiracist and race-conscious approaches a part of their classrooms or curriculum unless official curricular policies underwrite those approaches.

Interest convergence permits researchers of writing pedagogy, in particular, to more closely examine when race-based or race-conscious practices take place and how they intersect with overall institutional systems of whiteness. This research may include, for example, expanding on the work of Carmen Kynard in "Writing While Black: The Colour Line, Black discourses and Assessment in the Institutionalization of Writing Instruction" or Geneva Smitherman in "The Blacker the Berry, the Sweeter the Juice”: African American Student Writers and the National Assessment of Educational Progress. Each of these studies concerns the limits of blackness in whiteness-centric education institutions, such as most of the institutions in our country. Extending into curricular activities beyond assessment, the CRT principle of interest convergence can help analyze 
the ways that writing instructors value students' racial-cultural identities through pedagogy and assignment creation.

Some scholars are helping teachers and administrators perform this antiracist and race-conscious work in new critical books. In Performing Antiracist Pedagogy in Rhetoric, Writing, and Communication, edited by Frankie Condon and Vershawn Ashanti Young, contributing authors offer multiple perspectives on what antiracist pedagogy looks like in action when used in communicative disciplines. Asao B. Inoue demonstrates how antiracist approaches take shape in writing assessment in Antiracist Writing Assessment Ecologies: Teaching and Assessing Writing for a Socially Just Future. Entities such as WPA-GO ${ }^{33}$ and the CWPA People of Color Caucus support graduate student and WPA research on inclusive and just administrative approaches. My research in the connection between racialized experiences and college academic writing add to the scholarship here by specifying how these antiracist pedagogies and assessment ecologies effectually apply to supporting successful transitions of our students in the lowest racial hierarchy, our Black American students.

Affordances and Limitations of Critical Race Theory and Racial Methodologies

The application of CRT, critical race methodology, and racial methodology to my study of transitioning to postsecondary writing works well, because my central question concerns the experiences of Black American students at predominantly White higher education institutions. That stated, these theories and methodologies have their limitations. They include:

$\circ$ Race is complex and tracing its influence on individual and systems takes time. Racial formations develop from individual,

\footnotetext{
${ }^{33}$ Writing Program Administrators Graduate Organization
} 
cultural, and political designations. Tenets of CRT even theorize that these designations change over time and are based on the majoritarian (Solórzano and Yosso) cultural interests and needs. Racial Formation in the United States by Michael Omi and Howard Winant illustrates how ethnicity, class, and nation paradigms each construct race differently. Even though each of these paradigms has their limitations in providing an understanding of race relations in America, recognizing their impact is key to creating stronger racial methodologies in writing studies research.

Some of the same arguments about institutional values can be made with socioeconomic class, so researchers must consider questions of mobility. Relying on arguments around race alone limits the full understanding of how institutions align with values of whiteness. Whiteness and racism are linked to class distinction and social mobility, so critical race and racial methodologies must account for these considerations as well. For example, Omi and Winant argue that the Black middle-class is tied to Black underclass due to U.S. racial structures (28). Moreover, we must not forget the significance that visibility and embodiment have on difference in social institutions.

$\bigcirc$ Successful members of underrepresented or subjugated racial groups may not recognize the influence of institutional racism. JF2, a student interview participant in my study, explained, "I 
don't think I realized my racial identity and how it plays an important role in my development until, honestly, most recently. I am continuously seeing how this constructed divide influences my life and the lives of others." As a reminder, JF2 was an Honors Composition student during our interview, had attended an International Baccalaureate high school, and had switched her major from Civil Engineering to Math and Physics. Being a highachieving Black American student permits JF2, and others like her-and like me, a temporary alignment with whiteness (LadsonBillings) that may prevent her from articulating the impact of institutional racism. This ambiguity limits the application of racial methodology through interview methods. Since racism advances the social and material interests of the whole American cultural, "materially" and "psychically" (Delgado \& Stefancic), it is challenging to eliminate and to recognize, particularly when it benefits those of us from racially marginalized groups.

For my project specifically, I noted that racism is frequently a part of students' personal histories of literacies, even if they do not recognize this factor in their literacy education. Many of the students I interviewed have been high achievers their entire academic lives, so they fall into the phenomenon discussed in point three above. Most of them did not recognize the bearing that race has on their academic success in writing, because it had never been discussed. Regarding my exploration of institutional policies around transitioning, in some institutional practices, race is simultaneously evaded and 
recognized. The distinctions I create in Chapter Three work for a project of this size. For more extended institutional analyses around race in higher education, I would attend to the complexities of institutional racism, such as how colleges and universities contribute to racialized images and narratives. I focus on blackness and whiteness because of their historical place with America's larger racial stratification, but the spectrum of racial identity is much more complex, future projects would consider this in more detail.

Despite these limitations, my study shows why evading race in institutional policies further marginalizes those who do not align with whiteness (Ahmed). In the FYW classroom, this means that student learning outcomes meant to reflect universality and openness may reject racial and linguistic distinction in favor of racial and linguistic assimilation. CRT allows writing studies and writing pedagogy researchers to examine how assimilationist approaches in the curriculum perpetuate a racialized social system (Bonilla-Silva) that relies on the inherent authority of whiteness. For Black American students, whose racial distinction is always a factor in daily life whether they recognize it or not, these assimilationist practices can complicate their relationship with academic literacies and institutionalized writing standards. The research implications for studying both high school-to-college academic writing transition experiences as well as racialized perspectives in college institutionalized writing standards are central to my project. However, my proposition for a curriculum of civic responsibility to respond to institutional whiteness and racism poses research implications and applications of community-based writing pedagogy in FYW. 


\section{Implications for Community-Based Pedagogy in First-Year Writing}

A curriculum of civic responsibility treats academic writing practices as one resource for students to use towards community development and social change. My conception of civically responsible writing curricula resists venerating academic institutional discourses over public and social community discourses. Therefore, exposing new college students who have been subjugated by past literacy education experiences, based on perceptions about their racial identity, to the community engagement aspects of academic writing practices early in their college lives helps to create a positive and meaningful frame for the academic writing they will perform throughout college. This emphasis on the civic responsibility of writing acts as part of a college education in general should invite their community knowledge and lived experiences as well. Doing so early in their collegiate academic lives leads students to see themselves in the writing curriculum and to see the curriculum as useful to navigating their lives and as more than a skill for career-readiness.

In Chapter Two, I exemplify how the community-curriculum connection has been central to the rhetorical education of Black Americans. In providing a counter-story to Eurocentric perspectives about the ways that formal rhetorical education taught young Black Americans writing practices, I suggest that college writing programs can work to create civically responsible, culturally responsive curriculum at the transition level. College writing educators should consider what rhetorical practices, in service of whom, students are learning through the writing curriculum. If the ways that sociocultural contexts of right and wrong, desirable and expendable, position us are rhetorical, then they communicate an idea about who we are, what we know, and what value we hold in 
relation to others. I focus on Black American students' engagement with Black communities, because it helps students respond to the political-rhetorical ways of being in the "racialized social system" (Bonilla-Silva) that defines their racial identity.

Particularly for the 17, 18, and 19-year-old Black students in many first-year writing courses, who are beginning to establish beliefs about what it is to be perceived as Black in American society, writing curriculum emphasizing civic responsibility can help them navigate multiple ways of doing citizenship. Since Black Americans have been some of the most historically persecuted students by the American P-12 public education system (Smitherman; Ladson-Billings and Tate; Richardson; Kynard), practicing civic work through writing courses can help them understand liberatory purposes (Delpit) of a higher education, which can then be applied to building up their communities. The systemic oppression in P-12 sites of education has often resulted in underprepared teachers who are inexperienced in working with students' various literacies and rhetorical practices. Carmen Kynard explains,

The predominance of underpaid and/or under-trained educators in secondary schools, particularly as it relates to the multiple literacies of young people of colo[r], mirrors the structural racism that has organized much of the schooling that working class/working-poor Black and Latino students have received all along. (6)

Considering the civic responsibility of academic writing acts can help teachers frame the ways of doing academic writing and institutionalized rhetorical education as one resource for challenging sociocultural narratives and experiences. The Afrocentric theories of rhetorical education presented here offer a guide for further examining how the 
curriculum we teach in first-year writing courses contributes to the rhetorical needs of our students. By infusing the principles of civic responsibility in first-year writing, writing teachers eliminate much of the distance between academic discourses or institutional forms and public rhetoric and writing. We teachers also engage students' multiple sociocultural identities as part of our classroom writing practices. Michelle Hall Kells, in discussing a more civically engaged model of writing across the curriculum, illustrates how rhetorical participation in many native vernaculars and home communities often privileges listening and collaboration over the "rhetorical self-display" tactics encouraged in most academic discourses (377).

Along with Shirley Wilson Logan, I recommend that we look to all the schools referenced in Chapter Two as "a direction for current rhetorical education ... that would improve the quality of composition classes" (39) and writing programs by bringing civic responsibility to college writing curriculum. Moving away from the common conception of community-engaged and service learning courses, which assumes that all students experience these courses the same, my study highlights the ways that racialized experiences contribute to community engagement in the curriculum. As Ann E. Green argues in "Difficult Stories: Service-Learning, Race, Class, and Whiteness," community literacy and writing studies scholarship

must begin theorizing how service-learning is experienced differently by those from different groups and look closely at the gaps between our theories of service-learning and our theories of subject position(s), of race, class, gender, sexuality, and writing. (276) 
This project shows why a civically responsible approach to community-based writing courses and programs are categorically helpful to students transitioning to college-level writing from marginalized positions. To close this chapter, I discuss how I see this research applying to a real-life writing programs to create transition support for Black American students through race-conscious and civically responsible writing programs.

\section{Transitioning from the Margins: Race-Conscious and Civically Responsible Writing} Programs

Writing program administration plays a critical role in shaping academic transitions at many colleges. In The Activist WPA, Linda Adler-Kassner proposes that we, as writing program administrators, work to change the stories that the media and other publics tell about our students and our work as scholars of writing. Many of these stories relate to writing acts that happen around the high school to college transition (Budden et al.; Strachan; Mosley; Farris). High school graduates can't write. First-year college students aren't prepared for college-level writing. The responses from the student interviews I conducted for this study reveal false positives in these stories. Rather than considering whether students can write--because let's be honest, they have complex histories of composing that started long before they decided to apply to college-I argue that WPAs should focus on what motivates students to write and how sustainable those motivations are. As demonstrated through the Afrocentric education models outlined in Chapter Two of this dissertation and the interview responses detailed in Chapter Four, civic responsibility in rhetorical education writing curriculum is one sustainable motivation for many Black American students. 
First-year students enter FYW courses with several motivations for developing writing habits: to graduate, to pass a class, and to get a job name just a few. These motivations might be strong, but they are temporary. Creating a writing program based in civic responsibility for all students means that the program's culture values student community experiences that derive from race as well as other cultural and social identity factors. One of the education models that I detail in Chapter Two--the independent Black institutions--holds the philosophy that education should serve the community and communities should support education endeavors. Black Panther Liberation Schools, Freedom Schools, and Citizenship Schools also used as part of their approaches curricula that value students' experiences and communities.

This civically responsible approach has been used to transition several kinds of Black American students into several kinds of education. Civically responsible WPAs have the opportunity to create curriculum standards that encourage students to use writing to create and respond to community action. These standards must be race-conscious, because so many students need to respond to the realities of racial inequality. By consequence, the rhetorical skill of writing for primarily academic audiences and understanding the innerworkings of primarily academic communities limits students. Many Black American students, especially, must contend with the visibility of their racial identity which requires more focused rhetorical writing education than that for their less racially visible counterparts. From my lived experience, to move through society as a visibly racialized person, even today, presents rhetorical challenges distinctive to people of color. As I introduced in Chapter Three, I propose race- and community-conscious outcomes that can be assessed in the following ways: 
- Critical race narrative portfolios (Behm and Miller): Students write outside of traditional academic genres, students blur genres, and students critique dominant discourses.

- Grading contracts (Inoue): Students focus on rhetorical effectiveness rather than grammar and mechanics, and contracts include participation and writing as part of contribution to the classroom community. This practice relies on engagement with writing rather than some illusion of meritocracy.

- Assessment of several rhetorical traditions knowledge: Students read critical and creative texts from many vernacular traditions, and teachers assess them on their understanding of those traditions, including traditional academic essays. Appendix $\mathrm{C}$ includes a sample outcomes statement for a civically responsible writing program, sample syllabi for FYW courses with a sample grading contract, and a sample assignment for a first-year, civically responsible argumentative and research writing course.

As indicated by the recent WPA: Writing Program Administration article "Community Engagement in Writing Program Design and Administration” by Veronica House, community-centric writing programs have their challenges just as traditional writing programs do. However, as a model for supporting Black American students' transitions to college-level writing, writing programs using a curriculum of civic responsibility work to connect academic writing practices to community development. This dissertation project highlights the need for this type of curriculum at the transitionlevel, especially at predominantly White universities and colleges relying on community connections. Due to time and participant restrictions, I was limited in the type and 
amount of research I could do with this project. I plan to move this project into a crossinstitutional analysis of the absent presence of race, including analyzing institutional policies around transitioning at minority-serving institutions ${ }^{34}$ and selective liberal art colleges. Among other plans, this dissertation study has also started me on the trajectory of developing approachable models of antiracist first-year writing program administration, which includes considerations of curriculum content and design, text selection, teacher training, and assessment. My goal is to continue to focus on racial inequalities academic communities and especially in how we frame the role of civic engagement, social responsibility, and community work in our pedagogy.

For students in the contingent space of their first year- from which they can continue or exit-I suggest that writing in institutionalized rhetorical education may prepare students for White-centric participation in civic life. In the case of Black American students, even more, this limited use of academic writing practices offers little preparation for the community lives they may have to navigate. Our society with a racial social system built on the "valorization of whiteness" (Harris) and the vilification of blackness and brownness. Teaching academic writing through a lens of civic responsibility can prove critical in helping Black American students use academic writing to confront injustices as they transition to academic writing at the college level.

\footnotetext{
${ }^{34}$ I will begin serving as Assistant Director of Composition at a predominantly Latinx and Hispanic institution in Fall 2017, and I plan to build on this research there.
} 


\section{REFERENCES}

Adler-Kassner, Linda and Elizabeth Wardle. Naming What We Know: Threshold Concepts of Writing Studies. Logan: Utah State UP, 2015. Kindle file.

Ahmed, Sara. "A Phenomenology of Whiteness." Feminist Theory 8.2 (2007): 149-168. Print.

“A Huey P. Newton Story.” Luna Ray Films. PBS.org, 2002. Web. 24 May 2016.

Anderson, Noel S. and Haroon Kharem. Education as Freedom: African American Educational Thought and Activism. Lanham: Lexington Books, 2009. Print.

Anson, Chris. "Black Holes: Writing Across the Curriculum, Assessment, and the Gravitational Invisibility of Race." Race and Writing Assessment. Eds. Asao B. Inoue and Mya Poe. New York: Peter Lang, 2012. Print.

Anzaldúa, Gloria. Borderlands/La Frontera: The New Mestiza. Aunt Lute Books, 1987.

Balester, Valerie. "How Writing Rubrics Fail: Toward a Multicultural Model." Race and Writing Assessment, edited by Asao B. Inoue and Mya Poe, Peter Lang Publishing, 2012, pp.15-28.

Barnett, Timothy. "Reading 'Whiteness' in English Studies.” College English vol. 63 no. 1, 2000, pp. 9-37.

Bartholomae, Donald. "Inventing the University." Teaching Composition. 3rd ed. Ed. T.R. Johnson. Boston: Bedford/St. Martin's, 2008. Print. 
Behm, Nicholas and Keith D. Miller "Challenging the Frameworks of Color-blind Racism: Why We Need a Fourth Wave of Writing Assessment Scholarship.” Race and Writing Assessment, edited by Asao B. Inoue and Mya Poe, Peter Lang, 2012, pp. 127-38.

Bell, Derrick. "Brown v. Board of Education and the Interest-Convergence Dilemma." Harvard Law Review, vol. 93 no. 3, 1980, pp. 518-534.

Blommaert, Jan. “Sociolinguistic Scales.” Intercultural Pragmatics 4.1 (2007): 1-19. Print.

Bonilla-Silva, Eduardo. Racism Without Racists. Lanham: Rowman \& Littlefield, 2014. --."Rethinking Racism: Toward a Structural Interpretation.” American Sociological Review 62.3 (1997): 465-480.

Brandt, Deborah. "The Cognitive as the Social: An Ethnomethodological Approach to Writing Process Research.” Written Communication 9 (1992): 315-55. Print. Budden, Herb et al. "What We Talk about When We Talk about College Writing." Teaching Writing in High School and College: Conversations and Collaborations. Ed. Thomas C. Thompson. Urbana, Illinois: National Council of Teachers of English, 2002.

Brubaker, Rogers. "Ethnicity without Groups." European Journal of Sociology / Archives Européennes de Sociologie vol. 43 no. 2, 2002, pp. 163-189.

Carpenter, William and Bianca Falbo. "Literacy, Identity and the 'Successful' Student Writer." Identity Papers: Literacy and Power in Higher Education. Ed. Bronwyn Williams. Utah State University Press, 2006. 1-13. Print. 
Castagno, Angelina E. "Making Sense of Multicultural Education: A Synthesis of the Various Typologies Found in the Literature.” Multicultural Perspectives, vol. 11 no. 1,2009 , pp. 43-48.

Changa, Kalonji Jama (on Council of Independent Black Institutions). "There's a growing (long overdue) national wave of support." 18 May 2016. 9:54 p.m. Facebook.

Clary-Lemon, Jennifer. "The Racialization of Composition Studies: Scholarly Rhetoric of Race since 1990.” CCC, vol. 61 no. 2, 2009, pp. W1-W17.

Cobb, Charles, E. Jr. “Organizing Freedom Schools.” Teach Freedom: Education for Liberation in the African-American Tradition. Eds. Charles M. Payne and Carol Sills Strickland. NY: Teachers College Press, 2008. 69-74.

Collins, Hill Patricia. Black Feminist Thought: Knowledge, Consciousness, and the Politics of Empowerment. Routledge, 1991.

Condon, Frankie and Vershawn Ashanti Young, eds. Performing Antiracist Pedagogy in Rhetoric, Writing, and Communication, The WAC Clearinghouse and University Press of Colorado, 2016.

Conley, David. "Challenges in the Transition from High School to College." Minding the Gap: Why Integrating High School with College Makes Sense and How to Do It. Eds. Nancy Hoffman et al. Cambridge: Harvard Education Press, 2007. 93-103. Print.

Coogan, David. "Service Learning and Social Change: The Case for Materialistic Rhetoric." Writing and Community Engagement: A Critical Sourcebook. Eds. Thomas Deans and Barbara Roswell and Adrian J. Wurr. Boston: Bedford/St. Martin's, 2010. Print. 
Council of Independent Black Institutions. Home. Facebook: Council of Independent Black Institutions - CIBI. 18 May 2016. 9:54 p.m. Facebook.

Council of Writing Program Administrators et al. Framework for Success in Postsecondary Writing, 2011.

Council of Writing Program Administrators. "WPA Outcomes Statement for First-Year Composition.” CWPA, 2014.

Crenshaw et al. Critical Race Theory: The Key Writings that Formed the Movement. NY: The New Press, 1995.

Deans, Thomas. "English Studies and Public Service." Writing and Community Engagement: A Critical Sourcebook. Eds. Thomas Deans and Barbara Roswell and Adrian J. Wurr. Boston: Bedford/St. Martin's, 2010. Print.

Delgado, Richard and Jean Stefancic. Critical Race Theory: An Introduction. NY: NYU Press, 2006.

Delpit, Lisa. Other People's Children: Cultural Conflict in the Classroom. New York: The New Press, 1995. Print.

Denecker, Christine. "Transitioning Writers across the Composition Threshold: What We Can Learn from Dual Enrollment Partnerships.” Composition Studies 41.1 (2013): 27-50. Print.

Department of English. "Composition Student Learning Outcomes." University of Louisville. Department of English, n.d. Web. 10 Mar. 2016.

Dombek, Kristin, and Scott Herndon. Critical Passages: Teaching the Transition to College Composition. New York: Teachers College Press, 2004. 
Du Bois, W. E. B. The Souls of Black Folk. Chicago: A.C. McClurg \& Co.; [Cambridge]: University Press John Wilson and Son, Cambridge, U.S.A., 1903; Bartleby.com, 1999. www.bartleby.com/114/

Duffy, John. "Ethical Dispositions: A Discourse for Rhetoric and Composition." Watson Conference, Responsivity: Defining, Cultivating, Reacting. Spec. issue of JAC 34.1-2 (2014). Print.

Emery, Kathy, Sylvia Braselmann, and Linda Gold. Freedom School Curriculum: Mississippi Freedom Summer, 1964. 2004. PDF File.

Enoch, Jessica. Refiguring Rhetorical Education. Carbondale: SIU Press, 2008. Print. Fairclough, Norman. "Intertextuality and Assumptions.” Analysing Discourse: Textual Analysis for Social Research. London: Routledge, 2003. 39-62.

Farris, Christine. "Inventing the University in High School." CCC 61.1 (2009): W410417.

--. "Minding the Gap and Learning the Game: Differences that Matter Between High School and College Writing." College Credit for Writing in High School: The "Taking Care of" Business. Eds. Kristine Hansen and Christine R. Farris. Urbana, IL: National Council of Teachers of English, 2010.

Flower, Linda. Community Literacy and the Rhetoric of Public Engagement. Carbondale: SIU Press, 2008. Kindle file.

Fowler, Judy and Robert Ochsner. "Evaluating Essays Across Institutional Boundaries: Teacher Attitudes Toward Dialect, Race, and Writing." Race and Writing Assessment. Ed. Asao B. Inoue and Mya Poe. New York: Peter Lang, 2012. 111126. Print. 
Fox, Tom. "Race and Collective Resistance." Insurrections: Approaches to Resistance in Composition Studies. Ed. Andrea Greenbaum. Albany: SUNY Press, 2001. 71-86.

Freire, Paolo. Pedagogy of the Oppressed. New York: Continuum International, 2005.

General Education Curriculum Committee. "Critical Thinking Rubric." University of Louisville, 2013. PDF File.

--. “Cultural Diversity Rubric.” University of Louisville, 2013. PDF File.

--. "Effective Communication Rubric." University of Louisville, 2013. PDF File.

Gentile, James M. “College-Level Writing: A Departmental Perspective.” What is "College-Level” Writing? Eds. Patrick Sullivan and Howard Tinberg. Urbana, IL: National Council of Teachers of English, 2006. 311-329.

Gillespie, Deanna M. “ 'They Walk, Talk and Act Like New People”” Citizenship Education in Southeastern Georgia, 1960-1965." Teach Freedom: Education for Liberation in the African-American Tradition. Eds. Charles M. Payne and Carol Sills Strickland. NY: Teachers College Press, 2008. 42-55.

Gilyard, Keith. "African American Contributions to Composition Studies." College Composition and Communication 50.4(1999): 626-644. Print.

-- and Elaine Richardson. 'Students' Right to Possibility: Basic Writing and African American Rhetoric." Insurrections: Approaches to Resistance in Composition Studies. Ed. Andrea Greenbaum. Albany: SUNY Press, 2001. 37-51.

Glenn, Cheryl and Margaret Lyday and Wendy B. Sharer. Rhetorical Education in America. Tuscaloosa: Univ of Alabama P, 2004. Print.

Green, Ann E. "Difficult Stories: Service-Learning, Race, Class, and Whiteness." CCC 55.2 (2003): 276-301. 
Guerra, Juan. "Cultivating Transcultural Citizenship in a Discursive Democracy." Texts of Consequence: Composing Rhetorics of Social Activism for the Writing Classroom. Eds. Christopher Wilkey and Nicholas Mauriello. Cresskill: Hampton Press, 2012.

Guess, Teresa J. “The Social Construction of Whiteness: Racism by Intent, Racism by Consequence.” Critical Sociology, vol. 32 no. 4, 2006, pp. 649-673.

Hansen, Kristine and Christine R. Farris. College Credit for Writing in High School: The 'Taking' Care of Business. National Council of Teachers of English, 2010.

Hansen, Kristine et al. CWPA Position Statement on Pre-College Credit for Writing. Council of Writing Program Administrators, 2013. PDF File.

Harris, Cheryl. "Whiteness as Property." Critical Race Theory: The Key Writings That Formed the Movement. Eds. Kimberle Crenshaw, Neil Gotanda, Garry Peller, and Kendall Thomas. NY: The New Press, 1995. 276-291. PDF File.

Harris, Violet. "African American Conceptions of Literacy: A Historical Perspective.” Theory into Practice 31.4(1992): 276-286. Print.

Herzberg, Bruce. "Community Service and Critical Teaching." CCC 45.3 (1994): 307319.

Hoffman, Nancy, Joel Vargas, Andrea Venezia, and Marc S. Miller, eds. Introduction. Minding the Gap: Why Integrating High School with College Makes Sense and How to Do It. Cambridge: Harvard Education P, 2007.

Horner, Bruce. "Resisting Academics." Insurrections: Approaches to Resistance in Composition Studies, edited by Andrea Greenbaum, SUNY Press, 2001, pp. 169184. 
House, Veronica. "Community Engagement in Writing Program Design and Administration." WPA: Writing Program Administration, vol. 39, no. 1, 2015, 5471.

Ignatiev, Noel. How the Irish Became White. UK: Routledge Classics, 1995.

Inoue, Asao B. "Grading Contracts: Assessing Their Effectiveness on Different Racial Formations." Race and Writing Assessment. Ed. Asao B. Inoue and Mya Poe. New York: Peter Lang, 2012. 79-94. Print.

--. "Racial Methodologies for Composition Studies." Writing Studies Research in Practice: Methods and Methodologies. Eds. Lee Nickoson and Mary P. Sheridan. Carbondale: SIU Press, 2012. Kindle file.

--. "Whiteness as a Discourse." Conference keynote handout. Council of Writing Program Administrators. 15 July 2016. Google Document.

-- and Mya Poe, eds. Race and Writing Assessment. New York: Peter Lang, 2012. Print. James Madison University Writing Rubric. 1 Dec. 2008. Retrieved at http://www.jmu.edu/assessment/resources/JMU_Final_Writing_Rubric_f08.pdf Jennings, Chris and Jane Hunn. “"Why Do I Have to Take Remedial English?’ A Collaborative Model to Solve a National Problem.” Teaching Writing in High School and College: Conversations and Collaborations. Ed. Thomas C. Thompson. Urbana, Illinois: National Council of Teachers of English, 2002. Jordan, Jeanette et al. "Am I a Liar? The Angst of a HS English Teacher." What is "College-Level" Writing? Eds. Patrick Sullivan and Howard Tinberg. Urbana, IL: National Council of Teachers of English, 2006. 36-40. 
Journet, Debra. "Narrative Turns in Writing Studies Research.” Writing Studies Research in Practice: Methods and Methodologies. Eds. Lee Nickoson and Mary P. Sheridan. Carbondale: SIU Press, 2012. Kindle file.

Kates, Susan. Activist Rhetorics. Carbondale: SIU Press, 2001. Print.

Kells, Michelle Hall. "Writing Across Communities: Diversity, Deliberation, and the Discursive Possibilities of WAC." Writing and Community Engagement: A Critical Sourcebook. Eds. Thomas Deans and Barbara Roswell and Adrian J. Wurr. Boston: Bedford/St. Martin's, 2010. Print.

Kent, Alexander and Thomas Frohlich. "The 9 Most Segregated Cities in America." Huffpost Business. TheHuffingtonPost.com Inc, 27 Aug 2015, http://www.huffingtonpost.com/entry/the-9-most-segregated-cities-inamerica_us_55df53e9e4b0e7117ba92d7f. Accessed 2 Apr 2016.

Ketai, Rachel Lewis. "Race, Remediation, and Readiness: Reassessing the "Self" in Directed Self-Placement.” Race and Writing Assessment. Ed. Asao B. Inoue and Mya Poe. New York: Peter Lang, 2012. 141-154. Print.

Kirsch, Gesa. "From Introspection to Action: Connecting Spirituality and Civic Engagement." College Composition and Communication 60 (2009): W1 - W15.

Kynard, Carmen. "Workshop: Black Student Protest as the Language and Blueprint of Education." Education, Language, and Radical Tradition: A Teaching and Research Site on Race, Writing and College Classrooms. Accessed 1 March 2016. Web. 
--. "Writing While Black: The Colour Line, Black Discourses and Assessment in the Institutionalization of Writing Instruction.” English Teaching: Practice and Critique 7.2 (2008): 4-34.

Ladson-Billings, Gloria. "Just What is Critical Race Theory and What's it Doing in a Nice Field Like Education?" Qualitative Studies in Education 11.1 (1998): 7-30. Print.

-- and William F. Tate IV. “Toward a Critical Race Theory of Education.” Teachers College Record 97.1 (1995): 47-68. Print.

Lamos, Steve. "Institutional Critique in Composition Studies: Methodological and Ethical Considerations for Researchers." Writing Studies Research in Practice: Methods and Methodologies. Eds. Lee Nickoson and Mary P. Sheridan. Carbondale: SIU Press. Kindle Book.

Lee, Carol D. "Profile of an Independent Black Institution: African-Centered Education at Work." African Americans and Independent Schools: Status, Attainment, and Issues. Spec. issue of The Journal of Negro Education 61.2 (1992): 160-177. Print.

Leonardo, Zeus. "The Color of Supremacy: Beyond the Discourse of 'White Privilege'." Educational Philosophy and Theory 36.2 (2004): 137-152. Print. Levine, David. "The Birth of Citizenship Schools." Teach Freedom: Education for Liberation in the African-American Tradition. Eds. Charles M. Payne and Carol Sills Strickland. NY: Teachers College Press, 2008. 25-41. 
Lioi, Anthony and Nicole M. Merola. "The Muse of Difference: Race and Writing Placement at Two Elite Art Schools." Race and Writing Assessment. Ed. Asao B. Inoue and Mya Poe. New York: Peter Lang, 2012. 155-168. Print.

Lisman, C David. Toward a Civil Society: Civic Literacy and Service Learning. Westport: Bergin \& Garvey, 1998.

Logan, Shirley Wilson. Liberating Language: Sites of Rhetorical Education in Nineteenth-Century Black America. Carbondale: SIU Press, 2008. Print. --. “'To Get an Education and Teach My People’: Rhetoric for Social Change.” Rhetorical Education in America. Eds. Cheryl Glenn, Margaret Lyday, and Wendy B. Sharer. Tuscaloosa: Univ of Alabama P, 2004. 36-52.

Lomotey, Kofi. "Independent Black Institutions: African-Centered Education Models." The Journal of Negro Education 61.4 (1992): 455-462. Print.

Long, Elenore. "Pedagogical Practices." Community Literacy and the Rhetoric of Local Publics. West Lafayette: Parlor Press, 2008. 154-199. Print.

Lujan, Alfredo Celedon. "Salem Witch Trials: Voices." What is "College-Level" Writing? Eds. Patrick Sullivan and Howard Tinberg. Urbana, IL: National Council of Teachers of English, 2006. 41-57.

Lunsford, Andrea A. "Writing is Informed by Prior Experience." Naming What We Know: Threshold Concepts of Writing Studies. Eds. Linda Adler-Kassner and Elizabeth Wardle. Logan: Utah State UP, 2015. Kindle Book.

Martinez, Aja Y. “A Plea for Critical Race Theory Counterstory: Stock Story versus Counterstory Dialogues Concerning Alejandra's 'Fit' in the Academy." Composition Studies 42.2 (2014): 33-55. Print. 
Matsuda, Paul and Tony Silva, editors. Second Language Writing Research: Perspectives on the Process of Knowledge Construction. Lawrence Erlbaum Associates, 2005.

Mills, Charles W. The Racial Contract. NY: Cornell University Press, 1999.

Mosley, Milka. "The Truth about High School English." What is "College-Level"

Writing? Eds. Patrick Sullivan and Howard Tinberg. Urbana, IL: National

Council of Teachers of English, 2006. 58-68.

NCTE. “Students’ Right to Their Own Language.” CCC 25. 1974.

Nelson, Kimberly L. "The Great Conversation (of the Dining Hall): One Student's Experience of College-Level Writing." What is "College-Level" Writing? Eds. Patrick Sullivan and Howard Tinberg. Urbana, IL: National Council of Teachers of English, 2006. 283-296.

Newkirk, Thomas. "The Narrative Roots of Case Study." Methods and Methodology in Composition Research. Eds. Gesa Kirsch and Patricia A. Sullivan. Carbondale: SIU Press, 1992.

Office of Admissions. A Visitor's Guide to Campus. University of Louisville, n. d.

--. Check Out Ways to Visit UofL Today. University of Louisville, n. d.

--. It's Never Too Early to Plan for College. University of Louisville, n. d.

--. No Better Time to be a Louisville Cardinal. University of Louisville, n. d.

Olson, Gary. "Working with Difference: Critical Race Studies and the Teaching of Composition. Composition Studies in the New Millennium: Rereading the Past, Rewriting the Future. Eds. Lynn Z. Bloom, Donald A. Daiker, and Edward M. White. Carbondale: SIU Press, 2003. 208-221. 
Omi, Michael and Howard Winant. Racial Formation in the United States: From the 1960s to the 1990s. 2nd ed., Routledge, 1994.

Perlstein, Daniel. "Live the Truth: Politics and Pedagogy in the African American Movement for Freedom and Liberation." Education as Freedom: African American Educational Thought and Activism. Eds. Noel S. Anderson and Haroon Kharem. Lanham: Lexington Books, 2009. Print.

--. "Minds Stayed on Freedom: Politics, Pedagogy, and the African American Freedom Struggle.” American Educational Research Journal 39 (2002): 249-77. Print. Perryman-Clark, Staci. "Toward a Pedagogy of Linguistic Diversity: Understanding African American Linguistic Practices and Programmatic Learning Goals." TETYC 39.3 (2012): 230-246.

Powell, Malea. "A basket is a basket because...: Telling a Native Rhetorics Story." Oxford Handbook of Indigenous American Literature, edited by James H. Cox and Daniel Heath Justice, Oxford University Press (US), 2014.

Prendergast, Catherine. "Race: The Absent Presence in Composition Studies." CCC 50.1 (1998): 36-53.

Prosser, Inez B. "Non-Academic Development of Negro Children in Mixed and Segregated Schools.” Diss. University of Cincinnati, 1933. Print.

Richardson, Elaine. African American Literacies. Routledge, 2003.

--. "Coming from the Heart: African American Students, Literacy Stories, and Rhetorical Education.” African American Rhetoric(s): Interdisciplinary Perspectives. Eds. Elaine Richardson and Ronald L. Jackson II. Carbondale: SIU Press, 2004. Print. 
Royster, Jacqueline Jones. Traces of a Stream: Literacy and Social Change Among African American Women. Pittsburgh: University of Pittsburgh Press, 2000.

-- and Jean C. Williams. "History in the Spaces Left: African American Presence and Narratives of Composition Studies.” CCC 50.4 (1999): 563-584. Print.

Sackey, Donnie Johnson and Danielle Nicole DeVoss. "Ecology, Ecologies, and Institutions: Eco and Composition.” Ecology, Writing Theory, and New Media: Writing Ecology, edited by Sidney I. Dobrin, Routledge, 2012.

Sacramento State University Writing Rubric. 1 Dec. 2008. Retrieved at www.csus.du/wac/WAC/Teachers/rubric.doc.

Scott, Tony and Asao B. Inoue. "Assessing Writing Shapes Contexts and Instruction." Naming What We Know: Threshold Concepts of Writing Studies. Eds. Linda Adler-Kassner and Elizabeth Wardle. Logan: Utah State UP, 2015. Kindle Book. Sehulster, Patricia. "Forums: Bridging the Gap between High School and College Writing." Teaching English in the Two-Year College 39.4 (2012): 343-354.

Selfe, Cynthia L. and Gail E. Hawisher. "Exceeding the Bounds of the Interview: Feminism, Mediation, Narrative, and Conversations about Digital Literacy." Writing Studies Research in Practice: Methods and Methodologies. Eds. Lee Nickoson and Mary P. Sheridan. Carbondale: SIU Press. Kindle edition. Smitherman, Geneva. Talkin and Testifyin: The Language of Black America. Detroit: Wayne State University Press, 1977. Print.

--. "The Blacker the Berry, the Sweeter the Juice: African American Student Writers and the National Assessment of Educational Progress." Annual Meeting of the National Council of Teachers of English. Urbana: NCTE, 1993. PDF File. 
Solórzano, Daniel G. and Tara J. Yosso. "Critical Race Methodology: CounterStorytelling as an Analytical Framework for Education Research.” Qualitative Inquiry 8.1 (2002): 23-44. Print.

Sommers, Nancy and Laura Saltz. "The Novice as Expert: Writing the Freshman Year." CCC 56.1 (2004): 124-149.

Strachan, Wendy. "Talking about the Transition: Dialogues between High School and College Teachers." Teaching Writing in High School and College: Conversations and Collaborations. Urbana, IL. National Council of Teachers of English, 2002.

Sullivan, Patrick, and Howard Tinberg, eds. What is "College-Level" Writing? Urbana, IL: National Council of Teachers of English, 2006.

Tatum, Alfred. Fearless Voices: Engaging a New Generation of African American Adolescent Male Writers. Scholastic Inc., 2013.

Tatum, Beverly. Why are All the Black Kids Sitting Together in the Cafeteria? New York: Basic Books, 1997. Print.

Teranishi, Robert T. “Asian Pacific Americans and Critical Race Theory: An Examination of School Racial Climate." Equity \& Excellence in Education 35.2 (2002): 144-154.

The Community Engagement Steering Committee. Community Engagement Glossary of Terms. University of Louisville, 2011. PDF File.

The Office of Diversity and International Affairs. University of Louisville, 2 Sept 2016, http://louisville.edu/diversity/.

The Office of Institutional Effectiveness. "Tidewater Community College Student Demographics: Race/Ethnicity.” Tidewater Community College, 2016. PDF File. 
--. "Quick Facts.” Tidewater Community College. Accessed 31 Dec 2016. Web. 1 Dec 2016.

Thompson, Thomas C. Teaching Writing in High School and College: Conversations and Collaborations. Urbana, Illinois: National Council of Teachers of English, 2002.

University of Louisville. “About.” University of Louisville. n.d. Web. 11 Jan 2016.

--. "Diversity Plan 2011-2015." University of Louisville Office of Diversity, 2011. PDF

File.

--. The 2020 Plan, Making it Happen. University of Louisville. 2008. PDF file.

--. "The Total Package: UofL and the city of Louisville." Online video clip. YouTube. YouTube, 10 Apr. 2012. Web. 15 Feb. 2016.

--. "UofL Campus Tour Video - Student Life." Online video clip. YouTube. YouTube, 14 July 2014. Web. 15 Feb. 2016.

VanDeWeghe, Rick. "Scary Stories and Paradigm Shifts: Preparing High School Writers for College Writing." The English Journal 96.2 (2006): 62-66.

Vandiver, Beverly J. et al. "Validating the Cross Racial Identity Scale." Journal of Counseling Psychology 49.1 (2002): 71-85.

Virginia Beach City Public Schools. "Annual School Report Card.” Virginia Beach City Public Schools, 2016. PDF File.

Vivion, Michael J. "High School/College Dual Enrollment and the Composition Program." Writing Program Administration 15.1-2 (1991): 55-59.

Wacquant, Loïc J. D. "For an Analytic of Racial Domination." Political Power and Social Theory, vol. 11, JAI Press, 1997. 221-234. 
Wei, Debbie. "The Black Panther Party Legacy and Lessons for the Future." CivilRightsTeaching.org, 2004. Web. 24 May 2016.

Williams, Bonnie J. 'Students' 'Write' to Their Own Language: Teaching the African American Verbal Tradition as a Rhetorically Effective Writing Skill.” Equity \& Excellence in Education 46.3 (2013): 411-429.

Williams, Bronwyn. Introduction. Identity Papers: Literacy and Power in Higher Education. Logan, Utah: Utah State University Press, 2006. 1-13. Print.

--. "Pay Attention to the Man Behind the Curtain: The Importance of Identity in Academic Writing.” Journal of Adolescent \& Adult Literacy 49.8 (2006): 710715. Print.

-- and Mary Brydon-Miller. "Changing Directions: Participatory Research, Agency, and Representation." Ethnography Unbound: From Theory Shock to Critical Praxis. Eds. Sidney Dobrin and Stephen Brown. Albany, NY: SUNY Press. 2004. 241-257.

Winalski, Amanda. "Bam." What is "College-Level" Writing? Eds. Patrick Sullivan and Howard Tinberg. Urbana, IL: National Council of Teachers of English, 2006. $302-310$

Wilson, William Julius. The Declining Significance of Race: Blacks and Changing American Institutions. $2^{\text {nd }}$ ed. Chicago: University of Chicago Press, 1980. Print. Woodson, Carter G. Mis-Education of the Negro. U.S.: The Associated Publishers, 1933. Print. 


\section{APPENDIX A}

\section{Description of participants}

\section{OM1}

First-year student, Black American male, Mechanical Engineering major, Boone County High School (Florence, Kentucky), single-parent female living in poverty.

\section{NM1}

Older second-year student, Black American male, Accountancy major, Central High School Magnet Career Academy (Louisville, Kentucky), and single parent female living in poverty.

\section{NF2}

Third-year student, Black American female, Exercise Science major, duPont Manual High School (Louisville, Kentucky), and two-parents in home (married or unmarried) living well-above poverty but still working.

\section{NF3}

First-year student, Black American female, Biology major, Montgomery County High School (Mt. Sterling, Kentucky), and single-parent female living just above poverty.

DF1

First-year student, Black American female, Biology major, Bryan Station High School (Lexington, Kentucky), and uncertain of single-parent female income.

JF2

First-year student, mixed race African descent and European descent female, Civil Engineering major changed to Physics major, Atherton High School graduate (Louisville, Kentucky), and co-parenting divorced parents (with single-parent female as primary) living well-above poverty but still working.

FF1

First-year student, Black American female, Political Science major, out-of-state high school (Georgia), both parents in home, and uncertain of income.

FM1

Second-year student, Black American male, Atmospheric Science major, Ballard High School (Louisville, Kentucky), and uncertain of parents' income.

MM1

Second-year student, Black American male, Business Major, Male High School (Louisville, Kentucky), and single-parent female above poverty but still working. 


\section{Preliminary Interview Questions:}

1. Can you describe your experiences with writing when you were of grade school age? What about the kinds of writing you did for high school?

2. In which high school courses were you required to write? How did you approach writing assignments?

3. How has writing for school made you feel? When have you felt confident or good about things that you've written? When have you felt insecure or discouraged? When have you cared little or sincerely cared about the writing you do for course work?

4. Can you talk about the connection you make between writing and being a college student? Describe your own personal connection between these aspects or how you associate the two

5. What had you been told about college writing prior to attending college (either in school, at home, or by experts)? Who conveyed these ideas to you?

6. How are you approaching college writing assignments? How, if at all, does this differ to how you approached writing for high school courses?

7. What resources in-class and on-campus have you used to help with writing? How helpful have these resources been? Describe your experiences as best you can.

8. For what purposes do you write outside of school? What makes this easier or come more naturally than in-school writing?

9. What are some descriptors or adjectives that you associate with writing or "doing writing" in general?

10. What do you think when you hear the term "academic?" Would you consider yourself to be academic? Why or why not?

\section{Follow-up Interview Questions}

How do you think your racial identity has influenced your transition to college from high school? Please let me know whether the influence has been positive or negative. (Also, let me know if you think racial identity has had no influence.) 


\section{APPENDIX B}

Initial Survey Questions

Name:

Email address where you would like to be contacted:

1) Academic major/program (please write "undecided" if applicable):

2) Year in your undergraduate program (select one):

$\square$ Freshman

Sophomore

$\square$ Junior

$\square$ Senior

3) Name of High School and State Located:

4) Please provide your gender identity (i.e., female, male, transgender, etc.)

5) Your Racial Identity (please select as many as apply, as you identify):

$\square$ Black/African Descent

$\square$ Latin@/Chican@/South American Descent

$\square$ White/European Descent

$\square$ Asian Descent/Pacific Islander

$\square$ East Indian/North African/Middle Eastern

$\square$ Native North American

Mixed or Multi Racial (please specify):

6) Total Family Income Designation, when growing up (please select only one):

$\square$ Below poverty line

$\square$ At poverty line

$\square$ Just above poverty line

$\square$ Well above poverty line, but still working

Wealthy/Affluent

$\square$ Uncertain

6) Family Makeup, prior to attending college:

$\square$ Two-parents (married or unmarried)

Divorced parents, but co-parenting

Single parent female

$\square$ Single parent male

$\square$ Extended family parenting (aunts, uncles, grandparents, etc.)

Adopted, including any of the above family makeups

$\square$ Foster care 


\section{APPENDIX C: RACE- AND COMMUNITY-CONSCIOUS CURRICULUM}

\section{MATERIALS}

\section{Race-Conscious and Community-Conscious Outcomes Statement}

Can critically read and analyze the rhetorical practices of multiple cultures through content and genre

- Apply multiple linguistic traditions to related audiences while using appropriate tone

- Describe or demonstrate the cultural basis for grammar and style conventions

Ability to write for multiple public audiences

- Conduct audience analysis and historicize arguments within communities

- Develop projects directed to community action for non-academic communities

Understands how rhetorical traditions are formed and practiced

- Research rhetorical traditions or linguistic traditions including academic and racially- or ethnically-based

- Work with more than one rhetorical or linguistic tradition for course's major project

Recognizes how racial culture and other identity factors influence reception of a text

- Employs inclusive research practices, including research source perspectives from three or more cultures, both domestic and international

- Develops knowledge of the cultural implications of academic, peerreviewed research

- Effectively uses non-academic community knowledge, and primary lived experiences as part of research

Gives attention to the influence of style and usage on composing effective communication

- Chooses paragraph structure, sentence variety, and punctuation by demonstrating comprehension of their rhetorical purposes

- Reflects attention to target audience and specific purpose through application of discourse features 


\section{$\underline{\text { Cultural Literacies Research Essay }}$}

Background: In the previous units of the course, we have studied the cultural influences around academic writing practices within academic communities. This unit will require you to research how Black American, Chicano/a, or Mestizo/a vernacular English is appropriated in the media and online spaces.

Task: Relying on academic sources, linguistic-community knowledge, and lived experience, write a 5 to 6-page essay (approximately 1600 words), research the ways that news media and online spaces have appropriated Black American, Chicano/a, or Mestizo/a vernacular English to fit their purposes. You will present the results of your research on nationally-recognized media, independent media, a personal website, a popular culture website, and an academic website.

Instructions: You must submit an outline with source descriptions, a community analysis, a peer workshop draft, and a final essay draft for this project.

- Outline: Two pages with appended annotated bibliography of all sources. $10 / 14$

- Community Analysis: One- to two-page descriptive break down of linguistic community's use of vernacular tradition. 10/16

- Workshop Draft: Full draft of research essay for response from peers and instructor. 10/21

Outcomes:

- Describe or demonstrate the cultural basis for grammar and style conventions

- Research rhetorical traditions or linguistic traditions including academic and racially- or ethnically-based

- Employs inclusive research practices, including research source perspectives from three or more cultures, both domestic and international

- Effectively uses non-academic community knowledge, and primary lived experiences as part of research

- Chooses paragraph structure, sentence variety, and punctuation by demonstrating comprehension of their rhetorical purposes 
Sample Syllabus

\section{English 101: Introduction to College Writing Fall 2017 \\ MW 4:00-5:15 PM in HUM 104A \\ Email: jamila.kareem@louisville.edu \\ Or email from Blackboard \\ Phone: (502) 852-6896}

Professor Jamila Kareem

Office hours: TU 1:50 -3:50 PM

Office location: HUM 333A

Social justice commitment: This course treats writing as a community act and a method of achieving social justice. Social justice includes any act that work towards equal opportunity and rights for all people. While every assignment in this course will not directly be put towards this purpose, by taking this course, you are agreeing to study how writing and language practices can just as easily be used to silence or exclude particular groups, communities, or individuals or to uplift and enhance them.

In this section of English 101, you can expect to participate in experiential learning. That means you will put into real-world practice, the concepts that we study about writing. We will treat writing as a subject of study, something to learn about and learn to do. For this reason, we will treat this classroom space as a writing lab as well as space to learn about writing. Nearly every class will give you extensive time to work in your writing individually or collaboratively. To complete these tasks effectively, you will study writing from various genres and styles in addition to composing, revising, and editing in multiple genres and using different media.

Required Materials:

- Victor Villanueva. Bootstraps: From an American Academic of Color.

- Geneva Smitherman. Word from the Mother: Language and African Americans.

- Select readings found on Blackboard and online.

Prerequisites: Open to all incoming students.

Per the student learning outcomes, by the end of English 101, students should demonstrate the ability to produce writing that:

1. Can critically read and analyze the rhetorical practices of multiple cultures through content and genre

2. Ability to write for multiple public audiences

3. Understands how rhetorical traditions are formed and practiced

4. Recognizes how racial culture and other identity factors influence reception of a text 
5. Gives attention to the influence of style and usage on composing effective communication

\section{Grading:}

This course will be assessed with rubrics based on the student learning outcomes and based on the genre, audience, purpose, and context of your work. Your final grade will be based on the following evaluation rubric (non-negotiable):

\begin{tabular}{|c|c|}
\hline A range (combination of all factors): & $\begin{array}{l}\text { Attendance: }<=1 \text { unexcused absence and/or } 2 \text { late/ } \\
\text { early leaves } \\
\text { Low-stakes work: Completes all with high level of } \\
\text { critical thinking, rhetorical listening, and attention to } \\
\text { detail } \\
\text { High-stakes work: Completes all according to assign- } \\
\text { ment requirements, and meets required expecta- } \\
\text { tions. (Determined by on-time submission, } \\
\text { application of feedback to revisions, and performance } \\
\text { requirements) } \\
\text { Peer workshop: Participate in all }\end{array}$ \\
\hline$B$ range & $\begin{array}{l}\text { Attendance: }<=2 \text { unexcu absences and/or } 4 \text { late/ } \\
\text { early leaves } \\
\text { Low-stakes work: Completes all with expected level } \\
\text { of critical thinking, rhetorical listening, and attention } \\
\text { to detail } \\
\text { High-stakes work: Completes all according to assign- } \\
\text { ment requirements, and meets required expectations. } \\
\text { (Determined by on-time submission, application } \\
\text { of feedback to revisions, and performance of } \\
\text { requirements) } \\
\text { Peer workshop: Participate in all }\end{array}$ \\
\hline C range & $\begin{array}{l}\text { Attendance: <= } 3 \text { unexcu absences and/or } 4 \text { late/early } \\
\text { arrivals/leaves } \\
\text { Low-stakes work: Completes most with expected } \\
\text { level of critical thinking, rhetorical listening, and } \\
\text { attention to detail (missing } 2 \text { discussions, group } \\
\text { work, etc.) } \\
\text { High-stakes work: Completes all according to assign- } \\
\text { ment requirements, and meets most expectations. } \\
\text { (Determined by on-time submission, application } \\
\text { of feedback to revisions, and demonstrated understan- } \\
\text { ding of requirements; one late submission up to two } \\
\text { days) } \\
\text { Peer workshop: Missing no more than one session }\end{array}$ \\
\hline $\mathrm{D}$ range & $\begin{array}{l}\text { Attendance: } 4 \text { unexcu absences and/or } 5 \text { late/early } \\
\text { arrivals/leaves }\end{array}$ \\
\hline
\end{tabular}




\begin{tabular}{|c|c|}
\hline & $\begin{array}{l}\text { Low-stakes work: Completes some with less than } \\
\text { expected level of critical thinking, rhetorical listening, } \\
\text { and attention to detail (missing more than } 2 \\
\text { discussions, group work, etc.) } \\
\text { High-stakes work: Completes all according to assign- } \\
\text { ment requirements, but does not meet expectations. } \\
\text { (Determined by on-time submission, application } \\
\text { of feedback to revisions, and demonstrated understan- } \\
\text { ding of requirements; two late submissions up to two } \\
\text { days) } \\
\text { Peer workshop: Missing no more than one session }\end{array}$ \\
\hline F range & $\begin{array}{l}\text { More than } 4 \text { unexcu absences and/or more than } 5 \\
\text { tardies or early leaving } \\
\text { Missing more than two low-stakes assignments } \\
\text { Submits more than two high-stakes assignments late, } \\
\text { does not meet minimum requirements, or does not } \\
\text { submit } 1 \text { or more assignments at all. Misses final } \\
\text { assignment. } \\
\text { Misses more than one peer workshop }\end{array}$ \\
\hline Incomplete & Case-by-case basis (is VERY rare) \\
\hline
\end{tabular}

Course Major Projects:

1. Community Literacies Narrative. $\mathbf{9 / 8}$

2. Academic Document Cultural Analysis. 9/28

3. Cultural Literacies Research Essay. 10/25

4. Community Action Project. 12/5

\section{Grading Scale:}

$\begin{array}{llllllll}\text { A+ } & 97-100 \% & \text { B+ } & 87-89 \% & \text { C+ } & 77-79 \% & \text { D+ } & 67-69 \% \\ \text { A } & 93-96 \% & \text { B } & 83-86 \% & \text { C } & 73-76 \% & \text { D } & 63-66 \% \\ \text { A- } & 90-92 \% & \text { B- } & 80-82 \% & \text { C- } & 70-72 \% & \text { D- } & 60-62 \% \\ & & & & & & \text { F } & -59 \%\end{array}$

\section{Attendance Policy:}

Learning how to respond to an audience's needs requires extensive interaction with people, so your physical and mental presence in class is necessary. Please see the grading rubric for how attendance correlates to your final grade. In terms of participation, I am flexible, and technology allows us to be so. For example, if you need to miss a class, you may ask one of your classmates to Skype/Google Video chat the class session, and this will count as an excused absence, as long as you submit the in-class assignments. I will not accept this more than twice throughout the semester for each student. You may also make up a class during my office hours (not special hours), again, not more than twice.

Keep in mind: 
- If you have an issue please contact me as soon as possible.

- You will be counted absent if you sleep, use electronic devices during discussion, leave more than 20 minutes early or arrive more than 10 minutes late.

- Four (4) tardies or early departures equal one absence.

\section{Late Work}

See the course assessment rubric for late penalties. The following policy is non-negotiable for late work. Because of our duty as a class to each other, it is imperative that you complete assignments on time. I will return my feedback to you in a timely manner. If you are aware of an absence on a due date, you are required to submit the assignment a class period before the absence. If you are leaving for vacation or another personal matter, you are required to submit the assignment a class period before the extended absence. You may submit by email/upload/online post (pending what is required by the assignment) by the beginning of class on the due date (9:30am).

\section{Athletes Policy:}

I acknowledge athletics as essential component of the UofL community and understand that there may be potential conflict with class times. If you are an athlete, please keep these policies in mind:

- Absences are only excused if you have submitted a letter during the first two weeks of class

- You must submit assignments on the due date or before.

- The Late Policy still applies for all assignments

- Peer consultation can be done by the University Writing Center before the next class

Plagiarism: The University of Louisville's plagiarism policy applies in this course: "The University defines plagiarism as 'representing the words or ideas of someone else as one's own in any academic exercise." Thus, all writing you do for this course must be your own.... Please pay special attention to the quotes, paraphrases, and documentation practices you use in your papers." If you have any questions about plagiarism, please visit me during office hours or schedule an appointment outside of those hours. If you plagiarize, I reserve the right to grant you a failure for the course and your case may be reported to the College of Arts and Sciences. However, my goal is to help you understand how to express your thoughts and insights as well as engage with ongoing broad conversations about the topics of your choice.

Electronics Policy: Your participation and input is essential to this course. I do require the use of electronic devices for certain course activities, which means tablets and laptops will be present in class. These devices should be used as a 
resource. However, if you choose to use these devices for reasons other than contributing to class discussion, you will be counted as absent for that day.

Accessibility and Accommodations: Students who have a disability (temporary or permanent) or condition which may impair their ability to complete assignments or otherwise satisfy course criteria are encouraged to meet with their instructor to identify, discuss, and document any feasible instructional modifications or accommodations. Please inform your instructor about circumstances no later than the second week of the semester or as soon as possible after a disability or condition is diagnosed, whichever occurs earliest. For information and auxiliary assistance, contact the Disabilities Resource Center.

I assume that all of us learn in different ways, and that the organization of any course will accommodate each student differently. For example, you may prefer to process information by speaking and listening, so that some of the written handouts I provide may be difficult to absorb; or you might feel more capable of participating in discussions online rather than during class. Please talk to me as soon as you can about your individual learning needs and how this course can best accommodate them. If you do not have a documented disability, remember that other support services, including the Writing Center and the Learning Resources Center, are available to all students. Disabilities can be visible and invisible, and I am dedicated to ensuring that all students succeed in my course.

The University of Louisville is committed to providing access to programs and services for qualified students with disabilities. If you are a student with a disability and require accommodation to participate and complete requirements for this class, notify me immediately and contact the Disability Resource Center (Robbins Hall, 852.6938) for verification of eligibility and determination of specific accommodations. Visit the DRC website for more information: louisville.edu/disability/students

\section{Inclusion Statement}

From the Office of the President: "The University of Louisville strives to foster and sustain an environment of inclusiveness that empowers us all to achieve our highest potential without fear of prejudice or bias.

We commit ourselves to building an exemplary educational community that offers a nurturing and challenging intellectual climate, a respect for the spectrum of human diversity, and a genuine understanding of the many differences-including race, ethnicity, gender, gender identity, sexual orientation, age, socioeconomic status, disability, religion, national origin or military status-that enrich a vibrant metropolitan research university. 
We expect every member of our academic family to embrace the underlying values of this vision and to demonstrate a strong commitment to attracting, retaining and supporting students, faculty and staff who reflect the diversity of our larger society."

Your value as a member of this course community and the university community at large is vital to me, regardless of social identity factors. While at times, the topic of class discussions, readings, and other activities may take you out of your comfort zone, or even go against your individual perception of the world - as a liberal arts and humanities education should do to help you learn new things you are expected to keep an open mind and evaluate claims based on fact and knowledge, rather than preconceived notions alone. For questions, concerns, and problems related to discrimination based on race, ethnicity, color, nationality, gender identity, sexual orientation/preference, religion, veteran status, or other social or personal identity factors, you may contact Dr. TaylorArcher in the Office of Diversity. The office is located on the 2nd floor of Grawemeyer Hall and can be reached at (502) 852-5719.

\section{Title IX/Clery Act Notification}

Sexual misconduct (including sexual harassment, sexual assault, and any other nonconsensual behavior of a sexual nature) and sex discrimination violate University policies. Students experiencing such behavior may obtain confidential support from the PEACC Program (852-2663), Counseling Center (852-6585), and Campus Health Services (852-6479). To report sexual misconduct or sex discrimination, contact the Dean of Students (852-5787) or University of Louisville Police (852-6111).

Disclosure to University faculty or instructors of sexual misconduct, domestic violence, dating violence, or sex discrimination occurring on campus, in a University-sponsored program, or involving a campus visitor or University student or employee (whether current or former) is not confidential under Title IX. Faculty and instructors must forward such reports, including names and circumstances, to the University's Title IX officer.

For more information, see the Sexual Misconduct Resource Guide (http://louisville.edu/hr/employeerelations/sexual-misconduct-brochure)

Grievances: If you have questions or concerns about your progress in this course, please do not hesitate to come by during office hours to discuss these issues. If you are not satisfied with our discussion, you may see an Assistant Director of Composition in Humanities 333 (Contact: adcquery@louisville.edu or 852-6060). 
Important Note: I reserve the right to alter the terms of this syllabus. Situations such as cancelled classes or changes in our learning objectives, for example, might warrant such a change. 


\section{CURRICULUM VITA}

NAME: Jamila M. Kareem

ADDRESS: Department of Writing and Rhetoric University of Central Florida

Colbourn Hall (Building 18) Room 301

Orlando, FL 32816

DOB: $\quad$ Indianapolis, Indiana - August 27, 1984

EDUCATION

\& TRAINING: $\quad$ B.A., English

Indiana University Purdue University - Indianapolis

2003-07

M.A., English

Columbia University

2010-12

Ph.D., English/Rhetoric and Composition

University of Louisville

2013-17

APPOINTMENT: Assistant Professor, Writing and Rhetoric

Assistant Director of Composition

University of Central Florida, Orlando, FL

August 2017

AWARDS: $\quad$ Scholars for the Dream National Travel Award

National Council of Teachers of English

2015

Inclusiveness Travel Grant

Writing Program Administrators Graduate Organization 2015

Southern Regional Education Board Doctoral Scholar Fellowship 2014-2017 
PROFESSIONAL

SOCIETIES:
Council of Writing Program Administrators.

$2015-2017$.

National Council of Teachers of English.

2016-2017.

Southern Regional Education Board Doctoral Scholars. 2013 2017

\section{PUBLICATIONS:}

Kareem, Jamila M and Khirsten L. Echols. “(T)racing Race: Mapping Power in Racial Property Across Institutionalized Writing Standards and Urban Literacy Sponsorship Networks." Mobility Work in Composition: Translation, Migration, Transformation. Spec. issue of JAC. 2016.

Kareem, Jamila. "The Mogul Ethos and the American Dream in Contemporary Mainstream Rap." The Good Life and the Greater Good in a Global Context. Ed. Laura Savu. Lanham: Lexington Books, 2015. 226-252.

Kareem, Jamila. “(Un)Imagined Realities: Community Engagement as a Resource for Marginalized College Students.” Responsivity. Spec. issue of JAC. Fall 2014. Print.

\section{NATIONAL MEETING PRESENTATIONS:}

"Shadows in the Threshold: Accounts of Black Students Transitioning from Writing in High School to a Predominantly White Research University."

"Transitioning to Postsecondary Writing for Black Students: Where We've Been and Where We Need to Go."

"Transitioning with Civic Acts of Writing in FirstYear Composition: For Black Students, an Alternative to Pre-College Credit Models."
October 2016

\section{Conference.}

Louisville, KY
Council of Writing Program July 2016

Administrators Conference.

Raleigh, NC
Conference on College

Composition and

Communication.

Houston, TX
April 2016 
"Womanist Rhetorical

Pedagogy and the

Contemporary Rhetorical

Education of Black

Students."

"Learning for Their

Livelihood: Tracing the

Technoliteracy Lineages of

Returning Adult Students in

First Year Composition."

"Collaboration and

Collective Idea

Development throughout

the Writing Process."

"Transitioning from the

Margins: Civic

Responsibility and the

Rhetorical Education of

Black Students."

"Stereotype Threat in the

Pre-College to College

Writing Transition: A

Critical Race Theory

Approach."

"New Perspectives on

Classroom Inclusion:

Service Learning and

Marginalized College

Students."

Research Network Forum.

"Excavating Contemporary

Black America in Percival

Everett's Erasure."
Feminisms and Rhetorics.

Tempe, AZ

Computers \& Writing

May 2015

Conference.

Menomonie, WI

Digital Pedagogy Poster.

Conference on College

Composition and

Communication.

Tampa, FL

Qualitative Research

March 2015

Network. Conference on

College Composition and

Communication. Tampa, FL

A.C.E.S. KY: Black \&

February 2015

Latino Student Symposium.

Louisville, KY

Rethinking Intellectual

April 2014

Activism Conference.

Baltimore, MD

Conference on College

Composition and

Communication.

Indianapolis, IN

The Louisville Conference

February 2013 on Literature and Culture.

Louisville, KY

March 2014 
"Giving Students a Higher Education: Assessing the Need for Multicultural

Literature in Introductory

College English."

"'Write to Make it Right, Don't Like Where I Be':

Examining Lupe Fiasco's

The Cool as African

American Literature."
Indiana College English Association Conference.

Valparaiso, IN

The Louisville Conference on Language and Culture. Louisville, KY

February 2012

\section{INVITED PRESENTATIONS:}

“'Think-Tank' for Racial Conference on College Portland, Oregon and Social Justice in the Composition and Writing Program Communication.

Administrators Graduate March 2017

Organization and

Beyond."

"A Civic Responsibility Model for Transitioning Students into

Postsecondary Writing." (Workshop)
Transitioning to College Oxford, Mississippi Writing Symposium.

October 2015 